Cite this: Mater. Adv., 2021, 2, 4574

Received 23rd April 2021, Accepted 23rd June 2021

DOI: 10.1039/d1ma00373a

rsc.li/materials-advances
Check for updates

\section{Designing organic solvent separation membranes: polymers, porous structures, 2D materials, and their combinations}

\author{
Ameya Manoj Tandel, ${ }^{a}$ Wenji Guo, ${ }^{a}$ Kelly Bye, ${ }^{b}$ Liang Huang, ${ }^{a}$ Michele Galizia ${ }^{b}{ }^{b}$ \\ and Haiqing Lin (D) *a
}

\begin{abstract}
As the interest for membrane-based organic solvent separation increases, membrane materials exhibiting high permeance, high selectivity, and long-term stability against solvents are sought. Membrane technology has experienced tremendous progress by integrating well-established polymeric membranes with emerging materials such as porous polymers, metal-organic frames (MOFs), and two-dimensional (2D) materials. This review aims to provide a timely update on novel molecular architectures developed to surpass permeability and selectivity trade-off and improve stability. First, we describe the transport mechanisms of organic liquids in membranes and summarize the state-of-the-art commercial membranes. Second, various strategies in designing polymers to improve separation performance are presented, including chemical functionalization and cross-linking. Third, we critically review porous materials with well-controlled nanostructures, such as polymers of intrinsic microporosity (PIMs), covalently organic frameworks (COFs), carbon molecular sieves (CMS), and mixed matrix membranes (MMMs). Finally, membranes based on 2D materials with exciting separation properties are highlighted.
\end{abstract}

\section{Introduction}

${ }^{a}$ Department of Chemical and Biological Engineering, University at Buffalo,

The State University of New York, Buffalo, NY 14260, USA.

E-mail: haiqingl@buffalo.edu; Tel: +1-716-6451856

${ }^{b}$ School of Chemical, Biological and Materials Engineering,

University of Oklahoma, Norman, OK, 73019, USA

Organic solvents are widely used in the chemical, pharmaceutical, and food industries, and they must be separated from intermediate chemicals or products for reuse to minimize waste and lower the cost. ${ }^{1-5}$ Currently, organic solvent separation is

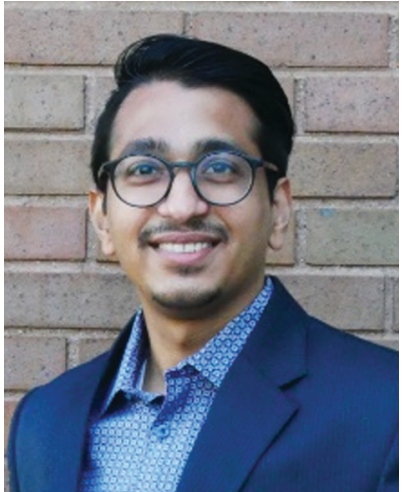

Ameya Manoj Tandel
Ameya Manoj Tandel received his Bachelor's degree in Chemical Engineering (Pharmaceutical Sciences and Technology) from the Institute of Chemical Technology (formerly UDCT, India) in 2016, and he joined Hikal LTD (India) as an Assistant Manager in the process engineering department with a major focus on reactor design, flow chemistry, and chemical reaction kinetics. He started his PhD in Chemical Engineering at the University at Buffalo, The State University of New York, under the aegis of Dr Haiqing Lin since 2019. His research work focuses on fine-tuning fractional free volume in polymers for organic solvent separation and water purification.

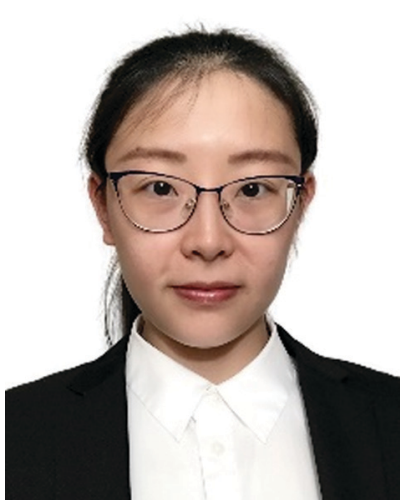

Wenji Guo
Dr Wenji Guo earned her PhD in Chemistry from Tsinghua University (China) in 2019. Then, she works as a postdoc in the Department of Chemical and Biological Engineering at the University at Buffalo, The State University of New York, since 2020. Her research focuses on the understanding of molecular transport mechanisms in highperformance membranes for gas and liquid separations. 
achieved using phase-changing processes such as distillation and evaporation, which are energy-intensive and consume $10-15 \%$ of the world's total energy. ${ }^{5,6}$ For example, separation of $p$-xylene and $o$-xylene with similar boiling temperatures requires $\sim 150$ theoretical plates for distillation. ${ }^{7,8}$ Therefore, new technologies superior to these conventional separation technologies are needed, particularly for the separation of thermolabile commodities or high boiling point solvents. ${ }^{3}$

Membrane technology has gained much attention for this application due to the avoidance of phase change, high energy efficiency, small footprint, and easy operation and maintenance. ${ }^{9-11}$ Fig. 1 shows a rapid increase of research publications in the last

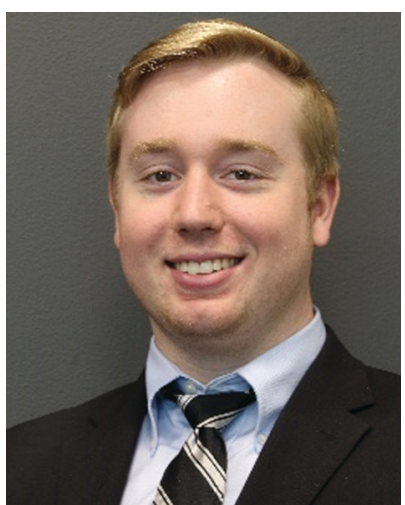

Kelly Bye
Kelly Bye joined the University of Oklahoma membrane lab as an undergraduate student in 2018 and graduated with a Master in Chemical Engineering in the Spring of 2021. His research was focused on understanding the fundamental transport mechanisms behind Organic Solvent Nanofiltration and Organic Solvent Reverse Osmosis including the development of structure-property correlations to help facilitate the intelligent design of new membrane materials. His accolades include receiving the Al Clark Award for Undergraduate Research, the University of Oklahoma CBME outstanding Junior Researcher Award, North American Membrane Society (NAMS) Undergraduate Poster Competition Winner, and Astronaut Scholarship Finalist. Since graduating, he has begun his career working as a chemical engineer at Renewable Energy Group, specializing in renewable diesel production.

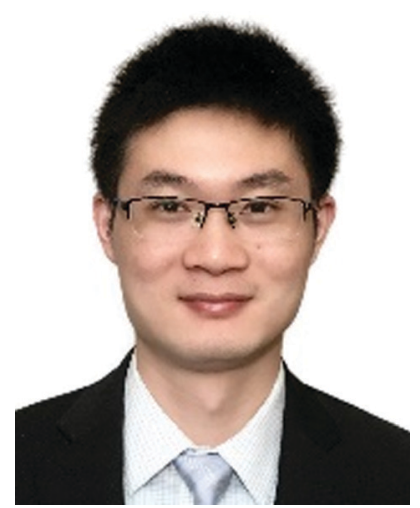

Liang Huang
Dr Liang Huang obtained his PhD in Polymer Chemistry and Physics from Tsinghua University (China) in 2016. He is currently a postdoc in the Department of Chemical and Biological Engineering at the University at Buffalo, The State University of New York. His research interests focus on $2 D$ materials, metal-organic frameworks (MOFs), and polymers for organic solvent nanofiltration, water purification, and $\mathrm{CO}_{2}$ capture.

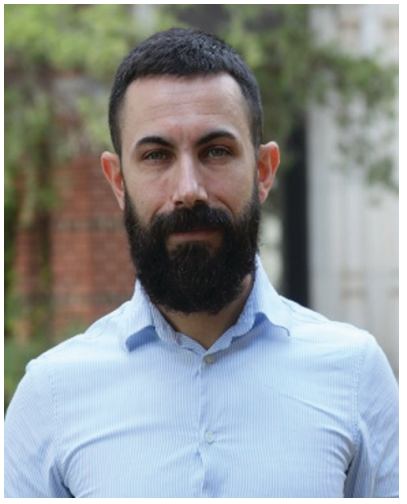

Michele Galizia
Michele Galizia joined the School of Chemical, Biological and Materials Engineering of the University of Oklahoma in 2017 after completing his post-doctoral training at the University of Texas at Austin. His research Group exploits fundamental principles of physical chemistry and thermodynamics to design, characterize and model polymer membranes for gas and organic solvent separations exhibiting pre-assigned selectivity and stability. Prof. Galizia has received a number of awards, including the National Science Foundation (NSF) CAREER award, the 2021 Class of Influential Researchers by I\&EC Research (ACS), the ACS-PRF New Doctoral Investigator, and the Best Reviewer Award from the Journal of Membrane Science. He has been highlighted as a rising star in membrane science by the journal Frontiers in Polymer Chemistry (Nature Publishing Group). He is the Associate Editor of the Journal of Polymer Engineering since 2018 and a member of the editorial board of the Journal of Membrane Science since 2021.

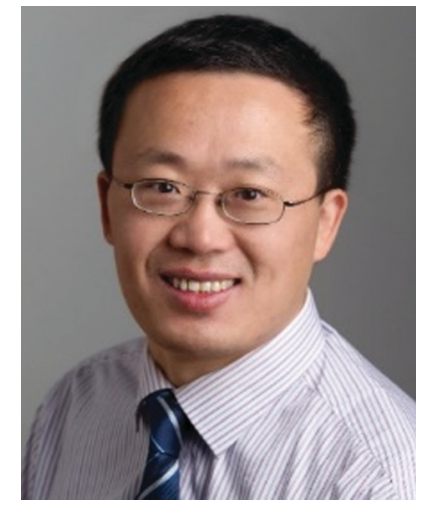

Haiqing Lin
Dr Haiqing Lin received his $P h D$ in Chemical Engineering from the University of Texas at Austin in 2005 and then joined Membrane Technology and Research, Inc. as a Senior Research Scientist. $\mathrm{He}$ joined the University at Buffalo, The State University of New York as an assistant professor in 2013 and was promoted to professor in 2021. He is a recipient of the NSF CAREER award in 2016 and the AIChE Separation Division Innovation Award in 2020. His research focuses on advanced membranes for gas separation and liquid purification. 


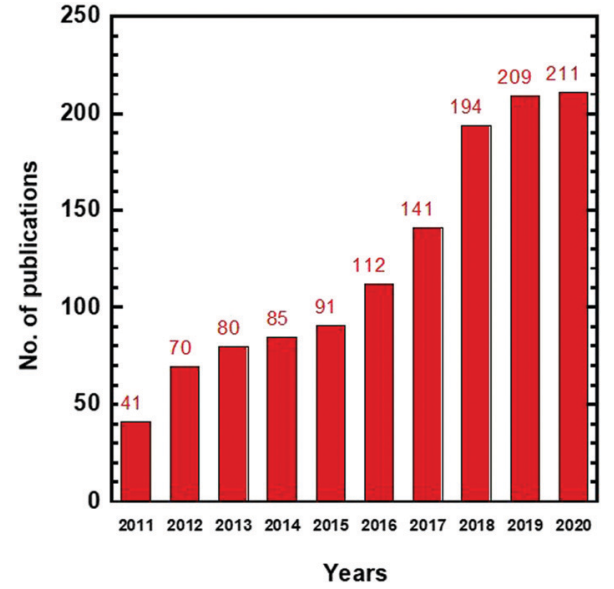

Fig. 1 Number of publications on solvent separations in the last 10 years. Data were obtained on March 3rd, 2021 from Web of Science with keywords of "organic solvent nanofiltration," "organic solvent reverse osmosis," and "organic solvent forward osmosis."

10 years, including organic solvent nanofiltration (OSN), organic solvent reverse osmosis (OSRO), and organic solvent forward osmosis (OSFO). Membrane technology has been extensively reviewed for petrochemical ${ }^{7,12}$ and pharmaceutical applications. ${ }^{13}$ Table 1 summarizes the key applications and the associated requirement for the size sieving ability of membranes, as characterized by molecular weight cut-off (MWCO) or pore sizes.

To make membrane technology competitive with conventional separation technologies, membranes exhibiting superior separation properties and excellent long-term stability are sought. To this end, materials with advanced separation properties have been reviewed, including polymers, ${ }^{8,14}$ cross-linked polymers, ${ }^{15,16}$ porous polymeric and carbonaceous materials, ${ }^{17}$ metal-organic frameworks (MOFs), ${ }^{18,19}$ covalent organic frameworks (COFs) ${ }^{18,20}$ two-dimensional (2D) materials, ${ }^{21}$ thin-film composite (TFC) membranes, ${ }^{22}$ surface-modified membranes, ${ }^{23}$ and mixed-matrix membranes (MMMs). ${ }^{24,25}$ Modeling of liquid transport in membranes has also been described, ${ }^{26-29}$ and important membrane materials were highlighted. ${ }^{10,14}$ The rapid growth of this field can benefit from a timely review of materials designs for OSN and OSRO applications, integrating high-performance material structures from various material platforms and their fabrication into industrial TFC membranes.

This review introduces a comprehensive landscape of membrane architectures developed and their structure-property relationship for organic solvent separation. First, we introduce state-of-the-art commercial membranes and the challenge in improving their separation properties, i.e., a trade-off between permeability and selectivity. Second, we summarize crosslinked polymers and strategies to improve their stability and performance. Third, polyamide (PA)-based TFC and thin-film nanocomposites (TFN) membranes prepared using interfacial polymerization (IP) are critically reviewed. Fourth, we highlight porous materials, such as porous organic cages (POC), MOFs, COFs, carbon molecular sieves (CMS), conjugated microporous polymers (CMPs) and MMMs. Finally, we present the emerging 2D materials for this application.

\section{State-of-the-art membrane technology}

\subsection{Transport mechanism in membranes}

While for many years scientists debated about the validity of the solution-diffusion $v s$. the pore flow mechanism in polymer membranes for organic solvent separation, the solutiondiffusion model has recently emerged as the standard framework to explore structure/property relationships for organic solvent nanofiltration and reverse osmosis membranes. ${ }^{58}$ In the last three decades, most research efforts focused on the development of new materials exhibiting superior solvent permeance. ${ }^{6,59}$ However, understanding the molecular mechanism underpinning small molecule transport in OSN membranes is essential to progress in the field, as it allows for the intelligent design of functional materials specifically tailored for certain separations. ${ }^{58}$

Membrane materials are characterized in terms of permeability coefficient, $P$. When the thickness of the active layer is unknown, permeance, $P / \ell$, is used in place of permeability, where $\ell$ is the thickness of the selective layer. However, in

Table 1 Examples of organic solvent separation applications and the required MWCO or pore sizes for membranes

\begin{tabular}{|c|c|c|}
\hline Applications & Examples & $\operatorname{MWCO}\left(\mathrm{g} \mathrm{mol}^{-\mathrm{o}}\right)$ \\
\hline $\begin{array}{l}\text { API or key intermediate purification } \\
\text { Impurity removal }^{30,48} \\
\text { Catalyst recovery }^{41-43} \\
\text { Peptides separation }^{44} \\
\text { Stereoselective separation }^{45-48}\end{array}$ & $\begin{array}{l}\text { Tetracycline/mepenzolate/chlorhexidine from solvents } \\
\text { Genotoxic impurity removal } \\
\text { Pd(II)acetate from solvents } \\
\text { Peptides from solvents } \\
(R) \text {-1-Phenylethanol over }(S) \text {-1-phenylethanol }\end{array}$ & $\begin{array}{l}350-1000 \\
6-10^{a} \AA\end{array}$ \\
\hline $\begin{array}{l}\text { BTEX separation }^{4,49} \\
\text { Dewaxing }^{50,51}\end{array}$ & $\begin{array}{l}p \text {-Xylene } / o \text {-xylene } \\
\text { Lube oil dewaxing }\end{array}$ & $\begin{array}{l}5.5-6.5^{a} \AA \\
800-1250\end{array}$ \\
\hline Food product purification ${ }^{52-55}$ & $\begin{array}{l}\text { Vegetable oil from hexane, } \\
\text { Free fatty acid (FFA) from vegetable oil }\end{array}$ & $150-900$ \\
\hline Transesterification for biodiesel ${ }^{56,57}$ & Methyl esters from homogeneous catalyst; glycerine and methanol & $150-900$ \\
\hline
\end{tabular}

${ }^{a}$ Membrane pore size (̊̊).BTEX: B-benzene, T-toluene, E-ethyl benzene and X-xylene isomers 
contrast to permeance, permeability is an intrinsic membrane material property and, as such, it should be used to develop structure-property correlations instead of permeance. ${ }^{14,58,60-62}$

Based on the solution-diffusion model, the permeability of species $i$ is given by: ${ }^{14,58}$

$$
P_{i}=D_{i} \times S_{i}
$$

where $D_{i}$ is the diffusion coefficient and $S_{i}$ is the sorption coefficient. The membrane selectivity is the ratio of the permeability of the components $i$-to- $j$, and can be de-convoluted into the sorption and diffusion selectivity as follows:

$$
\alpha_{i j}=\frac{P_{i}}{P_{j}}=\frac{D_{i}}{D_{j}} \times \frac{S_{i}}{S_{j}}
$$

where $S_{i} / S_{j}$ is the solubility-selectivity and $D_{i} / D_{j}$ is the diffusivityselectivity. Solubility-selectivity, $S_{i} / S_{j}$, is governed by the components' relative condensability (indicated by boiling temperature) and molecular interactions with the membrane material, ${ }^{14,58}$ and $D_{i} / D_{j}$ is determined by their relative molecular size and the membrane size-sieving ability. ${ }^{14,58}$ Often, rejection is used instead of selectivity to evaluate the membrane performance. However, analogously to permeance, rejection is not a fundamental membrane property, which hinders the development of fundamental structure-property correlations for OSN and OSRO. ${ }^{14,58}$

The experimentally measured flux of component $i$ through the membrane, that is, the steady-state flux with respect to the membrane, $n_{i}$, which is used to define permeability, is given by:

$$
n_{i}=j_{i}+\omega_{i} n_{i}
$$

where $j_{i}$ is the diffusive flux with respect to the center of mass of the polymer-penetrant system, and $\omega_{i}$ is the mass fraction of the species $i$ in the membrane. Therefore, $n_{i}$ inherently incorporates a diffusive contribution (i.e., $j_{i}$, the flux with respect to the center of mass) and a convective contribution (i.e., $\omega_{i} n_{i}$, the flux due to the bulk penetrant motion). The Fick's law is the standard constitutive equation for the diffusive flux:

$$
j_{i}=-\rho D_{i} \frac{\mathrm{d} \omega_{i}}{\mathrm{~d} x}
$$

where $\rho$ is the density of the solvent-swollen membrane, $\mathrm{d} w_{i} / \mathrm{d} x$ is the concentration gradient across the membrane, $D_{i}$ is the effective local diffusion coefficient, and $x$ is the generic abscissa along the membrane thickness. By combining eqn (3) and (4), the experimentally measured flux is given by:

$$
n_{i}=-\frac{\rho D_{i}}{1-\omega_{i}} \frac{\mathrm{d} \omega_{i}}{\mathrm{~d} x}
$$

When considering a gas separation membrane, $\omega_{i}$ (that is, the gas mass fraction in the membrane) is vanishing, therefore $1-\omega_{i} \cong 1$. This assumption, which has been erroneously extended to OSN/OSRO membranes by several researchers, leads to physically inconsistent results. For example, Volkov et al. reached the conclusion that ethanol diffusion coefficient through poly(1-trimethylsilyl-1-propyne) (PTMSP) exceeds ethanol selfdiffusion coefficient, which, in turn, led them conclude that the transport mechanism in OSN membrane cannot be described in terms of the solution-diffusion model. Unfortunately, this conclusion is not correct, as polymer membranes take up a significant amount of liquid solvent, as such, the term $\left(1-\omega_{i}\right)$ cannot be safely assumed equal to one. Therefore, integration of eqn (5) leads to the following integral expression for the steady-state flux:

$$
n_{i} \ell=\rho \bar{D}_{i} \ln \left(\frac{1-\omega_{i, \ell}}{1-\omega_{i, 0}}\right)
$$

where $\bar{D}_{i}$ is the effective, concentration-averaged diffusion coefficient, and $\omega_{i, \ell}$ and $\omega_{i, 0}$ are the mass fraction of species $i$ in the downstream and upstream membrane side, respectively.

$\bar{D}_{i}$ is inherently corrected for the effect of frame of reference (that is, convective effects) and still affected by non-ideal thermodynamic effects. In other words, $\bar{D}_{i}$ is the product of a kinetic diffusion-coefficient, $\bar{D}_{i}^{*}$, which accounts for hydrodynamic resistance to small molecule diffusion, and a thermodynamic factor, $\beta$, which accounts for penetrant-polymer interactions (that is, thermodynamic non-ideal effects):

$$
\bar{D}_{i}=\bar{D}_{i}^{*} \times \beta=\bar{D}_{i}^{*} \times \frac{\partial \ln a_{i}}{\partial \ln \omega_{i}}
$$

where $\bar{D}_{i}^{*}$ is the diffusion coefficients corrected for convective and non-ideal effects, $\beta$ is the thermodynamic factor, and $a_{i}$ is the activity of the sorbing species. Noteworthy, $\bar{D}_{i}^{*}$ is equivalent to the Maxwell-Stefan diffusion coefficient.

As a case study, we consider liquid ethanol transport in freestanding PTMSP films ( $c f$. Fig. 2A). Ethanol diffusion coefficients in PTMSP may be calculated using three methods. Method 1 neglects convective and non-ideal thermodynamic effects, according to the approach commonly used for gas separation membranes, therefore it provides an estimate of $D_{i}$. Method 2 relies on Eqn 6 and provides the diffusion coefficient corrected for convective effects (that is, $\bar{D}_{i}$ ). Finally, Method 3 relies on Eqn 6 and 7 to provide $\bar{D}_{i}^{*}$, that is the "true" diffusion coefficient corrected for convective and thermodynamic non-ideal effects. The three methods are compared in Fig. $2 \mathrm{~B}$, which shows that, if properly formulated, the solution-diffusion model provides, consistently with the expectations, mutual diffusion coefficients well below the solvent self-diffusion coefficient. In other words, if the solution-diffusion model is formulated to consider non-ideal and convective effects, which are non-negligible in OSN applications, it can correctly describe OSN polymer membranes without the need to resort to complicated transport models.

Fig. 2A shows the experimentally measured liquid ethanol permeability in PTMSP up to 35 bar: permeability gradually decreases with increasing pressure difference across the membrane. Fig. 2B shows liquid ethanol diffusivity in PTMSP, calculated using the three methods described above. Interestingly, diffusivity increases with increasing $\Delta p$. Relevant implications of this will be discussed hereafter. Finally, liquid ethanol sorption coefficient in PTMSP decreases with increasing $p$. This result indicates that, contrarily to what commonly speculated in the literature, sorption plays a role as important as diffusion, or even 

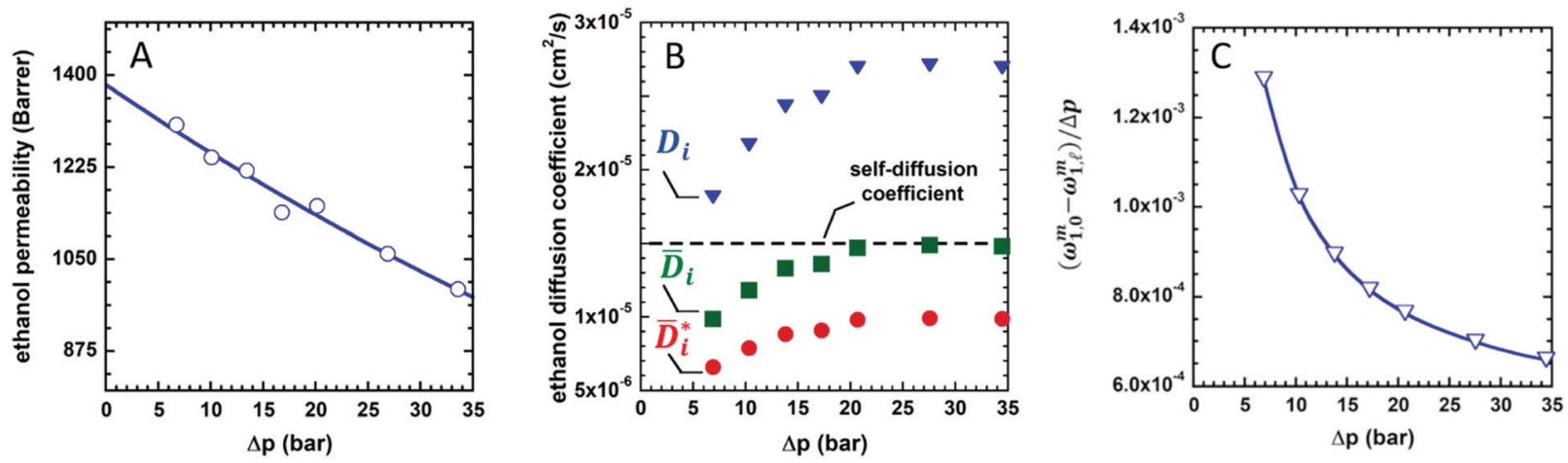

Fig. 2 (A) Liquid ethanol permeability in PTMSP with a thickness of $\ell(\mathrm{m})$ at room temperature as a function of $\Delta p .1 \mathrm{Barrer}=1.2 \times 10^{-10} \ell \mathrm{M}_{\mathrm{W}} / \rho(\mathrm{LMH} / \mathrm{bar}$ per $\mathrm{m})$, where $M_{\mathrm{W}}\left(\mathrm{g} \mathrm{mol}^{-1}\right)$ and $\rho\left(\mathrm{g} \mathrm{cm}^{-3}\right)$ are the molecular weight and density of ethanol, respectively. (B) Liquid ethanol diffusion coefficient in PTMSP as a function of $\Delta p^{58}$ calculated according to methods $1\left(D_{i}\right), 2\left(\bar{D}_{i}\right)$ and $3\left(\bar{D}_{i}^{*}\right)$, and $(C)$ liquid ethanol sorption coefficient in PTMSP as a function of $p^{58}$ Copyright 2020, Elsevier.

more important, in regulating solvent permeability through OSN membranes, at least in the case of ethanol transport in PTMSP.

Solvent flux can deviate from the linearity and eventually levels off as the pressure difference across a membrane increases. ${ }^{6}$ Often, in the literature, this phenomenon is ascribed to membrane compaction under pressure. The membrane compaction hypothesis implicitly assumes a pore flow transport mechanism through the membrane, which creates some confusion in the literature about whether OSN membranes are best described by the pore flow model, the solution diffusion model, or a combination of the two. Moreover, glassy polymers typically used in OSN experiments have very high Young's modulus, which makes them stiff enough to avoid compression under normal operating conditions. For example, Celazole ${ }^{\circledR}$ polybenzimidazole (PBI) membranes retain a Young's modulus of $5 \mathrm{GPa}$ upon exposure to solvents, which is clearly not compatible with membrane compaction at $10 \mathrm{~atm}$ or so. ${ }^{59}$ Recently, Bye and Galizia demonstrated that the origin of flux non-linearity is merely thermodynamic. Coupling Eqn 6 with the non-equilibrium lattice fluid model shows that any increase in $\Delta p$ across the membrane does not change solvent concentration in the upstream membrane face while causing a concentration decrease in the downstream face. Based on this argument, a $\Delta p$ must exist at which the solvent concentration in the downstream membrane side becomes zero. Based on Fick's law, when this condition is attained, the driving force for penetrant transport reaches its maximum value. Therefore, no further increase in solvent flux may be observed with increasing $\Delta p$, that is, a ceiling flux must exist. Therefore, solvent flux must gradually decline with increasing $\Delta p$ to approach its ceiling value.

The fact that flux non-linearity is not due to membrane compaction emerges, implicitly, from the analysis of Fig. 2B. Specifically, the liquid ethanol diffusion coefficient in PTMSP increases with increasing the pressure difference across the membrane. This result provides further evidence that membrane compaction does not take place, as compaction would cause a decrease in diffusivity instead of an increase. An important implication of this result is that flux non-linearity $v s$. $\Delta p$ can't be eliminated by properly designing the membrane material, as it has a thermodynamic origin and is not related to any membrane structural feature.

Although the validity of the solution-diffusion model for OSN polymer membranes has been unequivocally demonstrated, ${ }^{58,59,63}$ the pore flow model might still be invoked to describe solute and solvent transport in porous membranes based on MOFs, COFs, and carbon molecular sieves (CMS). ${ }^{3,59}$ While small molecule transport in dense materials occurs mainly in transient gaps between polymer chains, which continuously open and close as a consequence of thermal fluctuations (i.e., Brownian motion), penetrants transport in porous materials occurs through permanent pores with the size larger than the penetrant molecular size. The chemical potential gradient that drives small molecule transport across the porous membrane is not due to a concentration gradient, as in a solution-diffusion membrane, but to a pressure gradient, while the solute and solvent concentrations within a pore are uniform. ${ }^{64}$ The Darcy's law is used to express the flux of the specie $i, n_{i}$, through a porous membrane: ${ }^{65}$

$$
n_{i}=K \frac{\Delta p}{\ell}
$$

where $K$ is the permeability coefficient, $\Delta p$ is the pressure gradient across the membrane and, as usual, $\ell$ is the membrane thickness. The permeability coefficient, $K$, is obviously a membrane property, as it depends on its structure, pore size distribution, and tortuosity.

If the pores exhibit a uniform cylindrical shape, Darcy's law gives rise to the Hagen-Poiseuille equation, which describes solvent flux through a porous membrane, $n_{\mathrm{s}}{ }^{65}$

$$
n_{\mathrm{s}}=K_{\mathrm{s}} \frac{\Delta p}{A \eta}
$$

where $K_{\mathrm{s}}$ is the solvent permeability coefficient, $A$ is the pore cross-section area, and $\eta$ is the solvent viscosity, which is the main property affecting solvent transport. $K_{\mathrm{s}}$, in turn, depends on the membrane structure, such as porosity, $\varepsilon$, tortuosity 
factor, $\tau$, pore radius, $r$, and $\ell .:$

$$
K_{\mathrm{s}}=\frac{\varepsilon r^{2}}{8 \tau \ell}
$$

Several empirical models were developed to describe the solute transport in porous materials, most of which assume that solute transport is affected by molecular interactions with the pore wall and steric hindrance. ${ }^{66-68}$

Alternative pore flow models, not related to the Darcy's law, were developed starting from the Nerst-Plank equation. ${ }^{65}$ These models account for steric hindrance and electrostatic effects and, as such, they can also be used to describe the transport of aqueous solutions through porous membranes, such as the Donnan-Steric Pore Flow Model (DSPM): ${ }^{65,69}$

$$
n_{i}=-K_{i}^{\mathrm{d}} D_{i} \frac{\mathrm{d} C}{\mathrm{~d} x}+K_{i}^{\mathrm{c}} C_{i} v_{i}-\frac{z_{i} C_{i} F}{R T} K_{i}^{\mathrm{d}} D_{i} \frac{\mathrm{d} \psi}{\mathrm{d} x}
$$

where $K_{i}^{\mathrm{d}}$ and $K_{i}^{\mathrm{c}}$ are the diffusive and convective transport coefficients, respectively, $z_{i}$ is the solute valence, $\psi$ is the electrical potential, $x$ is the current abscissa throughout the membrane thickness, $C_{i}$ is the concentration of species $i, F$ is the Faraday constant and $v_{i}$ is the velocity of species $i$ through the pore.

\subsection{Trade-off between permeability and selectivity}

Membrane permeability can be increased by designing architectures with higher free volume, which decreases the sizesieving ability and thus diffusivity selectivity. Such permeability/ selectivity trade-off is widely reported for gas separation, water/salt separation, and liquid separations, and it provides a benchmark for any new membranes developed. ${ }^{70}$ Fig. $3 \mathrm{~A}$ shows an example upper bound plot of acetone permeance as a function of styrene dimer rejection. ${ }^{14,71}$ Fig. 3B depicts the upper bound for water/ $n$-butanol separation using pervaporation method with the separation factor as a function of water permeance. ${ }^{72}$ Membranes with higher permeance often exhibit lower selectivity (as indicated by rejection or separation factor) and vice versa.

Fig. 3C presents an upper bound plot for the separation of methanol over various solutes of $210-320 \mathrm{~g} \mathrm{~mol}^{-1}$ including dyes and PEG. ${ }^{73}$ The use of permeance selectivity of methanol over solutes (instead of rejection or separation factor) eliminates the effect of the operating conditions, such as feed pressure and composition, and enables a direct comparison of membrane properties. ${ }^{75}$ Fig. 3D displays the upper bound plot for methanol/Brilliant Blue dye separation using methanol permeability, eliminating the effect of the selective layer thickness and enabling a direct comparison of the selective layer materials.

\subsection{Commercial membranes}

Polymeric membranes have been developed for OSN applications due to their easily fine-tuned microstructures and great processabilities, such as polyimides (PI), polysulfone (PSF), poly(ether ether) ketone (PEEK), and PBI. Table 2 summarizes the separation performance of state-of-the-art commercial membranes. Their commercial sources had been documented
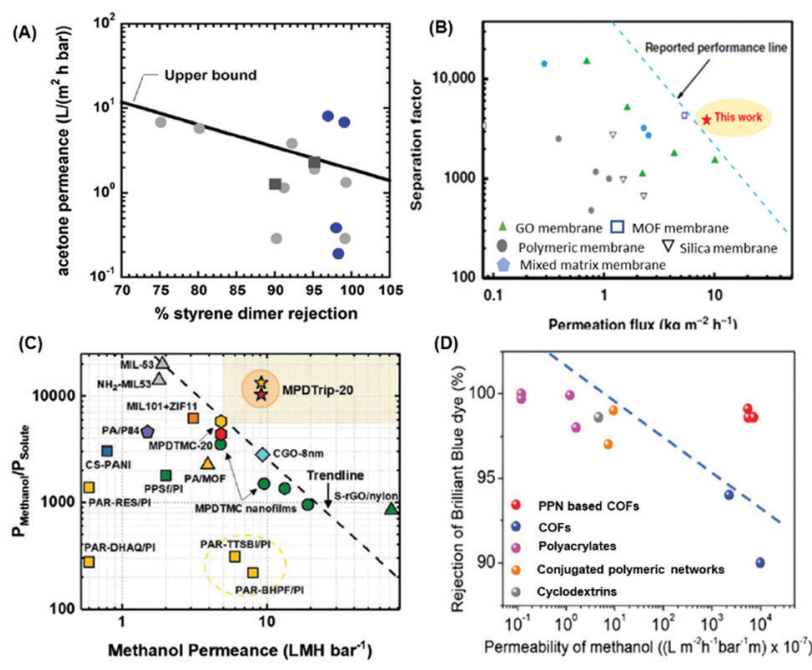

Fig. 3 Examples of upper bound plots. (A) Acetone/styrene dimer separation for integrally skinned asymmetric membranes (ISA, O), TFCs ( $\mathbf{\square})$, and polyacrylates (O). ${ }^{14}$ Copyright 2018, Frontiers in Chemistry. (B) Water/ $n$-butanol separation. ${ }^{72}$ Copyright 2019, Springer Nature. (C) Methanol permeance $v s$. selectivity of small solutes of 20 ppm dyes and 2000 ppm PEG (210-320 $\mathrm{g} \mathrm{mol}^{-1}$ ) for TFC membranes. ${ }^{73}$ Copyright 2020, WILEY-VCH. (D) Rejection of Brilliant Blue $\left(820 \mathrm{~g} \mathrm{~mol}^{-1}\right)$ vs. methanol permeability. ${ }^{74}$ Copyright 2020, Royal Society of Chemistry.

in the literature. ${ }^{3}$ PIs are the leading materials for OSN applications as they are relatively stable in organic solvents. ${ }^{76}$ StarMem $^{\text {TM }}$ (W.R. Grace), DuraMem ${ }^{\mathrm{TM}}$ (Evonik) and PuraMem ${ }^{\mathrm{TM}}$ (Evonik) are based on PIs and the tightest commercial membranes available for OSN. ${ }^{3,59}$ For example, DuraMem ${ }^{\mathrm{TM}} 300$ shows excellent performance with acetone permeance of $4.17 \mathrm{LMH}$ per bar and a rejection of 92.5\% for dimethyl styrene (236 $\mathrm{g} \mathrm{mol}^{-1}$ ); MPF-44 with a polydimethylsiloxane (PDMS) selective layer shows carbon tetrachloride $\left(\mathrm{CCl}_{4}\right)$ permeance of $\sim 0.53 \mathrm{LMH}$ per bar and a rejection of $97 \%$ for methylene blue. ${ }^{77,78}$

Commercial polyamide (PA)-based TFC membranes were also explored for OSN applications because they are produced on a large scale for water desalination by nanofiltration (NF) and thus inexpensive. ${ }^{38,79}$ However, they exhibit low solvent permeance. For example, NF90 exhibits ethanol permeance of $0.82 \mathrm{LMH}$ per bar, $^{38}$ while StarMem122 shows ethanol permeance of $2.41 \mathrm{LMH}$ per bar. ${ }^{80-83}$ More importantly, the commercial PA-based membranes are not engineered to be resistant to organic solvents, particularly for the porous support and nonwoven paper layer.

Table 2 shows various solvents and solutes used for testing. Most studies focused on common solvents, such as methanol, ethanol, and toluene. The solutes include large molecules, such as polystyrene (PS) oligomers and dyes, depending on the applications of interest.

One of the great challenges in OSN is the broad range of solvents involved, and membrane materials are not ubiquitously resistant. For example, DuraMem300 is not stable in certain chlorinated solvents, ${ }^{84}$ and it cannot be used at temperatures above $50{ }^{\circ} \mathrm{C} .{ }^{84}$ Therefore, new membranes with resistance to the solvents are being developed. More importantly, membrane 
Table 2 Summary of commercial membranes and their separation performance

\begin{tabular}{|c|c|c|c|c|c|c|c|c|}
\hline \multirow[b]{2}{*}{$\begin{array}{l}\text { Commercial } \\
\text { membranes }\end{array}$} & \multicolumn{2}{|l|}{$\underline{\text { Solvent }}$} & \multicolumn{4}{|l|}{$\underline{\text { Solute }}$} & \multicolumn{2}{|c|}{ Testing conditions } \\
\hline & Name & $\begin{array}{l}\text { Permeance } \\
\text { (LMH per bar) }\end{array}$ & Name & $\begin{array}{l}\text { Conc. } \\
\left(\mathrm{mg} \mathrm{L}^{-1}\right)\end{array}$ & $\begin{array}{l}\text { MW } \\
\left(\mathrm{g} \mathrm{mol}^{-1}\right)\end{array}$ & $\begin{array}{l}\text { Rejection } \\
(\%)\end{array}$ & $\begin{array}{l}\text { Flow } \\
\text { mode }\end{array}$ & $\Delta p$ (bar) \\
\hline \multirow[t]{8}{*}{ PI: STARMEM $122^{80-83}$} & Methanol & 5.48 & Sudan 408 & 10 & 464 & 91.4 & Dead-end & 30 \\
\hline & Ethanol & 2.41 & & & & 92.6 & & \\
\hline & Acetone & 4.65 & & & & 43.8 & & \\
\hline & $\begin{array}{l}\text { Methyl } \\
\text { ethyl ketone }\end{array}$ & 8.51 & & & & 50.3 & & \\
\hline & Toluene & 1.37 & & & & 78.7 & & \\
\hline & IPA & $\sim 0.7$ & Imatinib mesylate & 50 & 589 & $\sim 91$ & & 30 \\
\hline & Ethanol & 0.32 & Cooking oil & 126742 & 914 & 98 & & 20 \\
\hline & Toluene & 0.56 & PS oligomers & 1000 & $\sim 270$ & 90 & & 30 \\
\hline \multirow[t]{4}{*}{ PI: STARMEM $240^{78}$} & Ethanol & $\sim 5.4$ & Methylene blue & 11.2 & 319 & $\sim 42$ & & 13.8 \\
\hline & IPA & $\sim 5.1$ & & & & $\sim 72$ & & \\
\hline & Hexane & $\sim 4.7$ & & & & $\sim 50$ & & \\
\hline & $\mathrm{CCl}_{4}$ & $\sim 5.1$ & & & & $\sim 65$ & & \\
\hline \multirow[t]{2}{*}{ PI: DuraMem $500^{43,55,57}$} & Ethyl acetate & 0.29 & Methyl vanillate & 250 & 182 & 61.4 & Cross-flow & 20 \\
\hline & Acetone & 1.02 & Glyceryl trilinolate & 39200 & 885 & 86 & Dead-end & 26 \\
\hline PI: DuraMem $900^{57}$ & Ethyl acetate & 0.43 & Methyl vanillate & 250 & 182 & 26.2 & Cross-flow & 20 \\
\hline PI: PuraMem $380^{57}$ & Ethyl acetate & 2.06 & Methyl vanillate & 250 & 182 & 32.8 & & 20 \\
\hline \multirow[t]{2}{*}{ PI: PuraMem $280^{57,83}$} & Ethyl acetate & 1.24 & Methyl vanillate & 250 & 182 & 19.6 & & 20 \\
\hline & Toluene & 0.67 & PS oligomers & 1000 & $\sim 280$ & 90 & & 30 \\
\hline \multirow[t]{2}{*}{ PI: DuraMem $300^{55,85}$} & Acetone & 4.17 & PS oligomers & 10 & 236 & 92.5 & & 30 \\
\hline & Acetone & 0.11 & Glyceryl trilinolate & 39200 & 885 & 100 & Dead-end & 26 \\
\hline \multirow[t]{2}{*}{ PI: DuraMem $150^{55,81}$} & Acetone & 0.08 & Glyceryl trilinolate & 39200 & 885 & 100 & & 26 \\
\hline & Methanol & $\sim 0.35$ & Atenolol & 50 & 266 & $\sim 97.5$ & & 30 \\
\hline PI: PuraMem $280^{55}$ & Acetone & 3.93 & Glyceryl trilinolate & 39200 & 885 & 96.8 & & 26 \\
\hline PI: PuraMem $600^{55}$ & Acetone & 1.23 & Glyceryl trilinolate & 39200 & 885 & 88.5 & & 26 \\
\hline \multirow[t]{3}{*}{ PI: PuraMem S600 43} & Toluene & $\sim 2$ & Palladium(II)acetate & NS & 224 & $\sim 60$ & & 40 \\
\hline & IPA & $\sim 0.2$ & & & & $\sim 76$ & & \\
\hline & Methanol & $\sim 0.15$ & & & & $\sim 76$ & & \\
\hline PI: DuraMem $500^{86}$ & Acetonitrile & 0.8 & Acid fuchsin & 20 & 585 & 94.6 & Cross-flow & 10 \\
\hline PI: PuraMem $420^{86}$ & Acetonitrile & 0.3 & Acid fuchsin & 20 & 585 & 98 & & 10 \\
\hline NanoPro S-3011 87 & Methanol & 0.26 & Triphenylphosphine & 7.92 & 262 & 93 & & 20 \\
\hline PI: DuraMem $150^{88}$ & THF & 0.1 & PS oligomers & 2000 & 250 & $>99$ & & 30 \\
\hline PA: NF- $90^{38}$ & Ethanol & $\sim 0.82$ & 1-(5-Bromo-fur- & 26000 & 297 & $\sim 55$ & Dead-end & $20-40$ \\
\hline PA: NF- $270^{38}$ & & $\sim 0.56$ & 2-il)-2-bromo- & & & $\sim 21$ & & \\
\hline PA: BW30XLE ${ }^{38}$ & & $\sim 0.22$ & 2-nitroethane & & & $\sim 30$ & & \\
\hline \multirow[t]{4}{*}{ PDMS: MPF- $34^{78}$} & Ethanol & $\sim 0.32$ & Methylene blue & 11.2 & 319 & $\sim 42$ & & 13.8 \\
\hline & IPA & $\sim 0.065$ & & & & $\sim 72$ & & \\
\hline & Hexane & $\sim 0.54$ & & & & $\sim 50$ & & \\
\hline & $\mathrm{CCl}_{4}$ & $\sim 0.094$ & & & & $\sim 65$ & & \\
\hline \multirow[t]{5}{*}{ PDMS: MPF- $44^{77,78}$} & Methanol & 1.88 & Eosin B & 15 & 880 & 93 & & 20 \\
\hline & Ethanol & $\sim 0.15$ & Methylene blue & 11.2 & 319 & $\sim 91$ & & 13.8 \\
\hline & IPA & $\sim 0.03$ & & & & $\sim 81$ & & \\
\hline & Hexane & $\sim 0.094$ & & & & $\sim 91$ & & \\
\hline & $\mathrm{CCl}_{4}$ & $\sim 0.53$ & & & & $\sim 97$ & & \\
\hline PDMS: MPF- $50^{77}$ & Methanol & 2.5 & Eosin B & 15 & 880 & 97 & & 20 \\
\hline \multirow[t]{2}{*}{ PDMS: PERVAP $4060^{89}$} & Toluene & 2.2 & Tetraoctyl- & 870 & 546 & 92.5 & Cross-flow & 10 \\
\hline & Ethanol & 0.35 & ammonium & 789 & & 95.6 & & \\
\hline PDMS: MPF-60 89 & Methanol & 0.13 & bromide & 2373 & & 98 & & \\
\hline
\end{tabular}

technology always becomes more competitive as new materials with improved permeance and rejection outperforming the upper bound are developed.

\section{Cross-linked polymers}

Polymer cross-linking is an effective technique to enhance chemical stability against solvents and fine-tune the free volume, leading to improve size-sieving ability. ${ }^{90-93}$ Additionally, cross-linking reduces membrane swelling and solvent uptake ${ }^{94-96}$ and increases glass transition temperature $\left(T_{\mathrm{g}}\right)$ and degradation temperature. ${ }^{96,97}$ Two approaches have been adopted to develop cross-linked polymers. (1) Polymers with promising separation properties can be post-cross-linked using thermal or chemical methods, such as PIs, polyacrylonitrile (PAN), PBI, PEEK, and polyaniline (PANI). (2) Highly cross-linked PA-based TFC membranes (originally designed for water desalination) have been engineered using a bottom-up design approach. ${ }^{22}$ The representative results are summarized in Table 3 , and their details are discussed below.

\subsection{Post-cross-linked polymers}

3.1.1. Cross-linked PIs. PI membranes are often prepared using the phase inversion technique to form an integrally skinned asymmetric (ISA) structure. ${ }^{2,65}$ Polymers or precursors 
(i.e., poly(amic acid)) are dissolved in a mixture of solvents and co-solvents, and then exposed to a non-solvent for precipitation. The membranes are then cross-linked using diamines and conditioned with pore preserving agents, such as hexanediamine (HDA) and polyethylene glycols (PEGs), respectively. ${ }^{93,98-102}$

The processing conditions of phase-inversion, such as casting film thickness and evaporation time, can impact the membrane structure and thus OSN performance, ${ }^{92,93,103}$ For example, increasing the evaporation time decreased porosity without changing the pore size, thereby decreasing the permeance, while increasing the film thickness decreased the permeance; polymers with high molecular weight (>35 kDa) were preferred to obtain defect-free membranes; ${ }^{99}$ the introduction of a co-solvent in the dope solution with optimal solubility parameter tightened nanostructures due to delayed demixing; ${ }^{93,98}$ and increasing relative humidity created more open structures and decreased the solute rejection. ${ }^{93,98}$ Specifically, PMDA-ODA was fabricated into membranes, and the effect of the coagulation and imidization conditions on the structure/ property relationship was thoroughly investigated. ${ }^{101,102}$ Delayed solvent/anti-solvent demixing was essential to preclude the macrovoid formation, and thermal imidization resulted in mechanically stronger and tougher membranes than chemical imidization.

Fig. 4A and B shows the cross-linking of P84 with polyethyleneimine (PEI) and HDA, respectively. Fig. 4C shows that the cross-linking with PEI-1.8K decreased the pore size from $1.51 \pm 0.58 \mathrm{~nm}$ to $0.69 \pm 0.27 \mathrm{~nm}$, increasing the rejection of Rhodamine B and decreasing the ethanol permeance ( $c f$. Fig. 4D). ${ }^{104}$ Moreover, P84 substrate was modified with m-phenylenediamine (MPD), dopamine (DA), and 1,2,4,5-benzene tetracarboxylic acyl chloride (BTAC) to form PA TFC followed by chemical imidization to create PI-TFC membranes. ${ }^{105}$ This approach creates covalent bonding between the substrate and selective layer, thereby improving the membrane stability in harsh solvents (such as DMF) with a rejection of $99.9 \%$ for rose bengal, as shown in Table 3.

The membrane surface can be further modified. For example, membranes made of Matrimid ${ }^{\mathbb{R}} 5218$ were grafted with poly(ethylene glycol) (PEG) by plasma treatment to increase the porosity and hydrophilicity. ${ }^{106}$ The modified membrane showed a DMF permeance of $10.8 \mathrm{LMH}$ per bar but poor rejection of rose bengal $(72.93 \%)$ due to its instability in harsh solvents.

3.1.2. Cross-linked PBI. PBI has high $T_{\mathrm{g}}\left(410-430{ }^{\circ} \mathrm{C}\right)$, good mechanical properties, and strong size-sieving ability derived from the $\pi-\pi$ stacking and H-bonding interactions. ${ }^{32,114,162-165}$ However, PBI is not stable in NMP, DMF, and DMAc. ${ }^{111,166}$ Therefore, a variety of cross-linking methods have been developed to improve chemical stability as well as the size-sieving ability. ${ }^{32-34,111,114,166,167}$ For example, PBI can be easily doped by polyprotic acids (such as sulfuric acid or $\mathrm{H}_{2} \mathrm{SO}_{4}$ ), as shown in Fig. 5A. ${ }^{32}$ The $\mathrm{H}_{2} \mathrm{SO}_{4}$ cross-linking decreased the $d$-spacing of $5.06 \AA$ to $4.71 \AA ̊$ ( $c f$. Fig. 5B) and the MWCO from $2000 \mathrm{~g} \mathrm{~mol}^{-1}$ to $500 \mathrm{~g} \mathrm{~mol}^{-1}$ (Fig. 5C). ${ }^{32}$ PBI can also be cross-linked using trimesoyl chloride (TMC), ${ }^{34,168}$ yielding a robust membrane. Fig. 5D shows that the liquid permeance increased with increasing values of the product of their Hansen solubility parameter, molar volume, and viscosity. The cross-linked membrane showed acetonitrile permeance of $40.7 \mathrm{LMH}$ per bar and tetracycline rejection of $97.8 \%$.

PBI was cross-linked using glutaraldehyde (GA) in aqueous solutions at $\approx 23{ }^{\circ} \mathrm{C}$ and 1,2,7,8-diepoxyoctane (DEO) at $90{ }^{\circ} \mathrm{C},{ }^{112}$ and $\alpha, \alpha^{\prime}$-dibromo- $p$-xylene (DBX) and 1,4-dibromobutane (DBB). ${ }^{111,166}$ An ionically bonded composite structure was prepared using PBI cross-linked by DBX and hyperbranched PEI (HPEI) cross-linked sulfonated polyphenylsulfone (sPPSU), which exhibited solvent permeance of 2-12 LMH per bar and a rejection of $67-97 \%$ for tetracycline $\left(444 \mathrm{~g} \mathrm{~mol}^{-1}\right) .{ }^{113}$ PBI-DBX surface was further cross-linked using HPEI, leading to a selective layer of $47 \mathrm{~nm}$ with ethanol permeance of $4.5 \mathrm{LMH}$ per bar and complete rejection of tetracycline. ${ }^{33}$

PBI can be functionalized before cross-linking. For example, PBI was converted to hydroxylated PBI (PBI-OH) and then crosslinked with toluene-2,4-diisocyanate (TDI). ${ }^{114}$ PBI was also blended with $\mathrm{NH}_{2}$-PIM-1 followed by $\mathrm{HCl}$ treatment to create an ionically cross-linked porous structure, which showed a surface area $\sim 3$ times higher than the HCl-treated PBI. ${ }^{115}$ The membrane was stable in DMSO for 3 months while retaining MWCO and permeance. Interpenetrating polymer networks of polydopamine (PDA) and PBI were prepared and exhibited permeance of 9.6-19.2 LMH per bar for polar aprotic solvents and low MWCO of 230-320 $\mathrm{g} \mathrm{mol}^{-1}$. $^{116}$

3.1.3. Cross-linked PANI and PEEK. PANI has singlebonded amino groups and double-bonded imine groups with $\pi-\pi$ interactions and strong size-sieving ability. It has three structures due to the oxidation, i.e., Leucoemeraldine structure, oxidized-pernigraniline, and an intermediate stage of emeraldine base (EB) with equal protonated and unprotonated amino groups. ${ }^{120}$ However, PANI is soluble in DMSO and NMP, ${ }^{118,119}$ so it must be cross-linked for OSN applications. Fig. 6A and B shows the chemical cross-linking by GA and $\alpha, \alpha$-dichloro- $p$ xylene (DCX), respectively, improving chemical stability and reducing the MWCO to as low as $300 \mathrm{~g} \mathrm{~mol}^{-1} \cdot{ }^{117,118}$ PANI can also be thermally cross-linked (Fig. 6C), ${ }^{117}$ which led to MWCO of 150-300 $\mathrm{g} \mathrm{mol}^{-1}$ and improved stability in harsh solvents at elevated temperatures.

PEEK membranes are stable in various organic solvents and acids at elevated temperatures, depending on their degree of sulfonation (DS). ${ }^{169}$ DS can be changed by reacting PEEK with methane sulfonic acid (MSA) and/or $\mathrm{H}_{2} \mathrm{SO}_{4}$ to form SPEEK. Fig. 6D shows examples of PEEK modification to improve separation properties, such as multilayer coating of SPEEK and PEI, ${ }^{170}$ phenolphthalein based cardo structured PEEK (PEEKWC), ${ }^{171}$ incorporation of $N$-hydroxy succinimide in VAPEEK with $30 \%$ HDA cross-linking, ${ }^{121}$ and partial quaternization after di-halide or di-epoxide cross-linking with TAPEEK. ${ }^{172,173}$ Though PEEK membranes show great stability in various solvents, the solvent permeance and solute selectivity need to be further enhanced to make it as a commercially viable option ( $c f$. Table 3).

3.1.4. Cross-linked PAN. PAN has been fabricated into ultrafiltration (UF) membranes, which are inexpensive and show low fouling properties due to its hydrophilic nature. ${ }^{95}$ However, it is not stable in solvents such as DMF, 
Table 3 Summary of performance of cross-linked polymers, PA-based TFC and TFN, and MMMs for OSN application

\begin{tabular}{|c|c|c|c|c|c|c|c|c|}
\hline \multirow[b]{2}{*}{ Membrane materials } & \multicolumn{2}{|l|}{$\underline{\text { Solvents }}$} & \multicolumn{4}{|l|}{$\underline{\text { Solutes }}$} & \multicolumn{2}{|c|}{ Testing conditions } \\
\hline & Name & $\begin{array}{l}\text { Permeance } \\
\text { (LMH per bar) }\end{array}$ & Name & $\begin{array}{l}\text { Conc. } \\
\left(\mathrm{mg} \mathrm{L}^{-1}\right)\end{array}$ & $\begin{array}{l}\text { M.W. } \\
\left(\mathrm{g} \mathrm{mol}^{-1}\right)\end{array}$ & $\begin{array}{l}\text { Rejection } \\
(\%)\end{array}$ & $\begin{array}{l}\text { Flow } \\
\text { mode }\end{array}$ & $\begin{array}{l}\Delta p \\
\text { (bar) }\end{array}$ \\
\hline \multicolumn{9}{|l|}{ Cross-linked polymers } \\
\hline PMDA-ODA ${ }^{102}$ & DMF & 2.09 & Rose Bengal & 35 & 1017 & 92.7 & Dead-end & 10 \\
\hline Plasma grafted & Ethanol & 13.78 & Rose Bengal & 50 & 1017 & 83.61 & & 10 \\
\hline \multirow{4}{*}{ PEG400/Matrimid ${ }^{\circledR} 5218^{106}$} & IPA & 5.91 & & & & 99.64 & & \\
\hline & 1-Butanol & 4.89 & & & & 99.98 & & \\
\hline & THF & 23.79 & & & & 98.52 & & \\
\hline & DMF & 10.8 & & & & 72.53 & & \\
\hline \multirow[t]{2}{*}{ PI-PI ${ }^{105}$} & Ethanol & 2.03 & Rhodamine B & 100 & 1017 & 98 & Cross-flow & 10 \\
\hline & DMF & 1.15 & Rose Bengal & & & 99.9 & & \\
\hline $\mathrm{PI} / \mathrm{H}-\mathrm{PAN}{ }^{107}$ & Ethanol & 0.68 & CBBG250 & 100 & 854 & 99 & & 10 \\
\hline Hydrazine/PAN ${ }^{108}$ & Ethanol & 2.32 & Brilliant Blue $\mathrm{R}$ & 200 & 627 & $\sim 99.9$ & & 2 \\
\hline WS $_{2} /$ Hydrazine/PAN ${ }^{109}$ & Ethanol & 44.38 & Evans blue & 50 & 960 & 99 & Dead-end & 1 \\
\hline \multirow{2}{*}{ PDA/SPEEK/H-PAN ${ }^{110}$} & IPA & 0.1 & Rose Bengal & - & 1017 & 99 & & 20 \\
\hline & THF & 7.23 & & & & 97 & & \\
\hline \multirow[t]{2}{*}{$\mathrm{DBX} / \mathrm{PBI}^{111}$} & Acetonitrile & 11 & PEG 2000 & 1000 & 2000 & $\sim 96$ & Cross-flow & 10 \\
\hline & DMF & 6 & - & - & - & - & & \\
\hline \multirow[t]{2}{*}{$\mathrm{DBB} / \mathrm{PBI}^{111}$} & Acetonitrile & 7 & PEG 2000 & 1000 & 2000 & $\sim 90$ & & \\
\hline & DMF & 1 & - & - & - & - & & \\
\hline $\mathrm{GA} / \mathrm{PBI}^{112}$ & Ethyl acetate & 5.21 & - & - & - & - & Dead-end & 5 \\
\hline & Ethanol & 3.69 & Brilliant Blue R & 200 & 627 & $\sim 100$ & & \\
\hline $\mathrm{DEO} / \mathrm{PBI}^{112}$ & Ethyl acetate & 1.37 & - & - & - & - & & \\
\hline & Ethanol & 1.02 & Brilliant Blue R & 200 & 627 & $\sim 100$ & & \\
\hline & DMSO & 0.31 & - & - & - & - & & \\
\hline HPEI/sPPSU/DBX/PBI ${ }^{113}$ & Methanol & 6.43 & Tetracycline & 50 & 444 & 84 & & $2-5$ \\
\hline & Ethanol & 4.24 & & & & 94 & & \\
\hline & Acetone & 11.79 & & & & 81 & & \\
\hline & DMF & 10.49 & & & & 66 & & \\
\hline $\mathrm{H}_{2} \mathrm{SO}_{4} / \mathrm{PBI}^{32}$ & Methanol & 3.5 & Tetracycline & 50 & 444 & 98 & Cross-flow & 5 \\
\hline & Acetonitrile & 4.8 & - & - & - & - & & \\
\hline & Hexane & 7.2 & L- $\alpha$-Lecithin & 2000 & 758 & 99 & & \\
\hline $\mathrm{TMC} / \mathrm{PBI}^{34}$ & Acetone & 29 & Brilliant Blue $\mathrm{R}$ & 50 & 627 & 99.6 & Dead-end & 10 \\
\hline & Acetonitrile & 40.7 & Fast Green FCF & & 809 & 99.9 & & \\
\hline & Ethanol & 13.8 & Tetracycline & & 444 & 90.4 & & \\
\hline & IPA & 5.8 & Safranin $O$ & & 351 & 69.8 & & \\
\hline & Hexane & 80.8 & L- $\alpha$-Lecithin & 2000 & 758 & 92 & & \\
\hline GO/TDI/PBI ${ }^{114}$ & Acetone & $\sim 16$ & Mepenzolate & 100 & 420 & $\sim 100$ & Cross-flow & 10 \\
\hline $\mathrm{HCl} / \mathrm{NH}_{2}-\mathrm{PIM}-1 / \mathrm{PBI}^{115}$ & DMSO & $\sim 1.35$ & PS oligomers & 1000 & 310 & 90 & & 30 \\
\hline $\mathrm{PDA} / \mathrm{PBI}^{116}$ & Cyrene & $\sim 2$ & PS oligomers & 1000 & $\sim 180$ & 90 & & $10-30$ \\
\hline & DMF & $\sim 3.8$ & & & $\sim 240$ & & & \\
\hline & DMSO & $\sim 4.2$ & & & $\sim 300$ & & & \\
\hline GA/PANI ${ }^{117}$ & DMF & $\sim 0.43$ & & - & $\sim 300$ & 90 & & 30 \\
\hline DCX/PANI ${ }^{118}$ & DMF & $\sim 0.43$ & & - & $\sim 250$ & 90 & Dead-end & 30 \\
\hline & Acetone & $\sim 0.97$ & & & 236 & $\sim 98$ & & \\
\hline & Methanol & $\sim 0.97$ & & & 236 & $\sim 99$ & & \\
\hline GA/PANI ${ }^{118}$ & DMF & 0.33 & & & 250 & 90 & & \\
\hline Cross-linked PANI $(0.5 \mathrm{~h})^{119}$ & Methanol & 1.3 & & - & 236 & $\sim 78$ & & 30 \\
\hline Cross-linked PANI $(1 \mathrm{~h})^{119}$ & & 0.67 & & & 236 & $\sim 98$ & & \\
\hline PAMPSA/PANI ${ }^{120}$ & Methanol & 0.55 & Poly(propylene) & 4000 & 400 & $\sim 90$ & & 30 \\
\hline & IPA & $\sim 0.35$ & glycol (PPG) & & & $\sim 90$ & & \\
\hline EDA/VAPEEK ${ }^{121}$ & IPA & $\sim 0.5$ & Rose Bengal & 35 & 1017 & $\sim 69$ & Cross-flow & 20 \\
\hline BDA/VAPEEK ${ }^{121}$ & & $\sim 0.25$ & & & & $\sim 89$ & & \\
\hline HDA/VAPEEK ${ }^{121}$ & & $\sim 0.2$ & & & & $\sim 95$ & & \\
\hline Polyamide-based TFC membra & & & & & & & & \\
\hline MPD/TMC $(0.4 \%$ & Methanol & 26.3 & Methyl orange & 20 & 327 & 30.6 & Dead-end & 8.3 \\
\hline $\mathrm{NaOH} / \mathrm{DMF}$ activation $^{122}$ & & & Acid fuchsin & & 586 & 90.2 & & \\
\hline Triazine-piperazine $\mathrm{TFC}^{123}$ & & 9.75 & Reactive black & 20 & 992 & 98 & & 4 \\
\hline$\beta$-CD based PA TFC TF4 $^{124}$ & & $\sim 16$ & Methyl red & $10-20$ & 269 & 81 & & $0.5-10$ \\
\hline & & & Brilliant blue & & 625 & $>99$ & & \\
\hline MPD/TMC/DMF activation ${ }^{125}$ & & 52.22 & Acid fuchsin & 20 & 586 & 99.9 & & 10 \\
\hline & & & HNSA & & 246 & 98.5 & & \\
\hline MPD/Trip ${ }^{73}$ & & 8.7 & Sudan orange $\mathrm{G}$ & - & 216 & 99.1 & & 15.5 \\
\hline PIP-CB-6/TMC ${ }^{126}$ & & $\sim 3.5$ & Methylene blue & - & 319 & $\sim 96.5$ & & 6 \\
\hline $\mathrm{EtBr} / \mathrm{TMC}^{127}$ & & $\sim 17$ & Congo red & 100 & 697 & $\sim 91$ & & 1 \\
\hline $\mathrm{PEI} / \mathrm{TMC}^{128}$ & & $\sim 13.7-46.6$ & Rose bengal & 10 & 1017 & $\sim 99$ & & 5 \\
\hline MPD/TMC/aramid hydrogel ${ }^{37}$ & Methanol & 54 & - & 20 & - & - & & 4 \\
\hline & DMF & 34 & Erythrosin B & & 836 & $\sim 97$ & & \\
\hline & Acetone & 70 & - & & - & - & & \\
\hline
\end{tabular}


Table 3 (continued)

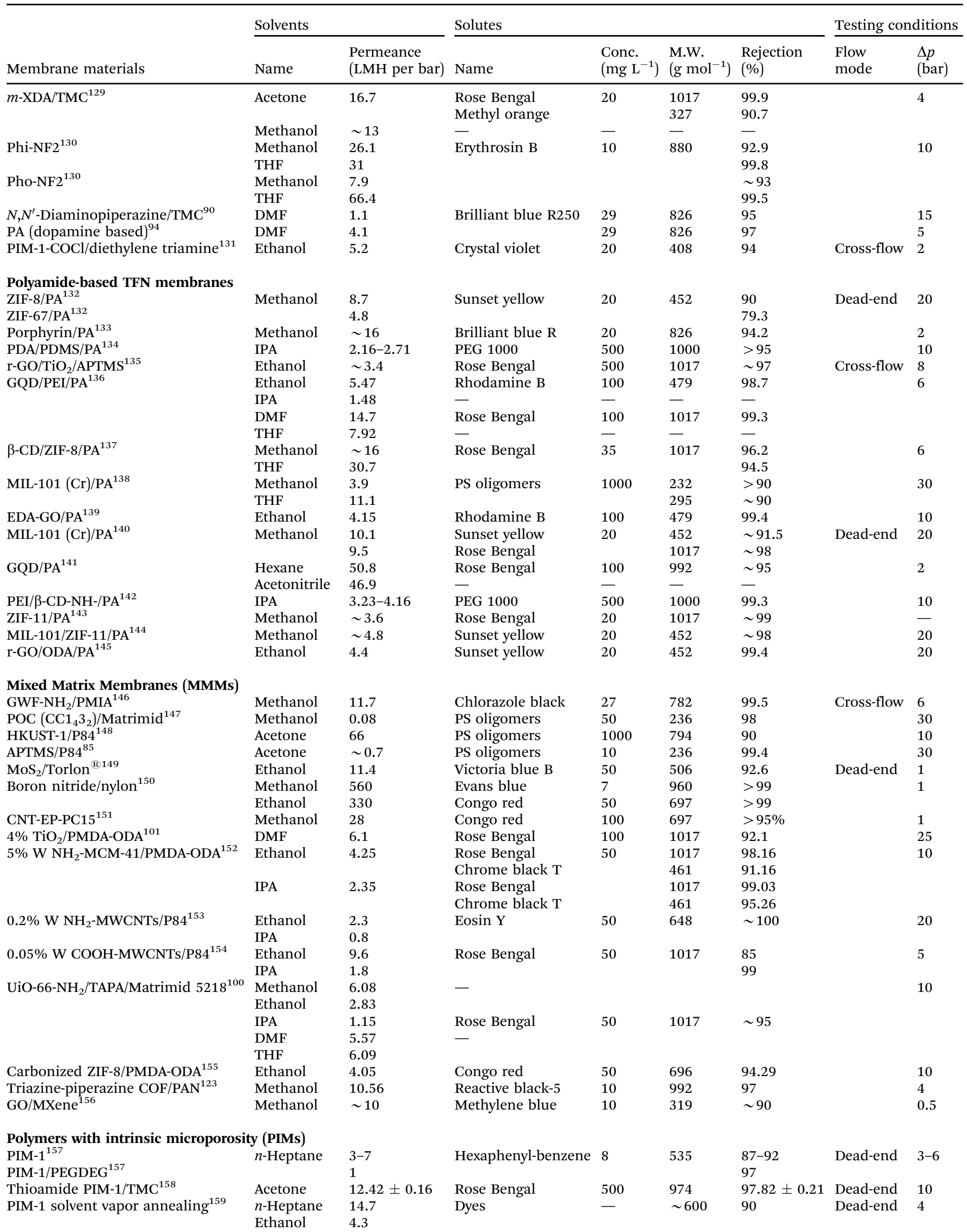


Table 3 (continued)

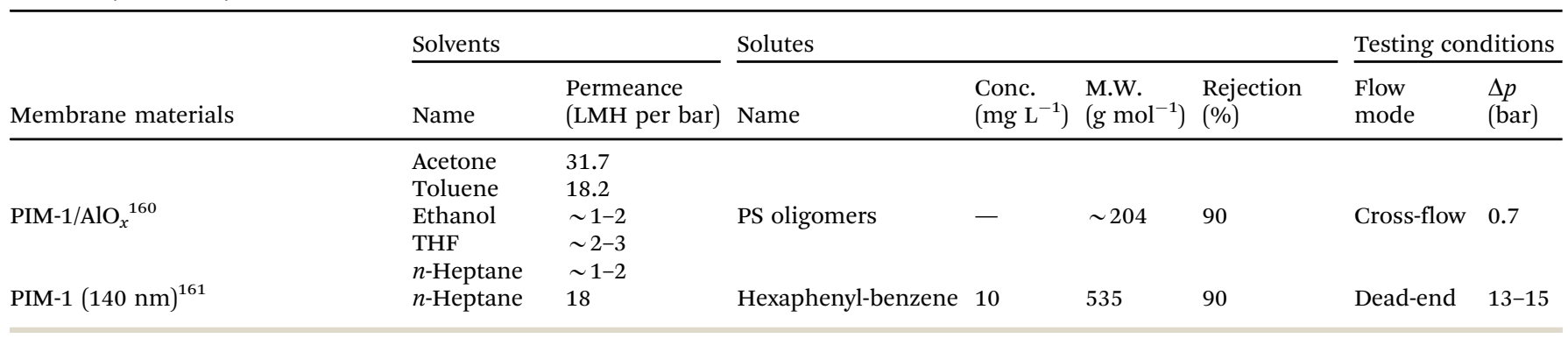

(A)

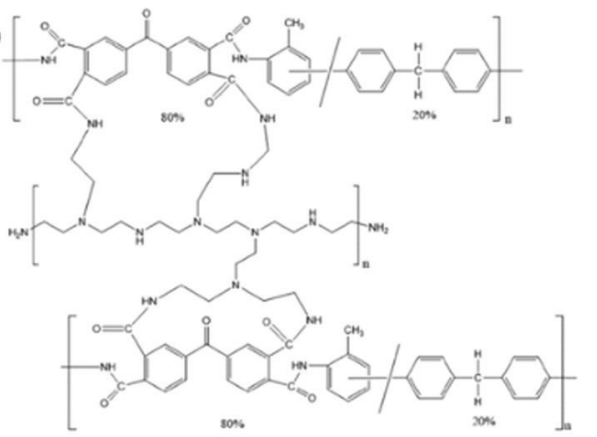

(C)

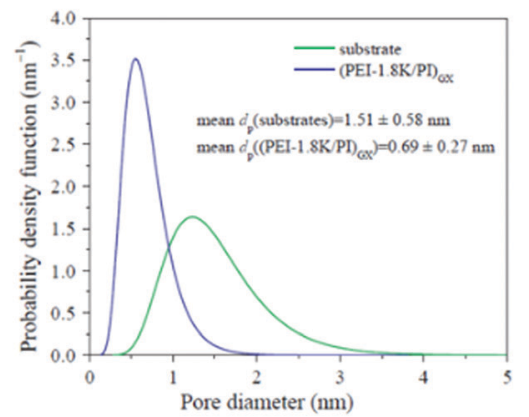

(B)

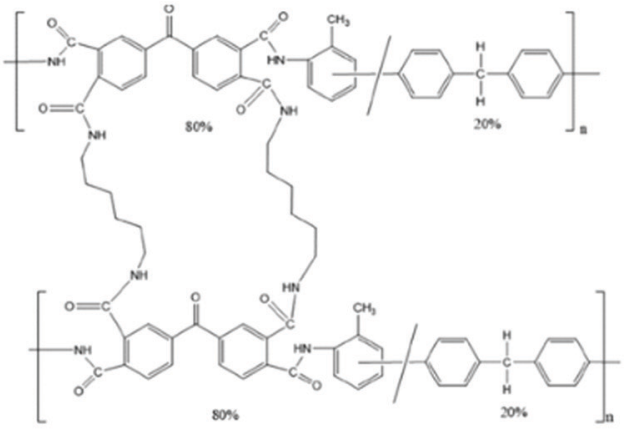

(D)

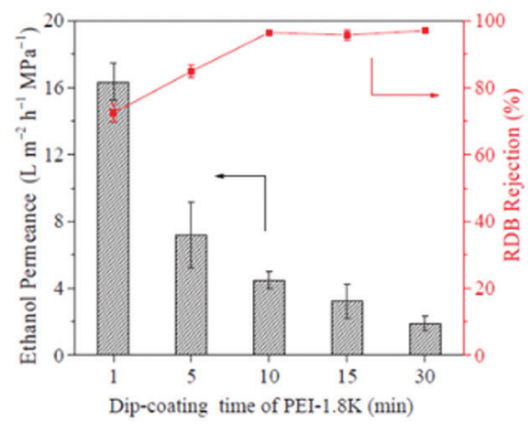

Fig. 4 Cross-linking mechanism of P84 hollow fibers (HF) membranes with (A) PEI and (B) HDA. Effect of cross-linking on (C) the decreased pore size and (D) ethanol permeance and rhodamine $\mathrm{B}(\mathrm{RDB})$ rejection. ${ }^{104} 1 \mathrm{LMH} / \mathrm{MPa}=0.1 \mathrm{LMH} /$ bar. Copyright 2020, Elsevier.

NMP, and THF. Cross-linking can improve their mechanical and chemical stability and lower the MWCOs for OSN applications. Fig. 7 shows that PAN hollow fiber membranes (HFMs) were cross-linked using hydrazine at $70{ }^{\circ} \mathrm{C}$ to form $\mathrm{C}$ PAN via a nucleophilic addition reaction. Increasing the crosslinking time from 8 to $18 \mathrm{~h}$ increased the $\mathrm{N}$ content in the membranes. The 18-h-cross-linked membranes were stable in DMF and NMP for more than 2 months and exhibited ethanol permeance of $2.32 \mathrm{LMH}$ per bar with a rejection of greater than 99.9\% for Remazole Brilliant Blue R $\left(626 \mathrm{~g} \mathrm{~mol}^{-1}\right){ }^{108}$ PAN was also cross-linked by thermal treatment at $180-260{ }^{\circ} \mathrm{C}$, which decreased the pore size and increased the selectivity. ${ }^{174}$ Moreover, the $-\mathrm{CN}$ groups can be converted to carboxylic $(-\mathrm{COOH})$ groups by exposure to a strong base $(\mathrm{NaOH})$. The obtained hydroxylated PAN (H-PAN) can then be further functionalized to tune the nanostructures for OSN applications (cf. Table 3). ${ }^{107,110,175,176}$

\subsection{Bottom-up design of highly cross-linked PA TFC membranes}

TFC membranes can be prepared from polymers by solution coating (such as perfluoropolymers with chemical stability ${ }^{177-181}$ ), polyelectrolytes ${ }^{182-184}$ via layer-by-layer coating, and diamines and acid halides by IP. ${ }^{73,124,125,127,181}$ In this section, we are limiting our discussion on new advanced ultrathin PA TFC prepared using IP. PA-based TFC membranes have been extensively explored for OSN applications due to the excellent stability of highly crosslinked PAs in various solvents. More importantly, similar to the $\mathrm{NF}$ and RO membranes for water desalination, the PAs can be produced using interfacial polymerization (IP) on a large scale, resulting in the selective layer as thin as $10 \mathrm{~nm}^{73,126,127,173,185,186}$ In this process, a porous support (such as $\mathrm{PI},{ }^{187}$ polyethersulphone (PES), ${ }^{188}$ polyketone, ${ }^{173} \mathrm{PAN}^{189}$ and ceramic ${ }^{122}$ ) is immersed in an aqueous solution containing diamines (such as 
(A)

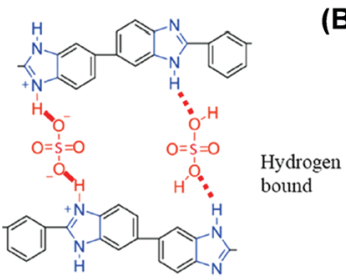

(C)

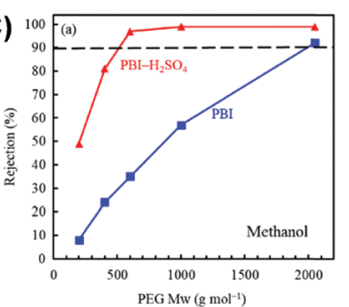

(D)
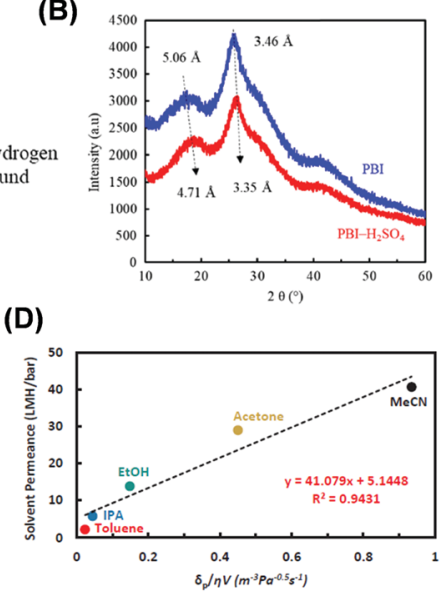

Fig. 5 (A) Reaction mechanism of PBI interaction with acids such as $\mathrm{H}_{2} \mathrm{SO}_{4}$ using $\mathrm{H}$-bonding and proton transfer mechanisms, (B) changes in $d$-spacing for $\mathrm{PBI}$ and $\mathrm{H}_{2} \mathrm{SO}_{4}$ cross-linked $\mathrm{PBI}$ hollow fibers (HF) using $\mathrm{XRD}$, and (C) MWCO measurement for $\mathrm{PBI}$ and $\mathrm{H}_{2} \mathrm{SO}_{4}$ cross-linked PBI using PEG isomers. ${ }^{32}$ Copyright 2019, Elsevier. (D) Relationship between solvent permeance against Hansen solubility parameter $\left(\delta_{\mathrm{p}}\right)$, viscosity $(\eta)$, and molar volume ( $V$ ) of solvent. ${ }^{34}$ Copyright 2018, Elsevier.

MPD) and then exposed to an organic solution containing acid halides (such as TMC). The diamine and acid halide react rapidly at the interface, forming to a thin, highly cross-linked PA layer, as shown in Fig. 8A. Moreover, sub-10 nm PA selective layers with a crumpled structure were formed using calcium hydroxide as a sacrificial layer (Fig. 8B and C) due to Rayleigh Benard convection, resulting in extremely high methanol permeance of $\sim 13$ LMH per bar after the DMF activation. ${ }^{125}$ Ultrathin selective layers were also prepared using ethidium bromide (EtBr) and TMC without any sacrificial layer and exhibited methanol permeance of $\sim 17$ LMH per bar and MWCO of $\sim 700 \mathrm{~g} \mathrm{~mol}^{-1}$ (cf. Table 3). ${ }^{127}$

The PA structure can be finely tuned by selecting appropriate monomers to improve the free volume and thus permeance. ${ }^{129}$ For example, Fig. 8D shows that replacing TMC with a contorted acyl chloride increased the $d$-spacing from $3.6 \AA$ to $3.9 \AA$ and methanol permeance by $80 \%$ while retaining the rejection profile. ${ }^{73}$ Fig. $8 \mathrm{E}$ shows that such TFC membranes exhibited excellent rejection of small solutes such as Sudan Orange $\mathrm{G}\left(216 \mathrm{~g} \mathrm{~mol}^{-1}\right)$ dye. The effect of amine-containing monomers on the separation properties of the TFC membranes was also extensively investigated. ${ }^{125}$ Different amines, ${ }^{73,130,186,190,191}$ acid halides and reaction conditions ${ }^{126,190,192}$ influenced the membrane structure and thus separation properties. Fig. $8 \mathrm{~F}$ and $\mathrm{G}$ shows eclectic amines and acid halides utilized to prepare PA TFC. Aromatic amines usually rendered more rigid structures than aliphatic amines. ${ }^{186}$
(A)
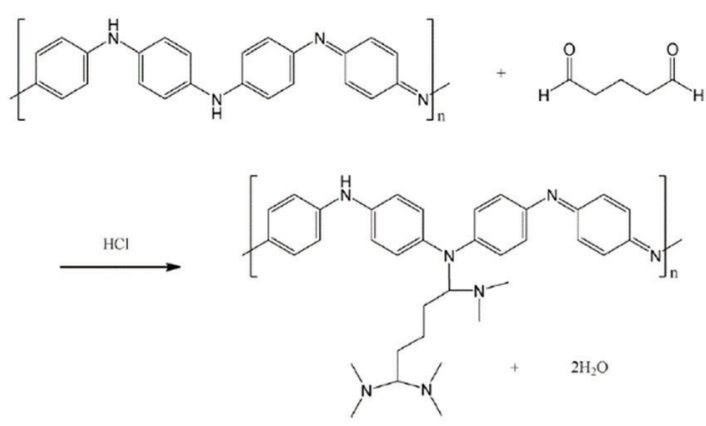

(B)

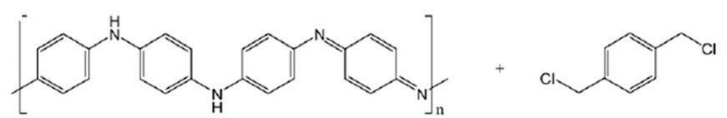

(C)
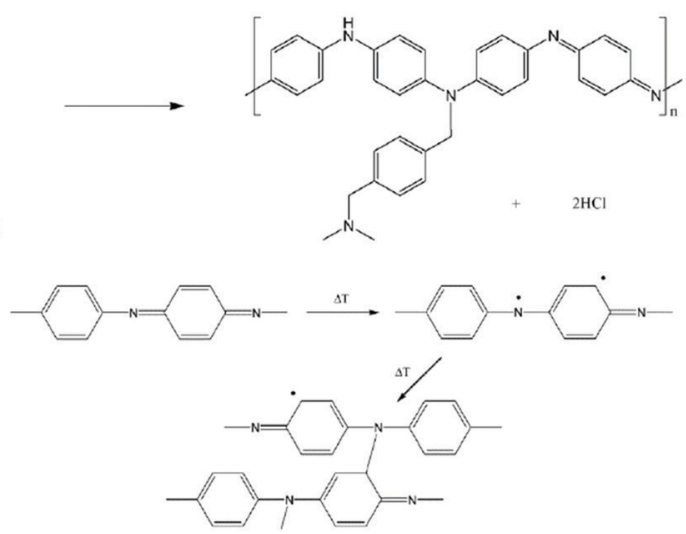

(D)

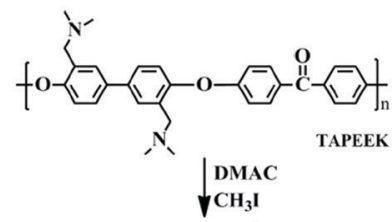

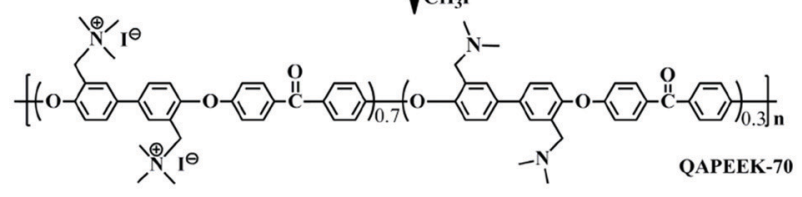
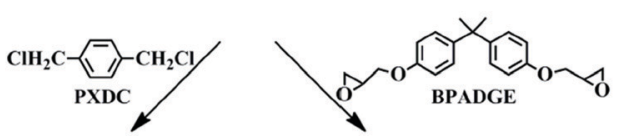

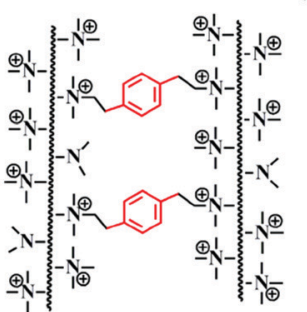

Cross-linked structure 1

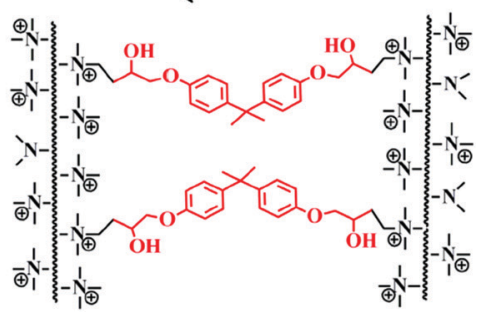

Cross-linked structure 2

Fig. 6 Cross-linking PANI with (A) glutaraldehyde (GA), (B) $\alpha, \alpha^{\prime}$-dichloro-p-xylene (DCX), and (c) thermal treatment. ${ }^{118}$ Copyright 2009 , Elsevier. (D) Cross-linking TAPEEK using methyl iodide followed by PXDC (DCX) or BPADGE (Bisphenol A diglycidyl ether). ${ }^{172}$ Copyright 2016, Elsevier. 


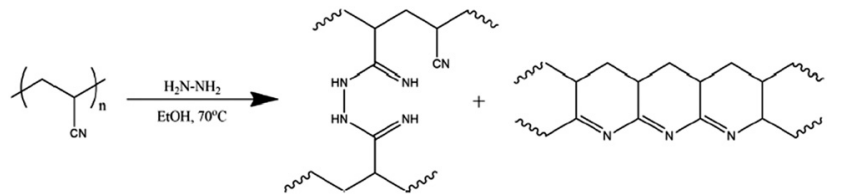

Fig. 7 Cross-linking PAN using hydrazine and forming intermolecular hydrogenated naphthyridine-type cyclic structures. ${ }^{108}$ Copyright 2017 . Elsevier.

Increasing the cross-linking density often increased the solute rejection and decreased the solvent permeability due to the tighter packing of the polymer chains.

The PA properties can be optimized by introducing additives to the aqueous or organic phase. For example, sodium dodecylsulfate (SDS, a surfactant) was used to control a uniform diffusion of diamine into the organic phase, resulting in homogeneous polymerization with a uniform PA layer with strong size-sieving ability. ${ }^{193}$ TFC membranes prepared using piperazine (PIP), TMC, and SDS exhibits a rejection of $30 \%$ and $93 \%$ for $\mathrm{Li}^{+}$(Stokes radius, $\left.r_{\mathrm{s}}=2.4 \AA\right)$ and $\mathrm{Ba}^{2+}\left(r_{\mathrm{s}}=2.9 \AA\right)$, respectively. PEG was also added to the aqueous phase to avoid the pore collapsing, and some other additives (such as strong base $(\mathrm{NaOH})$, triethylamine (TEA), camphorsulfonic acid, and IPA) were used to improve the amine diffusion into the organic phase by enhancing the contact between two phases or by eliminating hydrogen halide formed during the chemical reaction thereby enhancing the rate of reaction. ${ }^{88,190,194}$ The effect of the porous support on the membrane separation properties was also investigated, including material type, porosity, surface roughness, and surface hydrophilicity. ${ }^{37,88}$

\section{Microporous materials}

Newly emerged porous materials have provided new platforms in designing high-performance OSN membranes, including PIMs, POCs, MOFs, COFs, CMS, CMPs, and 2D materials. These materials have well-controlled pore size distributions, yielding enormous opportunities for structure optimization to achieve targeted separation performance, surpassing the permeability/ selectivity tradeoff. ${ }^{18-20}$ Zeolites are another class of microporous materials, which are extensively explored for organic solvent separation based on the intrinsic properties of the structure, such as precise pore size (4-7 $\AA$ ) and sufficiently higher surface area for solvent uptake (1500-2000 $\mathrm{m}^{2} \mathrm{~g}^{-1}$ ), offered by the functional chemistry utilized during preparation. ${ }^{195-198}$ However, in this section, we limit our discussion to microporous materials obtained from polymers and polymerderived materials.

\subsection{PIMs}

PIMs emerged as an interesting material platform for OSN applications ${ }^{199-201}$ due to their continuous interconnected

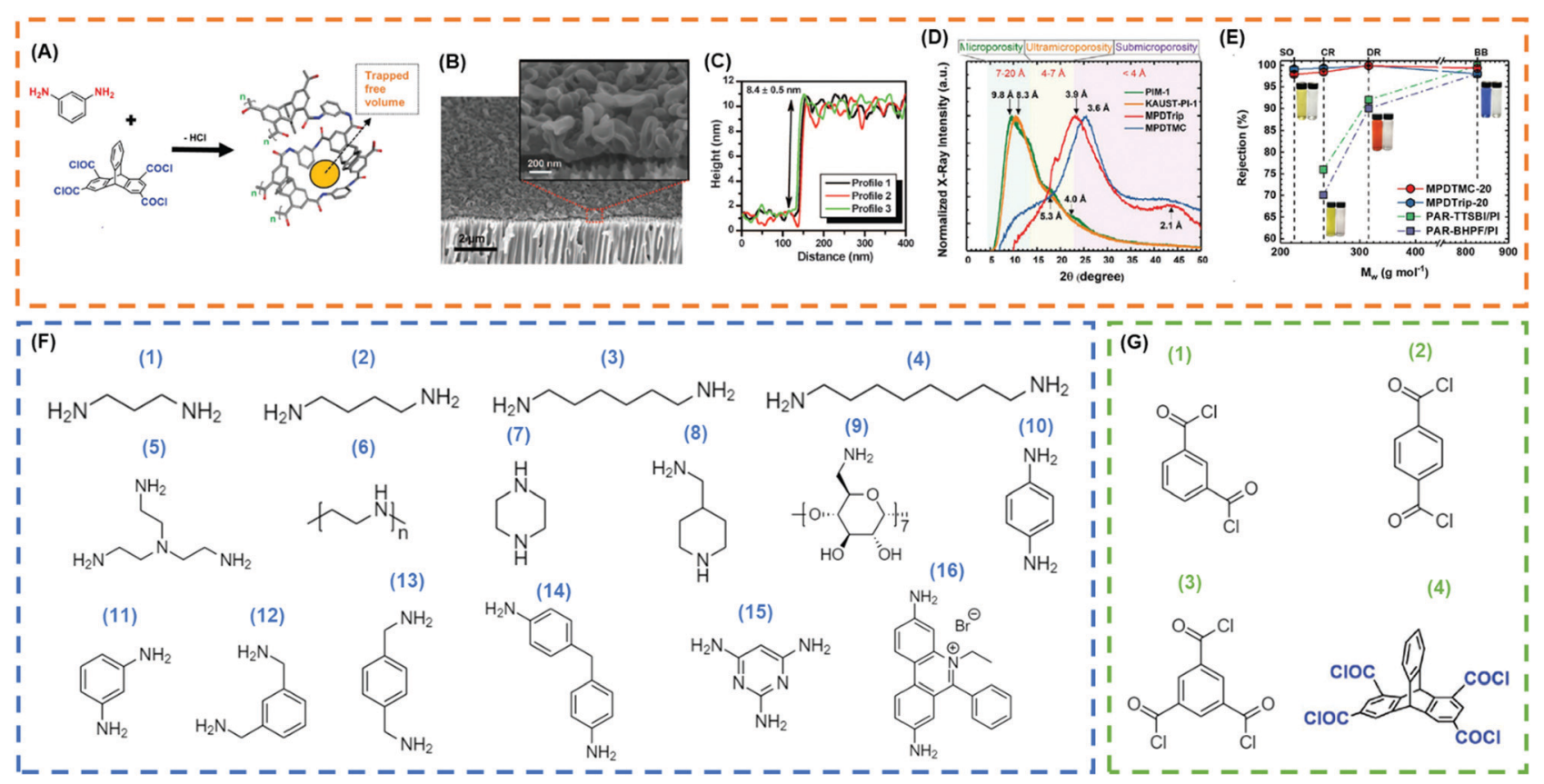

Fig. 8 (A) Reaction between MPD and triptycene-1,3,6,8-tetraacetyl chloride (Trip) to form a PA layer with high free volume. ${ }^{73}$ Copyright 2020 , WILEY$\mathrm{VCH}$. (B) SEM imaging of MPD/TMC TFC suggesting improved surface area due to crumpled surface. ${ }^{125}$ (C) AFM imaging of MPD/TMC films on silicon wafer suggesting PA selective layer is less than $10 \mathrm{~nm} .{ }^{125}$ Copyright 2015, Science. (D) Comparison of XRD patterns of PA layers derived from MPD/TMC

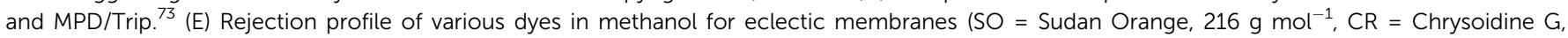
$249 \mathrm{~g} \mathrm{~mol}^{-1}, \mathrm{DR}=$ Disperse Red, $314 \mathrm{~g} \mathrm{~mol}^{-1}, \mathrm{BB}=$ Brilliant Blue R, $826 \mathrm{~g} \mathrm{~mol}^{-1}$ ). ${ }^{73}$ Copyright 2020, WILEY-VCH. (F) Frequently used amines for IP: (1) propanediamine, (2) butanediamine, (3) hexanediamine, (4) octanediamine, (5) tris(2-aminoethyl)amine, (6) PEl, (7) piperazine, (8) 4-(aminomethyl)piperidine, (9) amino- $\beta$-cyclodextrin, (10) $p$-phenylenediamine, (11) MPD, (12) $m$-xylenediamine, (13) $p$-xylenediamine, (14) 4,4'-diaminodiphenylmethane, (15) 2,4,6-triaminopyrimidine, and (16) ethidium bromide. (G) Frequently used acyl chloride for IP: (1) isophthaloylchloride, (2) terephthaloyl chloride, (3) TMC, and (4) trip. 
voids less than $2 \mathrm{~nm}^{131,202}$ These polymers have rigid and contorted backbones with a limited degree of freedom for bond rotations, leading to a high BET surface area of 600-800 $\mathrm{m}^{2} \mathrm{~g}^{-1} \cdot{ }^{161,201}$ Fig. 9A shows the chemical structure of typical PIMs for OSN applications. PIMs are stable in non-polar solvents, and their microporous structure expands in polar solvents (such as methanol and acetone), causing instability on interconnected voids of the membranes. ${ }^{131}$ To improve the stability for OSN applications, PIMs are modified, ${ }^{157,159}$ such as chemical functionalization, cross-linking, and blending.

Fig. 9B shows the use of catalytic Buchwald-Hartwig reaction to couple alkyl halides and amines to eliminate dibenzodioxin linkages of PIM-1. ${ }^{1}$ The SBAD structure decreased the interconnected microvoids of PIM-1 because of the aromatic rings in each monomer and contained narrow ultramicropore distribution around 2-10 ̊.. Fig. 9C shows all SBAD structures showed better rejection for 1,3,5-triisopropylbenzene (TIPB) with lower toluene permeance (0.2-0.7 LMH per bar) than the pristine PIM-1. Fig. 9D shows that the SBAD separated hydrocarbons based on their size and branching and exhibited the MWCO of $\sim 250 \mathrm{~g} \mathrm{~mol}^{-1}$, which was $\sim 3.6$ times lower than the PIM-1. Fig. 9E shows intrinsically microporous PEEK incorporating spirobisindane, Troger's base, and triptycene contorted structures. ${ }^{203}$ These structures exhibited higher $T_{\mathrm{g}}$ and $\sim 10$ times higher surface area than PEEK membranes. The MWCO was around 450-520 $\mathrm{g} \mathrm{mol}^{-1}$.

To cross-link PIMs, the -CN groups can be activated to acid halide $(-\mathrm{COCl})^{131}$ or thioamide $\left(-\mathrm{CSNH}_{2}\right),{ }^{158}$ which are then cross-linked by amines or TMC, respectively. For example, PIM-1 functionalized with thioamide was cross-linked by TMC to improve stability, leading to a membrane with acetone permeance of 12.4 LMH per bar. ${ }^{158}$ PIMs can also be crosslinked by vapor phase infiltration using solvents ${ }^{203}$ or metal oxide. ${ }^{160}$ PIM-1 was also blended with PBI and acids (such as $\mathrm{HCl})$ to create ionically stabilized structures, which showed great stability in harsh polar solvents such as DMF, DMSO, and acetonitrile. ${ }^{115}$ The blending retained the interconnected voids of the PIM-1.

\subsection{Superhighways - COFs}

COFs have created an unprecedented avenue for molecular separation due to their excellent compatibility with chemicals and well-controlled channels for molecular sieving. COFs have low density, high crystallinity, large surface area, and good control over pore size and properties by fine-tuning the type of monomers, chemical reaction, and method of preparation., ${ }^{2,101,204-206}$ COFs are classified either based on the type of functionalities they contain or by the method of preparation. On the basis of functionality, COFs

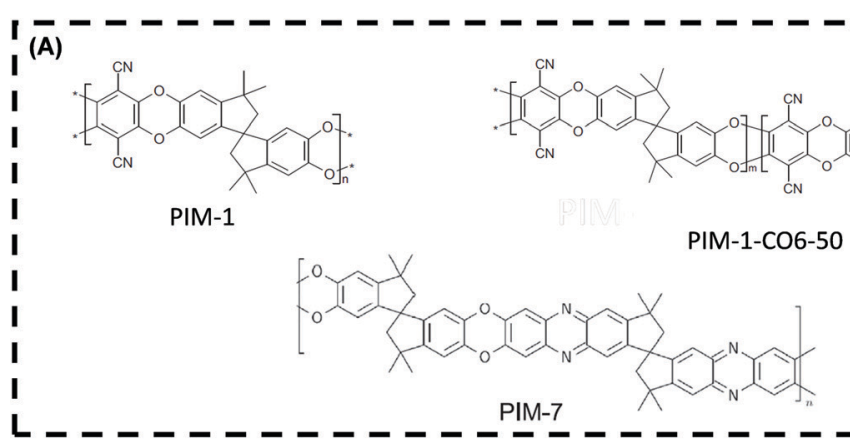

(B)
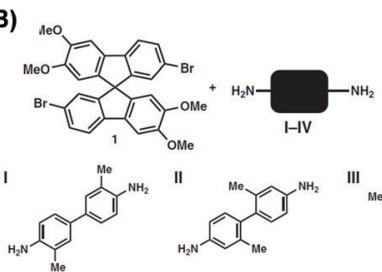

SBAD-1

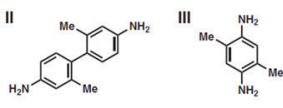

SBAD-2
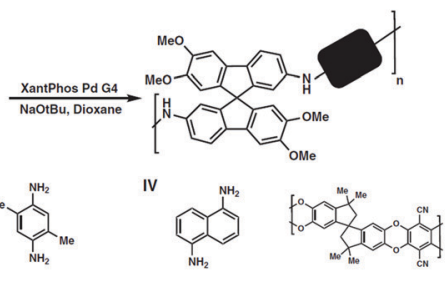

SBAD-4

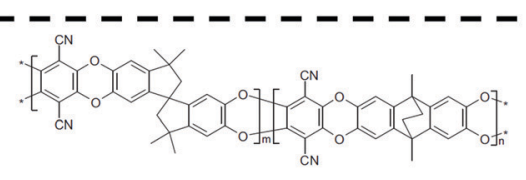

PIM-1-C1-50

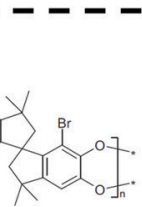

(C)

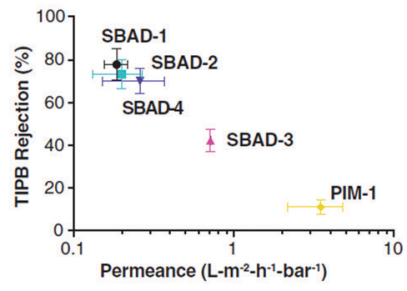

(D)

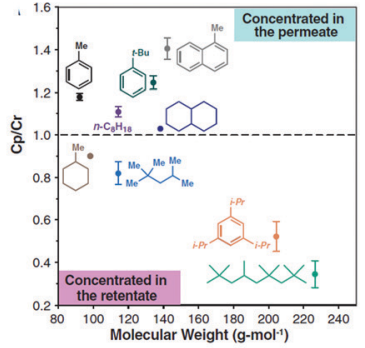

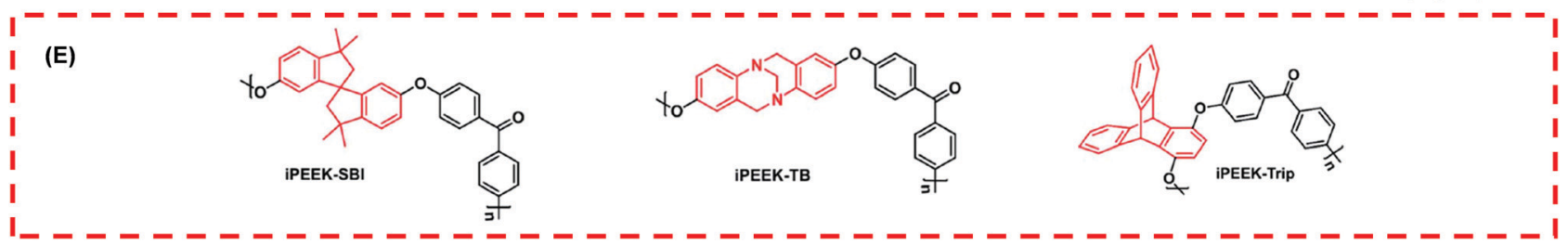

Fig. 9 (A) Chemical structures of frequently used PIMs for OSN applications. ${ }^{157,201}$ Copyright 2012 and 2018, Elsevier. (B) Reaction mechanism between 7, $7^{\prime}$-dibromo-2,2',3,3'-tetramethoxy-9,9'-spirobifluorene (aromatic halide) and various diamine (I to IV) based on the availability of aromatic rings and amino groups leading to form SBAD-X structures. ${ }^{1} \mathrm{X}$ : based on the monomer used. (C) \% Rejection of TIPB against permeance in toluene for various SBAD-X and PIM-1 at 15 bar and $22{ }^{\circ} \mathrm{C}^{1}$ (D) Ratio of solute concentration in permeate to retentate side against MW of solute for SBAD-1 at 40 bar and $22{ }^{\circ} \mathrm{C}^{1}$ Copyright 2020, Science. (E) Chemical structures of intrinsically porous PEEK. ${ }^{203}$ Copyright 2020, Royal Society of Chemistry. 
are classified in 6 types: (a) imine-based, ${ }^{207,208}$ (b) boronbased, ${ }^{209}$ (c) keto-enamine based, ${ }^{72,210}$ (d) triazine-based, ${ }^{211}$ (e) urea-based, ${ }^{212}$ and (f) $\mathrm{C}-\mathrm{C}$ bonded. ${ }^{74,213}$ In this section, COFs are explicated in terms of their methods of preparation, including solvothermal process (SVT), IP, Langmuir-Blodgett (LB), and Layer-by-layer stacking (LBL). Table 4 records the structures and separation properties of representative COFs.

4.2.1. SVT. Fig. 10A shows a typical SVT method to synthesize COFs, where crystals grow on a solid support using heat treatment and then agglomerate to form thin films. ${ }^{74}$ However, this method elicits certain drawbacks such as harsh processing conditions, non-uniformity of COFs on the support, creation of powder particles, and difficulty in transferring the films on supports. ${ }^{214}$ To overcome these challenges, a process of low-temperature $\left(60-90{ }^{\circ} \mathrm{C}\right)$ annealing of $4,4^{\prime}, 4^{\prime \prime}$-(1,3,5-triazine2,4,6-triyl)trianiline (TTA), 4,4'-azodianiline (Azo), and 1,3,5triformylphloroglucinol (Tp) using an organic linker of $p$-toluene sulfonic acid (PTSA) was developed to create mechanically strong and defect-free membranes exhibiting excellent performance for OSN applications. ${ }^{210}$ COF-LZU-1 film of $400 \mathrm{~nm}$ thin was developed in $\mathrm{Al}_{2} \mathrm{O}_{3}$ ceramic tube by functionalizing the surface using 3-Aminopropyltriethoxysilane (APTE) followed by aldehyde and amine addition at $120{ }^{\circ} \mathrm{C}$ for $72 \mathrm{~h} .{ }^{215}$ The film thickness and pore size distribution can be tuned by adjusting monomers, reaction temperature, and reaction time.

4.2.2. IP. Fig. 10B shows that COF membranes can be formed using IP with aldehyde in the organic phase and amine in the aqueous phase. ${ }^{216}$ However, the high diffusivity of the amine into the organic phase leads to non-uniform COF films and powder. To eliminate this problem, amines are treated with acids to form salts to reduce their diffusivity into the organic phase. For example, a family of COFs was synthesized using PTSA and various amines by Schiff-base reaction and to create freestanding COF films. ${ }^{216}$ Specifically, longchain amines such as 2,2'-bipyridine-5, $5^{\prime}$-diamine (Bpy) led to open structures with a pore cavity of $25 \AA$, surface area of $1151 \mathrm{~m}^{2} \mathrm{~g}^{-1}$, pore volume of $0.918 \mathrm{~cm}^{3} \mathrm{~g}^{-1}$, and acetonitrile permeance of $339 \mathrm{LMH}$ per bar.

COF films were also formed using amine and aldehyde in the organic phase and a catalyst (such as acids) in the aqueous phase. This approach precludes the formation of nanospheres/ nanoparticles and results in uniform and defect-free membranes. ${ }^{217}$ Most studies have focused on the use of different amines to prepare COFs with different structures. On the other hand, stacking of $\mathrm{COF}$ can be tuned from $\mathrm{AA}$ to $\mathrm{AB}$ by incorporating functional groups in aldehyde, which created a steric effect and reduced the pore size from $1.1 \mathrm{~nm}$ to $0.6 \mathrm{~nm}$ to give precise molecular separation. ${ }^{218}$

4.2.3. LB. In this method, very precise control over membrane thickness can be achieved. The reaction between amine and aldehyde happens at the liquid-air interface under compression with precise control of the surface pressure, resulting in defect-free COF films. Fig. 10C shows that $\beta$-ketoenamine COF film as thin as $2.9 \pm 0.3 \mathrm{~nm}$ was prepared and studied for solvent permeation. ${ }^{219}$ The effect of the amine structures on the COF properties was studied. For example, 9,9-dipropylfluorene-2,7-diamine (DPF) and 9,9-dinonylfluorene2,7-diamine (DNF) were used to prepare COF films with Tp and an acid catalyst $\left(\mathrm{Sc}(\mathrm{OTf})_{3}\right) .^{220}$ DPF-Tp and DNF-Tp COFs had water contact angles of $81^{\circ}$ and $141^{\circ}$, respectively, as DNF has a longer carbon chain and thus greater hydrophobicity than DPF. Moreover, DPF-Tp COF showed larger pore sizes and thus higher permeance for polar and non-polar solvents than DNF-Tp COF.

4.2.4. LBL stacking. This approach is originated from monolayer or multilayer stacking of GO using pressureassisted filtration. Nanosheets of COFs are dispersed in solutions, which were then filtered or dip-coated on a support to form continuous films. Fig. 10D depicts that cationic COF was prepared using ethidium bromide (EB) and Tp using IP to create COF nanosheet dispersion, which was then vacuum filtered on nylon-6 support to create membranes. ${ }^{221}$ EB COF had a pore size of $16.8 \AA$ and outstanding permeance for various solvents. The thickness and porosity of the COF layer can be manipulated by changing the monomers and the concentration of COF nanosheet dispersion. Nanosheets can also be exfoliated and re-stacked. ${ }^{22}$ For example, the imine linkages in COF were protonated using trifluoroacetic acid (TFA) followed by the deposition on a support. ${ }^{223}$ However, the exfoliation decreased crystallinity and surface area, and it is time-consuming and labor-intensive.

The superior dye separation performance in the COFs was also explained by adsorption, instead of molecular sieving. ${ }^{224}$ For example, three COF membranes (TAPB-PDA, BND-TFB, and BND-TFP) were studied for the separation of dye molecules (140-850 $\mathrm{g} \mathrm{mol}^{-1}$ ) and can adsorb the dyes on the surface. Furthermore, TAPB-PDA pellets were exposed to aqueous solutions of rhodamine $\mathrm{B}(\mathrm{RB})$ and showed a rejection of $\sim 99 \%$ at a flow rate of $0.5 \mathrm{~mL} \mathrm{~min}^{-1}$ and $78 \%$ at $2.0 \mathrm{~mL} \mathrm{~min}^{-1}$. Increasing the flow rate decreased the retention time and thus rejection. Therefore, the effect of the dye adsorption needs to be carefully examined to understand the effect of the pore size and molecular sieving on the dye separation performance.

\subsection{CMS}

CMS membranes are attractive for organic solvent separations due to their unique bimodal porous structures consisting of ultra-micropores of less than $6 \AA$ (resulting in high selectivity) and micropores of 6-20 $\AA$ (leading to high permeability), as shown in Fig. 11A. ${ }^{4,49,227-230}$ CMS can be prepared by pyrolysis of polymer precursors, and their structure and properties are influenced by polymer precursors and carbonization conditions (including the atmosphere, temperature, and ramping rate). ${ }^{4,49,231,232}$

Fig. 11B shows that polyvinylidene fluoride (PVDF) was cross-linked using $p$-xylylenediamine before carbonization to form C-PVDF CMS with an idealized bimodal structure and good mechanical strength. ${ }^{4}$ Fig. $11 \mathrm{C}$ shows that the permeance of aromatic hydrocarbons decreased with increasing molecular size in C-PVDF CMS. Moreover, increasing the pyrolysis temperature increased the number of ultramicropores and thus FFV and hydrocarbon permeability. ${ }^{227,233}$ 
Table 4 Summary of structures and performance COFs for OSN applications

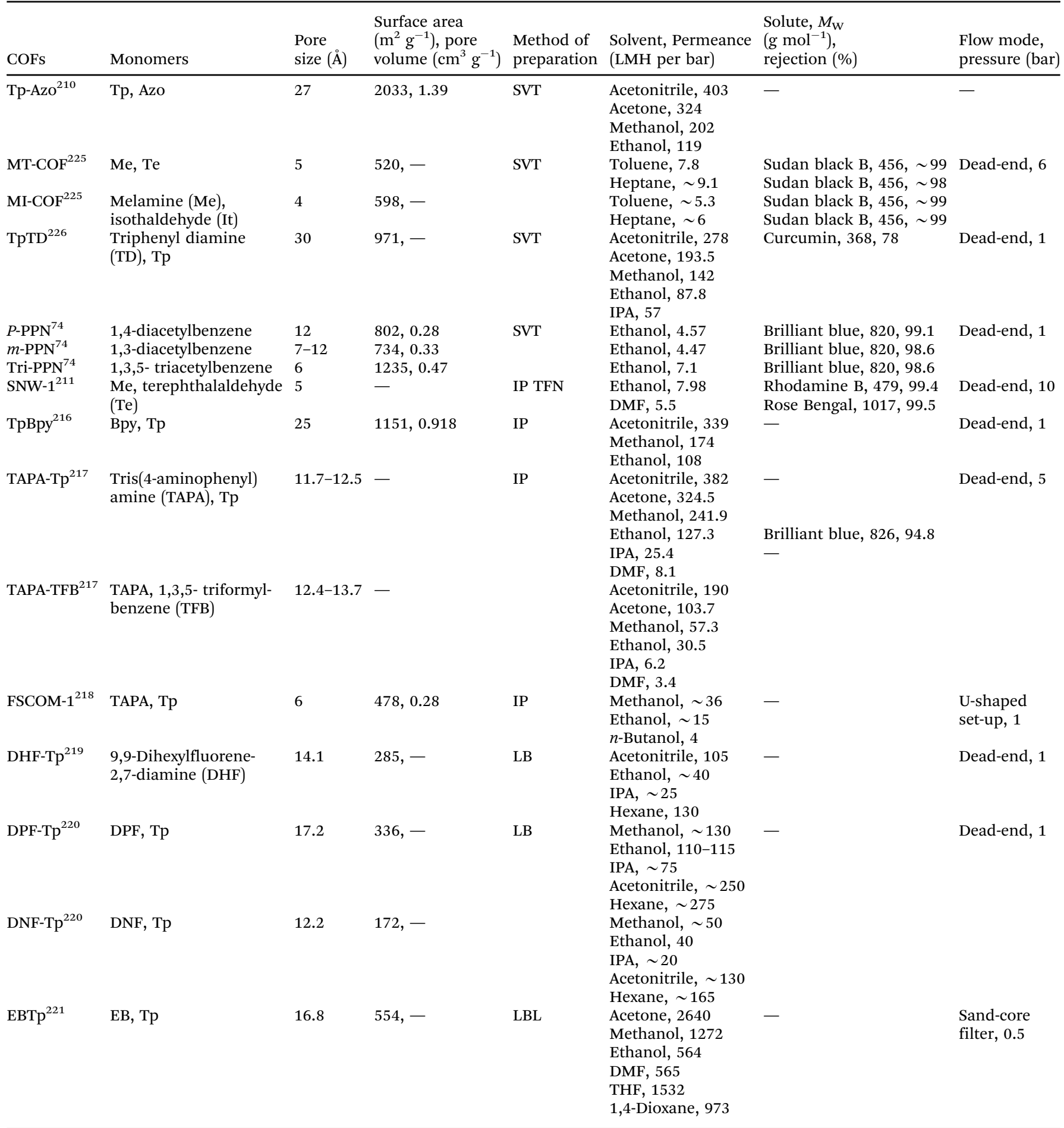

The effect of carbonization temperature on PIM-1 CMS structures was also investigated. ${ }^{49}$ Fig. $11 \mathrm{D}$ shows that introduction of the $\mathrm{H}_{2}$ in the carbonization atmosphere increased the interlayer spacing and eschewed generation of $\mathrm{SP}^{2}$ hybridized carbon backbones, making the structure highly contorted and increasing the permeability. For example, increasing the $\mathrm{H}_{2}$ content from 0 to $4 \%$ increased the pore size and the hybridization carbon ratio of $\mathrm{SP}^{3} / \mathrm{SP}^{2}$ from 0.24 to 0.65 (Fig. $10 \mathrm{E}$ ) and the $p$-xylene permeability from $2.8 \times 10^{-16}$ to $8.5 \times 10^{-14} \mathrm{~mol} \mathrm{~m} \mathrm{~m}^{-2} \mathrm{~s}^{-1} \mathrm{~Pa}^{-1}$ while decreasing the $p$-xylene/o-xylene selectivity from 38.9 to 18.8 (Fig. 10F).

Amorphous carbon with diamond-like-carbon (DLC) structures have also been studied for organic solvent separation due to their tunable functional chemistries and pore sizes by 

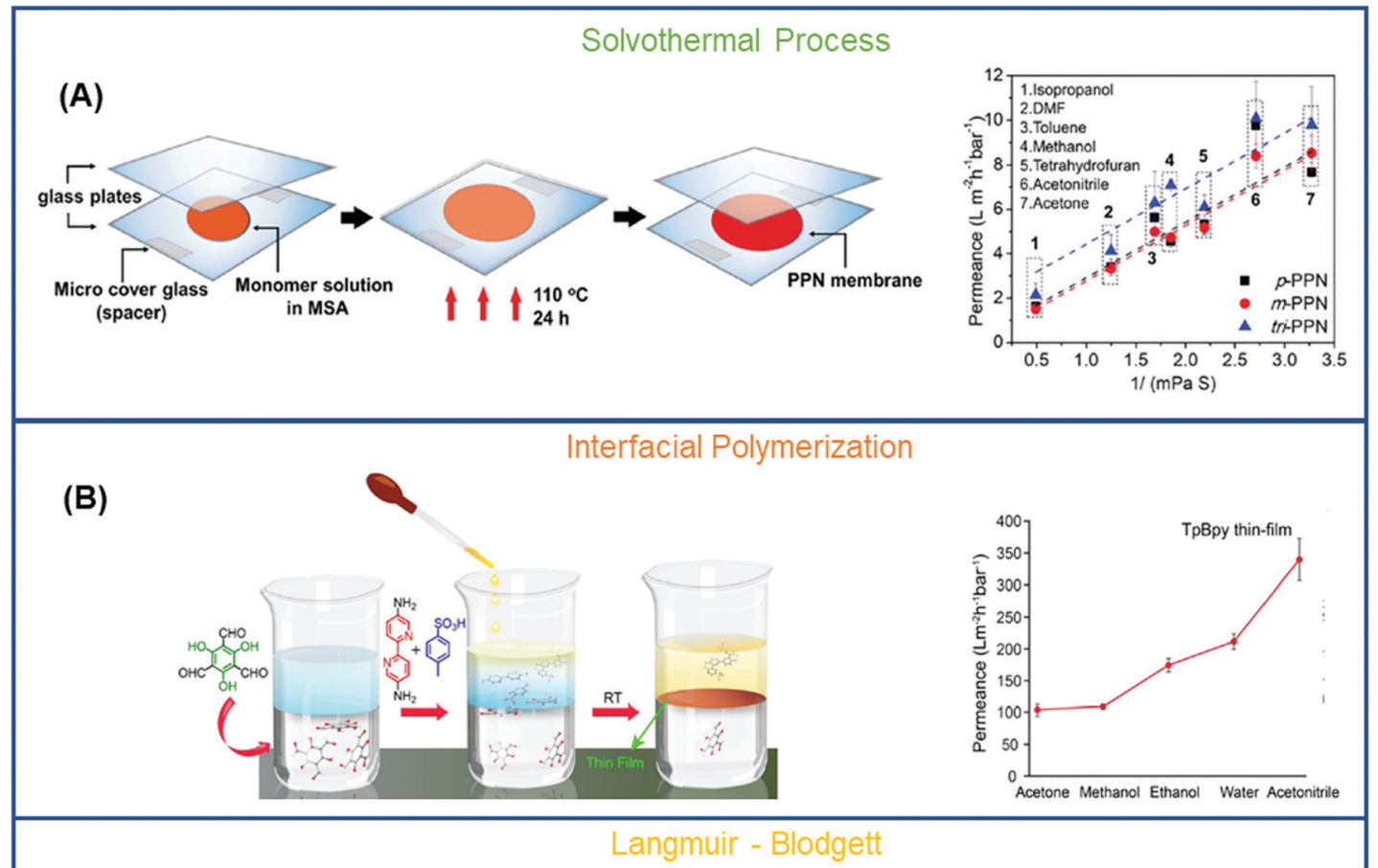

(C)
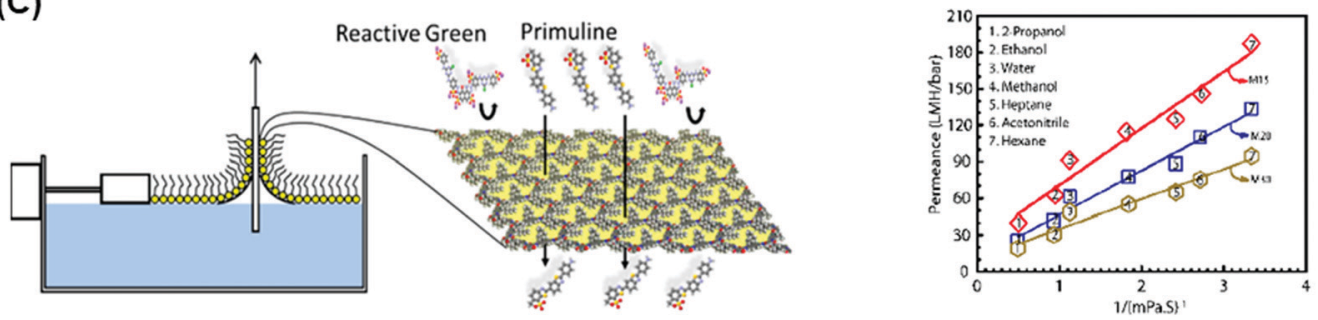

Layer - by - layer stacking

(D)
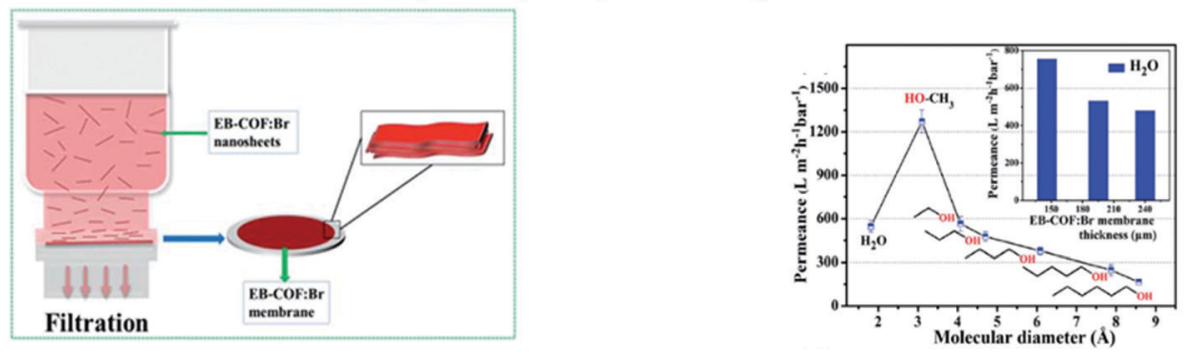

Fig. 10 Schematic representation for the preparation and performance of COFs prepared by using (A) SVT, ${ }^{74}$ (B) IP, ${ }^{216}$ (D) LB ${ }^{219}$ and (D) LBL ${ }^{221}$ methods. Copyright 2018 and 2020, The Royal Society of Chemistry. Copyright 2017 and 2018, American Chemical Society.

adjusting processing conditions, such as the power and time of plasma treatment or chemical vapor deposition (CVD) and types of monomers/precursors. ${ }^{10,234}$ For example, ultrathin $\sim 35 \mathrm{~nm}$ films with Young's modulus as high as 90-170 GPa were prepared using calcium hydroxide as a sacrificial layer and various monomers (such as methane, acetylene, butadiene, and pyrene). ${ }^{235,236}$ For example, the DLC prepared from acetylene showed ethanol permeance of 55.75 LMH per bar and a rejection of almost 100\% for protoporphyrin-IX (PPh-IX, $562.7 \mathrm{~g}$ $\mathrm{mol}^{-1}, 1.47 \mathrm{~nm}$ ), better than state-of-art commercial membranes (Table 2).

\subsection{Creating microchannels in polymers}

Porous fillers with desirable pore size and porosity can be incorporated into polymers to form MMMs to fine-tune the free volumes and separation properties without significantly sacrificing mechanical properties and processability. ${ }^{147}$ These fillers can be multiwall carbon nanotubes (MWCNTs), ${ }^{153,154}$ graphene oxides (GO) ${ }^{114}$ silanes, ${ }^{85}$ molybdenum disulphide, ${ }^{149}$ boron nitride, ${ }^{150}$ metal oxide,${ }^{160,237}$ MOFs, ${ }^{238-241}$ cyclodextrins, ${ }^{242}$ and zeolites. ${ }^{243,244}$ Moreover, porous organic cages (POC) and CMPs have recently emerged. These fillers can be dissolved in coating solutions or introduced during the IP process. 
(A)

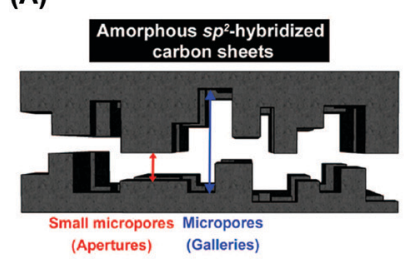

(B)
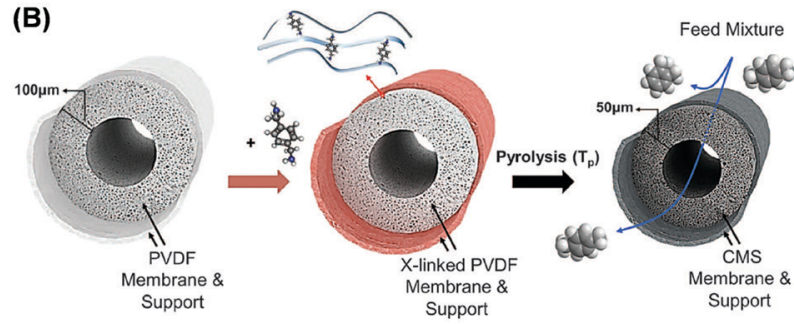

(C)

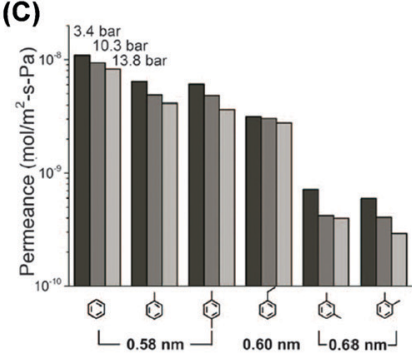

(D)

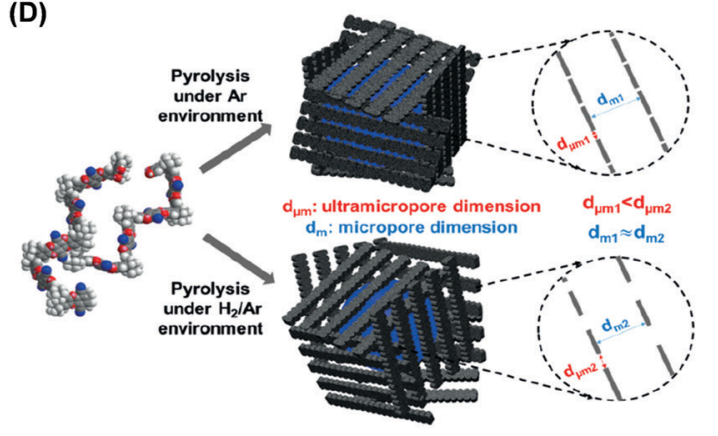

(E)

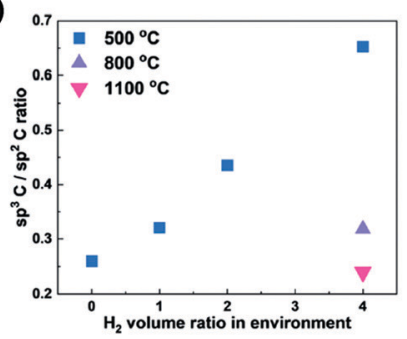

(F)

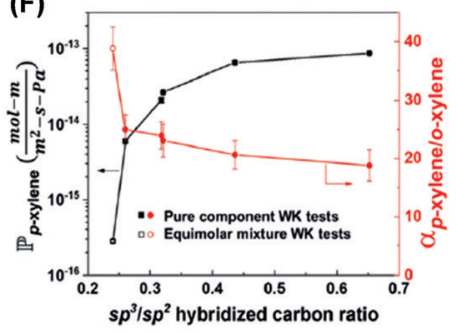

Fig. 11 (A) Schematic representation of bimodal CMS slit-like structure consisting of ultramicropores and micropores. (B) Cross-linking of PVDF hollow fibers using $p$-xylenediamine followed by carbonization to form CMS. (C) The permeance of aromatic hydrocarbons through C-PVDF CMS as a function of their molecular size at 3.4, 10.3, and 13.8 bar. $^{4}$ Copyright 2020, Science. (D) Increase of ultramicropore sizes by $\mathrm{H}_{2}$ in the carbonization atmosphere. (E) Effect of the $\mathrm{H}_{2}$ content in the pyrolysis atmosphere on the $\mathrm{SP}^{3} / \mathrm{SP}^{2}$ carbon ratio in CMS. (F) $p$-xylene/o-xylene separation properties as a function of $\mathrm{SP}^{3} / \mathrm{SP}^{2}$ carbon ratio. ${ }^{49} 1 \mathrm{~mol} \mathrm{~m} \mathrm{~m}{ }^{-2} \mathrm{~s}^{-1} \mathrm{~Pa}^{-1}=3.6 \times 10^{5} \ell \mathrm{MW}_{\mathrm{W}} / \rho\left(\mathrm{LMH}\right.$ per bar $\left.\mathrm{m}^{-1}\right)$. Copyright 2019, Wiley-VCH.

4.4.1. TFN membranes prepared by IP. IP-based TFN membranes have been extensively investigated due to the flexible platform (with both aqueous and organic solutions) and maturity in producing on a large scale. ${ }^{132}$ Various fillers have been incorporated, including cyclodextrins, ${ }^{137,142}$ MOFs, ${ }^{50,137,138,143,144,245-248}$ inorganic halides, ${ }^{249}$ metal oxides, ${ }^{250} \mathrm{GO},{ }^{135,139}$ quantum dots, ${ }^{136,141,251,252}$ polysiloxane, ${ }^{134}$ porphyrin, ${ }^{133}$ and ZIFs. ${ }^{137,247}$ Several examples are summarized in Table 3. There are two strategies by which porous fillers can be added to polymers to form TFN membranes.

(1) Fillers are dispersed into the organic or aqueous solution before IP to create highly entangled PA/fillers networks. For example, the inclusion of sulfothiacalix[4]arene (STCAss) and sulfocalix[4]arene (SCA) as porous ionic structures into the PA selective layer increased the ethanol permeance by $\sim 100 \%$ and salt rejection. ${ }^{253}$

(2) Fillers can be distributed uniformly on the support before the IP to preclude defects and achieve good polymerfiller interaction (Fig. 12A). Fig. 12B shows SEM images of MIL-101 (Cr) uniformly distributed on the P84 support prepared using Langmuir Schaefer (LS) method followed by the IP to form 3 distinct layers: (a) a bottom layer of cross-linked support, (b) a middle layer of the MOFs creating distinct channels for solvent transport, and (c) a top layer of PA. The obtained LS-TFN membranes showed crumpled structures (imparting higher surface area) and enhanced methanol permeance of 10.1 LMH per bar, higher than conventional TFN membranes (7.7 LMH per bar), as shown in Fig. 12C-E. The addition of the fillers also retained the rejection of small dyes (Fig. 12F). ${ }^{140}$ This approach uses fewer nano-fillers than the first approach, where fillers are dispersed throughout the whole selective layer. However, it is faced with several challenges: (a) incompatibility between the support and PA layer with the nano-fillers due to the absence of the strong bonding, (b) leaching of the fillers under high pressures, (c) agglomeration of the fillers at high loadings leading to non-selective pathways, and (d) non-uniform distribution of the fillers.

4.4.2. MMMs by blending. Nanofillers can be directly dispersed in polymers to create highways for the solvent to cross while rejecting solutes, surpassing the permeability/selectivity trade-off. MOFs are frequently studied due to their excellent compatibility with polymers. For example, homochiral MOFs were first synthesized by post-modification of MIL-53- $\mathrm{NH}_{2}$ with L-histidine or L-glutamic and then dispersed in polyethersulfone (PES). The MMMs demonstrated enantioselectivity for racemic 1-phenylethanol with the enantiomeric excess value up to $100 .^{48}$ Nevertheless, it is challenging to obtain a uniform distribution of MOFs in polymers, particularly for high loadings. To eliminate the aggregation of nanoparticles, the MOFs can be fabricated by in situ growth in polymers. ${ }^{148,254-258}$ For example, HKUST-1 was fabricated in situ in carboxyl-functionalized PI to create a uniform pore size of $\sim 0.82 \mathrm{~nm}$, achieving an improved rejection of PS oligomers in organic solvents. ${ }^{148}$

4.4.3. POC. POCs have excellent compatibility with polymers and thus have been used to fabricate MMMs. ${ }^{259}$ POCs differentiate from COFs and MOFs as they do not require any additional crosslinkers for cage-cage or cage-polymer intermolecular interactions. Moreover, POCs can often be dissolved in solvents and thus can be solution-processed with other materials. ${ }^{260}$ Fig. 13A and B shows the incorporation of $2,2^{\prime}, 7,7^{\prime}$-tetra(carbazol-9-yl)-9,9'spirobifluorene (porous cavities) into PDA/CNT fibers by electro- 
(A)

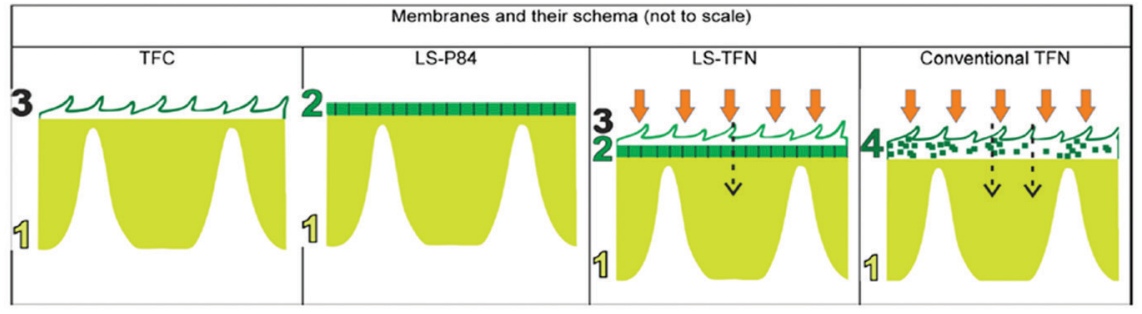

(B)

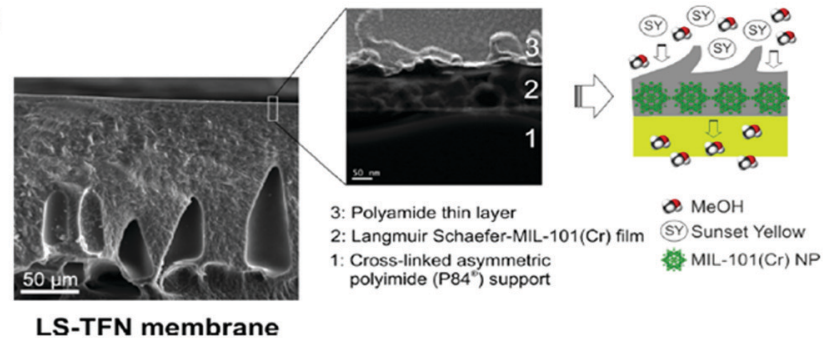

(C)

LS-TFN membrane

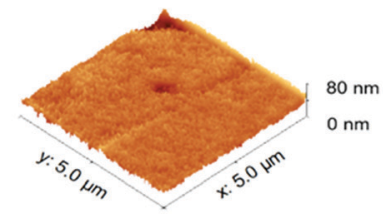

(E)

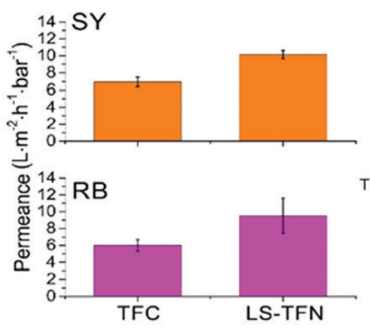

(F)

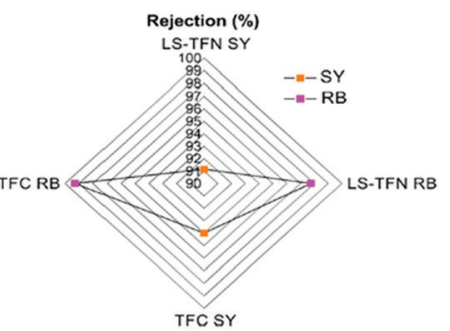

Fig. 12 (A) Schematic representation of conventional PA TFC membrane, formation of MIL-101 (Cr) nanoparticles using LS method on the support, LS-TFN membrane, and conventional TFN membrane. (B) SEM imaging of LS-TFN membranes. Comparison of AFM images of (c) the PI support and (d) the MOF layer deposited on the support. (E) Methanol permeance of TFC and LS-TFN membranes at 20 bar and $20^{\circ} \mathrm{C}$. (F) Rejection profile of sunset yellow (SY, $450 \mathrm{Da}$ ) and rose bengal (RB, $1017 \mathrm{Da})$ for TFC and LS-TFN membranes. ${ }^{140}$ Copyright 2018, American Chemical Society.

polymerization, which led to superhydrophobic structures (Fig. 13C and $\mathrm{D}$ ). Fig. 13E and $\mathrm{F}$ shows that the membranes were stable in various solvents and exhibited methanol permeance of $28 \mathrm{LMH}$ per bar and low MWCO of 550-700 $\mathrm{g} \mathrm{mol}^{-1}{ }^{151}$ One major challenge is that the POCs can aggregate due to the strong cage-cage interactions, leading to defects. To overcome this issue, POCs (CC3) were created from ethylenediamne (EDA) and cyclohexanediamine (CHDA) with a precise ratio (4:2 instead of $1: 5)$ to reduce cagecage (non-polar) interactions and avoid the cage precipitation in the polymer, resulting in high POC loadings $(20 \mathrm{wt} \%)$ in Matrimid. ${ }^{147}$

4.4.4. CMP. CMPs are a new class of polymers with $\pi-\pi$ conjugated skeleton forming continuous, interconnected nanopores. CMPs differentiate from other nanoporous materials (which are often non-conjugated) and conventional conjugated structures (which are non-porous). ${ }^{262}$ They are amorphous and robust due to the highly conjugated networks. ${ }^{263}$ The chemical functionality and structures can be tuned based on the types of chemical reactions, building blocks, and synthetic routes used for their preparation. ${ }^{264}$ CMPs were first prepared in 2007 using various alkynes and halogen monomers and had high surface areas of $500-850 \mathrm{~m}^{2} \mathrm{~g}^{-1}$ and well-controlled pore sizes. ${ }^{265}$
These promising results instigated great interest in studying these materials for organic solvent separations.

Highly conjugated CMPs were synthesized using 1,3,5-triethynylbenzene (1,3,5-TEB) and three di-halobenzenes (1,4-dibromobenzene, 1,3-dibromobenzene, and 1,2-dibromobenzene) to form $p$-CMP, $m$-CMP and $o$-CMP, respectively. ${ }^{263}$ The $p$-CMP, $m$-CMP, and $o$-CMP showed BET surface areas of 513, 383, and $593 \mathrm{~m}^{2} \mathrm{~g}^{-1}$, respectively. The $p$-CMP and $m$-CMP exhibited pore sizes less than $1.5 \mathrm{~nm}$, and $o$-CMP had a pore size of $2.2 \mathrm{~nm}$. The $p$-CMP of $\sim 50 \mathrm{~nm}$ showed excellent methanol permeance of $22 \mathrm{LMH}$ per bar with complete rejection of small dyes (PPh-IX, $562.7 \mathrm{~g} \mathrm{~mol}^{-1}$ ). The CMPs can be further tuned by chemical posttreatment to improve pore sizes and size-sieving ability. For instance, a thiophene-based CMP (TTB-CMP) was oxidized using $m$-CPBA to form TTB-CMPO, which decreased the pore sizes from 1.73 and $1.47 \mathrm{~nm}$ to 1.48 and $1.18 \mathrm{~nm}$, respectively, as shown in Fig. $13 \mathrm{G}$ and $\mathrm{H}^{261}$ Consistently, the post-modification reduced the MWCO from 800 to $500 \mathrm{~g} \mathrm{~mol}^{-1}$ and methanol permeance from 32 to $21 \mathrm{LMH}$ per bar. Fig. 13I presents that both TTB-CMP and TTB-CMPO membranes $(50 \mathrm{~nm})$ showed an inverse relationship between solvent permeance and viscosity. 
(A)

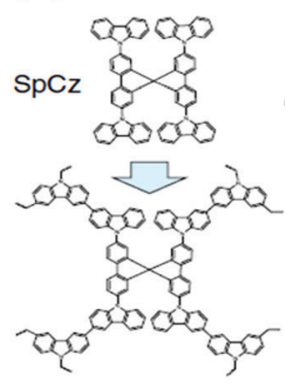

Polycarbazole (PC)

(C)

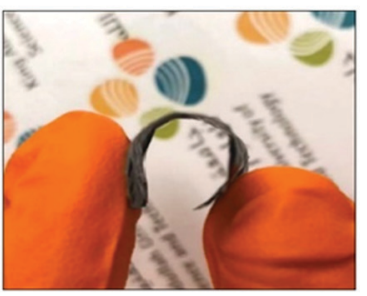

(G)

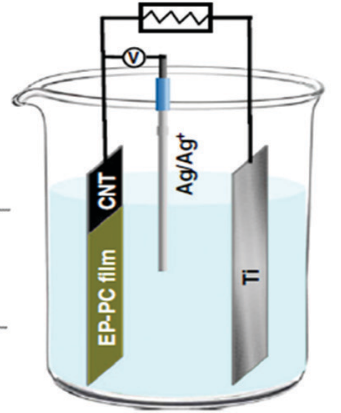

(D)

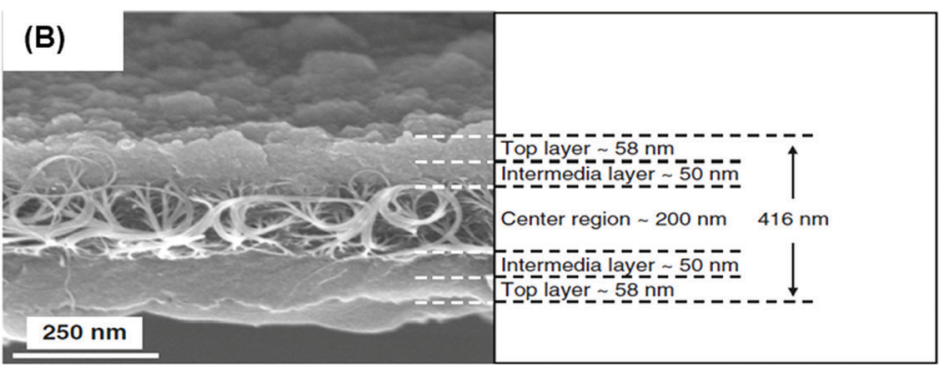

(E)
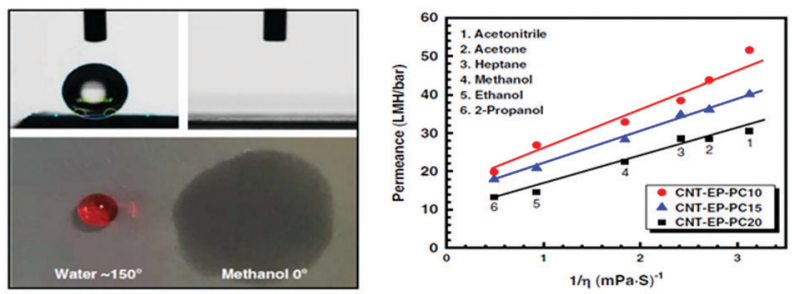

(H)

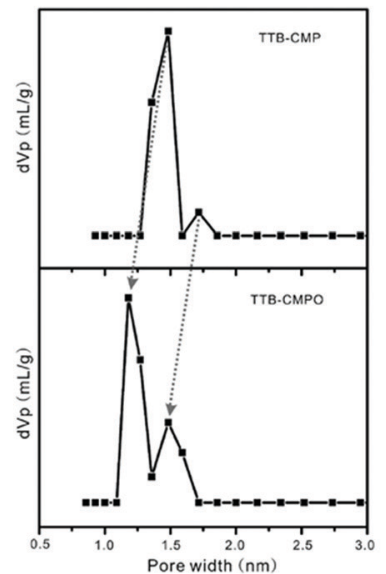

(F)

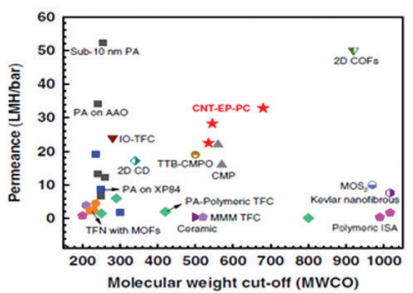

(I)

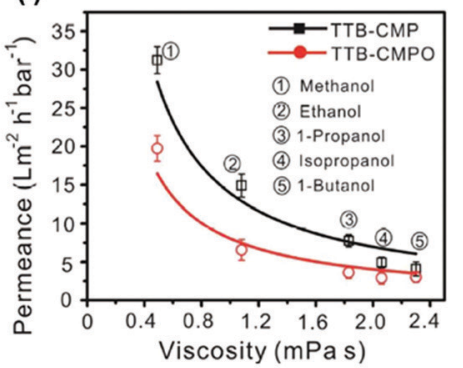

Viscosity ( $\mathrm{mPa}$ )
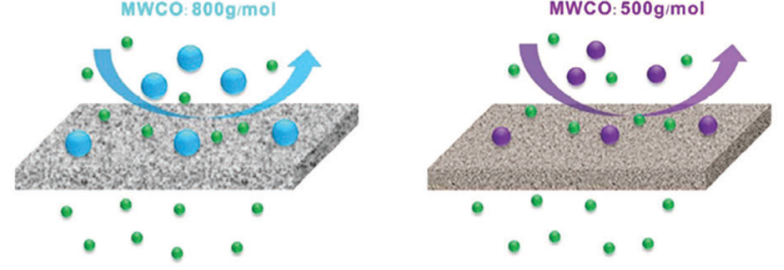

Fig. 13 (A) Schematic representation of an electro-polymerization process to prepare MMMs. (B) cross-sectional SEM image of the membrane. (C) Photograph of an example membrane. (D) Contact angle measurement on a membrane with water and methanol. (E) Correlation between permeance and viscosity of organic solvents through MMMs. (F) Performance comparison with other membranes. ${ }^{151}$ Copyright 2020 , Nature Communication. (G) Schematic representation of in-situ post-oxidation of TTB-CMP into TTB-CPMO using $m$-chloroperbenzoic acid ( $m$-CPBA) to improve selectivity. (H) Reduction in the pore size distribution of TTB-CMP to TTB-CMPO from 1.73 and $1.47 \mathrm{~nm}$ to 1.48 and $1.18 \mathrm{~nm}$. (I) Relationship between solvent permeance as a function of solvent viscosity for CMP and post-modified CMP. ${ }^{261}$ Copyright 2019, Wiley-VCH.

\section{2D materials}

2D nanosheets, such as graphene and its derivatives, MXene, and $\mathrm{MoS}_{2}$, have atomic thickness and lateral dimensions up to micrometer-scale. These 2D nanosheets can be assembled in parallel and explored for OSN applications, ${ }^{266-268}$ such as graphene-derivatives, ${ }^{267,269}$ transition-metal dichalcogenides, ${ }^{109}$ boron nitride, ${ }^{150}$ and layer double hydroxide. ${ }^{270}$ Lamellar membranes are often prepared using filtration, ${ }^{271}$ evaporation-assisted method, ${ }^{272}$ and spin-coating. ${ }^{273}$ The interconnected subnanometer channels with a narrow pore size distribution can provide fast and selective molecular transport. ${ }^{274}$ Generally, 2D material-based membranes have better resistance to chemicals and physical aging than polymeric membranes, and they have lower costs and better mechanical properties than conventional ceramic membranes. ${ }^{275}$

\subsection{GO membranes}

GO is the most studied graphene derivatives for membrane applications because of its excellent processability, filmforming ability, and versatility for modification. Particularly, it has great resistance towards organic solvents. The separation properties are primarily governed by two aspects: (a) the length of the mass transport pathway (nanochannels) and (b) the interlayer spacing between the adjacent nanosheets. Two methods are used to tune the GO lamellar structures to achieve desirable solvent permeance and solute rejection: (a) reducing the tortuosity or length of the pathway to enhance the 
permeance and (b) applying spacers or cross-linkers between adjacent nanosheets to tune the size of nanochannels and sizesieving ability.

5.1.1. Adjusting the length of the pathway. By manipulating the size of GO nanosheets, the layer alignment and length of the tortuous pathway for molecular transport can be tuned. ${ }^{276,277}$ Fig. $14 \mathrm{~A}$ and B show that larger nanosheets lead to a more tortuous pathway. On the other hand, larger nanosheets make it easier to form a highly laminated structure and achieve an ultrathin defect-free membrane, which in turn decreases the length of the pathway.

Ultrathin high laminate GO (HLGO) membranes with only $8 \mathrm{~nm}$ thickness were fabricated from large flake GO solutions without further modification (Fig. 14C). ${ }^{276}$ The large flakes $(10-20 \mu \mathrm{m})$ were obtained from Hummer's GO suspension by the specific duration of ultrasonic exfoliation and stepwise centrifugal separation process. Then the suspension was vacuum-filtered to form the membranes. Fig. 14D displays a narrow peak in the XRD pattern of the obtained GO membranes, suggesting a laminar structure. ${ }^{277}$ The high laminated alignment benefited from large overlapping areas between large nanoflakes. ${ }^{278}$ For laminar membranes, the defects are inevitable if only a few 2D nanoflakes randomly stacking on the substrate and are often eliminated by increasing the number of the GO layers, which, however, would decrease the permeance. By contrast, due to the high laminated structure, the minimum thickness required for a defect-free GO membrane was successfully reduced to $8 \mathrm{~nm}$ (inset of Fig. 14D). Therefore, the HLGO membrane showed excellent permeance for all tested solvents and nearly $100 \%$ rejection of the dyes in methanol, including Chrysoidine G, Brilliant Blue, and Rose Bengal at pressures up to 2 bar.

Small flake GOs (SFGO) were used to reduce the tortuosity of the pathway. ${ }^{277}$ SFGO membranes had higher methanol permeance $(\sim 100 \mathrm{LMH}$ per bar by dead-end filtration at 1 bar) than HLGO membranes made from large flakes ( $~ 8$ LMH per bar). SFGO membranes also showed relatively high rejection of the dyes, such as $>95.03 \%$ for acid fuchsin, $>95.73 \%$ for acid red 94 , and $>99.9 \%$ for alcian blue. However, the SFGO membranes were not easy to form uniform and homogeneous laminates (Fig. 14E) because of the weak interlayer interaction between the small overlapping areas. ${ }^{278}$ Therefore, $\mathrm{La}^{3+}$ cations were added as a cross-linker and spacer (Fig. 14F) during the fabrication, and thicker selective layers $(>70 \mathrm{~nm})$ were needed (Fig. 14G). A large porous flake GO membrane, ${ }^{279}$ used for gas separation ${ }^{280}$ and water treatment, ${ }^{281}$ might be a way to solve the dilemma to achieve an ultrathin membrane with reduced tortuous pathways.

5.1.2. Adjusting the interlayer spacing to improve permeance and selectivity. The interlayer spacing and chemistry of the GO membranes can be manipulated via intercalation or cross-linking. Original GO membranes have small interlay gaps and thus low diffusion coefficients for solvents, while intercalation can enlarge the interlayer spacing to achieve desired selectivity and permeance. For example, the interlayer spacing of the GO membranes was increased by exposure to organic
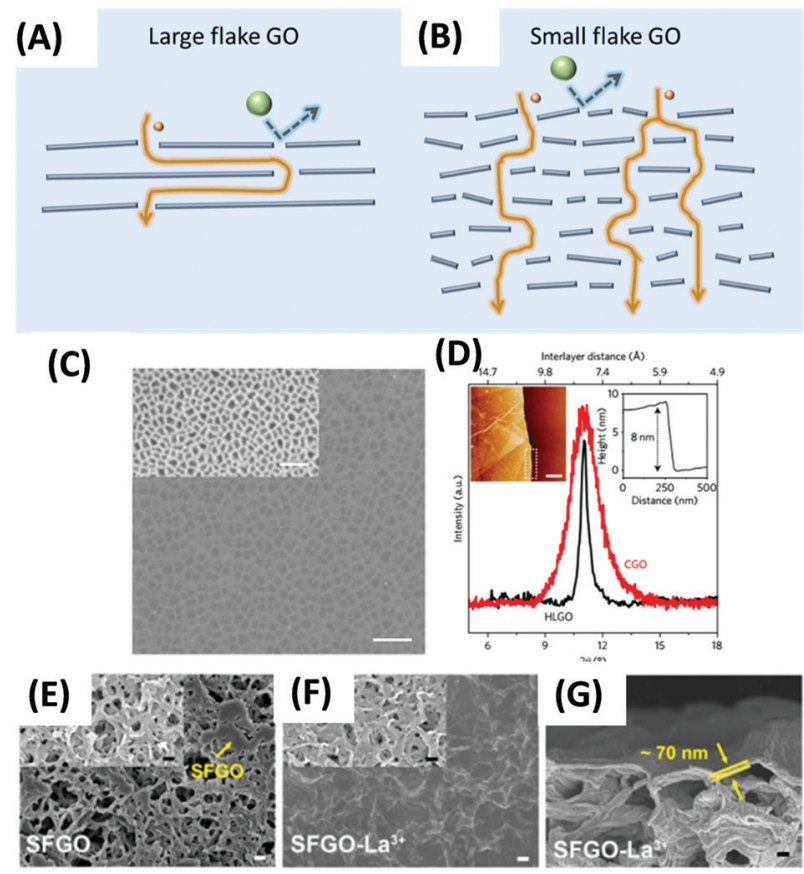

Fig. 14 Schematic of the size-dependent laminar structure of GO membranes formed with (A) large nanosheets and (B) small nanosheets. The interspace of adjacent $\mathrm{GO}$ sheets allows the permeation of organic solvents (yellow sphere) while rejecting solute molecules (green sphere). (C) SEM image of HLGO membrane deposited on an anodic aluminum oxide (AAO) support (scale bar, $1 \mu \mathrm{m}$ ) and the bare AAO membrane (inset with the scale bar of $500 \mathrm{~nm}$ ). (D) XRD patterns for HLGO membrane (black line) and conventional GO (CGO) membrane (red line); AMF image (inset on the left corner with the scale bar of $500 \mathrm{~nm}$ ) and height profiles (inset on right corner) of HLGO membrane on a silicon wafer. ${ }^{276}$ Copyright 2017, Nature Publishing Group. SEM images of (E) SFGO membranes (made from small nanosheets) and (F) the SFGO-La ${ }^{3+}$ membrane (scale bar, $1 \mu \mathrm{m}$ ). Insets are the underlying nylon substrates (scale bars, $1 \mu \mathrm{m}$ ). The yellow arrow in (E) indicates that it is difficult for SFGO to fully cover the substrate. (G) Cross-section SEM image of the SFGO-La ${ }^{3+}$ membrane (scale bar, $200 \mathrm{~nm}$ ). ${ }^{277}$ Copyright 2020, the American Association for the Advancement of Science.

solvents and reduced by thermal reduction. ${ }^{269,282}$ Fig. 15A shows that the solvated membranes exhibited large interlayer $d$-spacing, high acetone permeance (215 LMH per bar at pressures up to 5 bar), and high rejection to negative-charged molecules (larger than $3.4 \mathrm{~nm}$ ). However, the membranes needed to be kept in solvents, and the drying would make the nanosheets re-stack irreversibly.

The intercalation of planar molecules with the high conjugated system, such as porphyrin ${ }^{283}$ and MXene, ${ }^{156}$ was successfully used to noncovalently modify the size of nanochannels. Fig. 15B displays that TMPyP (5,10,15,20-tetrakis(1-methyl-4pyridinio)porphyrin) with positive charges and porphyrin rings was assembled between the GO flakes via electrostatic interaction and $\pi-\pi$ stacking. By adjusting the loading level of TMPyP, the interlayer spacing was varied from 0.64 to $1.03 \mathrm{~nm}$. The best TMPyP-intercalated membranes exhibited better rejection for negative-charged dyes and three times higher permeance than the GO membrane. They also showed a linear relationship 
(A)

between the methanol permeance and the transmembrane pressure up to 4.0 bar. More importantly, the TMPyPintercalated membranes remained stable in the dry state. The membrane also showed the potentials to remove VB12 from methanol, an important application in pharmaceutical industries. MXene was also used to intercalate GO membranes. ${ }^{156}$ Due to the 2D structure and hydrophilic property, MXene nanosheets increased the interlayer spacings, long-term stability, and solvent wettability of the GO membranes. When the weight content of the MXene was $70 \%$, the membranes achieved high flux for acetone (48.32 LMH), ethanol (10.76 LMH), and isopropanol (6.18 LMH) while the rejection rate of MB dye remained over $90 \%$ at 0.5 bar. Also, they remained stable after $48 \mathrm{~h}$ of water or ethanol filtration using a cross-flow device.

The intercalated membranes face the challenge of permeancerejection trade-off for OSN applications. Very recently, a 2D-dualspacing channel GO membrane was reported to achieve high methanol permeance of $290 \mathrm{LMH}$ per bar and $90 \%$ rejection of dyes larger than $1.5 \mathrm{~nm} .{ }^{284}$ The intercalation of $\mathrm{SiO}_{2}$ was formed in situ from the precursors between adjacent GO nanolayers. The 2019, American Chemical Society.
(C)

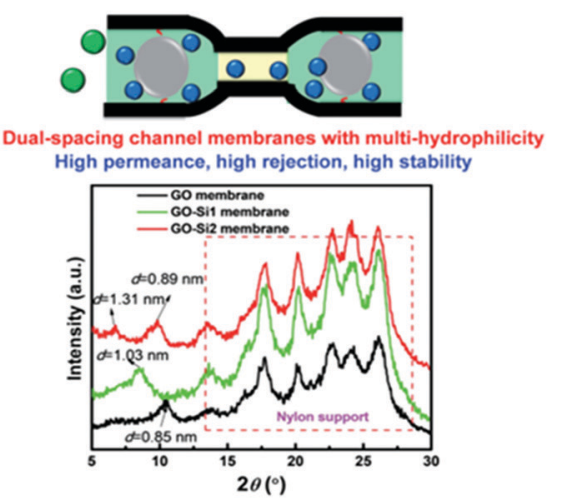

(D)
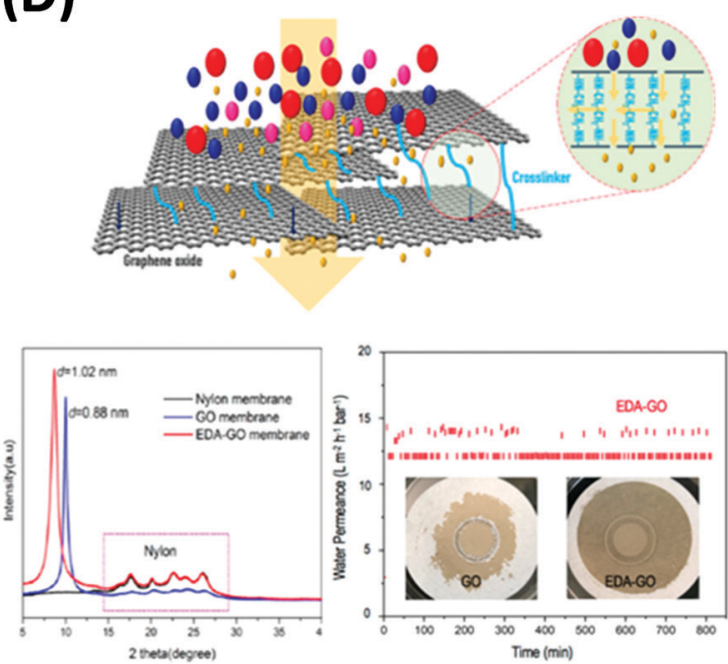

Fig. 15 (A) Solvent solvated rGO membranes (S-rGO) with increased $d$-spacing confirmed by XRD patterns. ${ }^{269,282}$ Copyright 2015 and 2016 , John Wiley and Sons. (B) rGO membranes intercalated with porphyrin molecules to manipulate the $d$-spacings. ${ }^{283}$ Copyright 2017, Elsevier. (C) Dual-spacing channel (EDA-GO) membranes, including the test over 800 min in water. ${ }^{285}$ Insets: the images of pristine GO and EDA-GO membrane after the tests. Copyright

microenvironments provided by the $\mathrm{SiO}_{2}$ nanoparticles increased the interlayer spacings and hydrophilicity, and thus solvent permeance. Meanwhile, the microenvironments free of $\mathrm{SiO}_{2}$ nanoparticles retained the narrow channels and high rejection for the solutes. Fig. $15 \mathrm{C}$ shows that the intercalation with $\mathrm{SiO}_{2}$ precursors increased the $d$-spacing from $0.85 \mathrm{~nm}$ to $1.03 \mathrm{~nm}$, and the formation of the $\mathrm{SiO}_{2}$ nanoparticles led to dual spacings of 1.31 and $0.89 \mathrm{~nm}$. Hierarchically nanostructured GO membranes were also synthesized by intercalating COF nanoparticles. ${ }^{286}$ Combining with the nanopores from COF, the GO membranes demonstrated methanol permeance of $60 \mathrm{LMH}$ per bar and a rejection of higher than $99 \%$ for methylene blue (MB).

Multivalent cations, ${ }^{287,288}$ diamines, ${ }^{289,290}$ urea, ${ }^{291}$ and thiourea ${ }^{292}$ have been used as cross-linkers to modify the physical and chemical microenvironments inside the GO membranes to realize specific functions, such as modulation of the interlayer spacing, inhibition of the swelling, and enhancement of the long-term stability. Multivalent cations, such as $\mathrm{Mg}^{2+}$ and $\mathrm{La}^{3+}$, have been applied to form a controllable stacked GO structure for OSN applications. ${ }^{276,277}$ Fig. 15D shows the GO membrane 
cross-linked by ethylenediamine (EDA) to control the nanochannel size and enhance the strength. ${ }^{285}$ The XRD pattern indicated that the nanochannel size increased by the crosslinker from $0.88 \mathrm{~nm}$ to $1.02 \mathrm{~nm}$, leading to acetone permeance of $30 \mathrm{LMH}$ per bar at a transmembrane pressure of 1 bar. The cross-linking also increased the membrane's stability in aqueous tests, which was important for industrial applications since water is unavoidable in many OSN processes.

\subsection{Other $2 \mathrm{D}$ materials-based membranes}

Boron nitride (BN) exists in multiple forms, including amorphous form (a-BN) and crystal form consisting of the cubic form (c-BN), wurtzite form (w-BN), and hexagonal form (h-BN). Single h-BN layers can be exfoliated from the bulk and have a structure similar to graphene and outstanding chemical stability. ${ }^{293} \mathrm{H}-\mathrm{BN}$ has been considered as an alternative material to build high-performance OSN membranes. However, it is challenging to prepare $\mathrm{BN}$ membranes due to the poor dispersibility of h-BN layers. A one-step mechano-chemical process was developed to prepare water-dispersible functionalized fewlayered h-BN flakes, which were then fabricated into membranes via vacuum filtration. ${ }^{294}$ The $\mathrm{BN}$ membranes exhibited good stability in harsh chemical environments (after soaking in basic, acidic, and oxidative solutions for one month) and a broad range of solvents at high temperatures. ${ }^{150}$ A $2 \mu \mathrm{m}$ thick membrane showed an ethanol flux of $330 \mathrm{LMH}$ and a $99 \%$ rejection for Congo red at 1 bar. ${ }^{150}$

Transition metal dichalcogenides (TMDs) have a formula of $\mathrm{MX}_{2}$, where $\mathrm{M}$ is transition metal from group 4-7 (i.e., Mo or W) and $\mathrm{X}$ is a chalcogen (such as $\mathrm{S}$ or Se). TMDs can be exfoliated into nanosheets by chemical or hydrothermal exfoliation and assembled into layered membranes. One of the key concerns is the stability and durability of the membranes when exposed to liquids. The membranes made from chemically exfoliated $\mathrm{MoS}_{2}$ are less stable than those made from the hydrothermally prepared $\mathrm{MoS}_{2}{ }^{295}$ The structure of the laminates can also be manipulated using a glycerol-supported drying process. $\mathrm{WS}_{2}$ can also be exfoliated in liquid solvents. ${ }^{109}$ The membranes exhibited ethanol permeance of $44.38 \mathrm{LMH}$ per bar and rejection of $99 \%$ for Evans blue using a dead-end cell at 1 bar. $^{109}$ Solvated $\mathrm{MoS}_{2}$ membranes $\left(\mathrm{S}-\mathrm{MoS}_{2}\right)$ were also prepared and showed acetonitrile permeance of $5207 \mathrm{LMH}$ per bar, $\sim 20$ times higher than that reported for GO membranes. S-MoS $\mathrm{Mom}_{2}$ branes also exhibited a rejection rate higher than $99 \%$ for dyes larger than $1.5 \mathrm{~nm}$ and isopropanol permeance of as high as $707 \mathrm{LMH}$ per bar under a cross-flow mode. ${ }^{296}$ However, the stability of the membranes in organic solvents still needs further investigation.

Layered double hydroxides (LDH) consist of regularly arranged, positively charged brucite-like 2D layers and chargecompensating anions located in interlayer galleries. ${ }^{297,298}$ They can be fabricated into membranes for OSN applications. For example, LDH with different divalent cations were fabricated into membranes and evaluated for OSN applications. ${ }^{270} \mathrm{LDH}$ nanosheets can also be used as intercalation agent in TMD laminates to achieve ultrafast solvent permeation. ${ }^{299}$
MXene is another alternative 2D material showing potential application for OSN. ${ }^{206,300}$ MXene is transition metal (e.g., $\mathrm{Ti}$ and Mo) carbides, nitrides, or carbonitrides (formula, $\left.\mathrm{M}_{n+1} \mathrm{X}_{n} \mathrm{~T}_{x}, n=1-4\right)$, which can be exploited from the MAX phase using hydrofluoric. ${ }^{301}$ For example, double-layered $\mathrm{Ti}_{3} \mathrm{C}_{2} \mathrm{Tx}$ MXenes membranes showed acetone and acetonitrile permeance as high as $5000 \mathrm{LMH}$ per bar and rejection up to $96 \%$ for the dye molecules larger than $2.0 \mathrm{~nm}$, such as reactive black (RB) in isopropanol. The superior solvent separation properties were ascribed to the regular and straight interlayer channels built up by rigid MXene blocks, compared with GO membranes with flexible GO sheets and irregular wrinkles. ${ }^{302}$ Additionally, crumpled 2D MXene lamellar membranes were prepared by filtering cryo-dried $\mathrm{Ti}_{3} \mathrm{C}_{2} \mathrm{~T}_{x}$ nanosheets and exhibited larger interlayer spacing, higher acetone permeance (3745 LMH per bar), and better rejection to dye molecules smaller than $2 \mathrm{~nm}$ than the non-crumbled membranes when tested using a vacuum filtration device. ${ }^{303}$

\subsection{Nanoporous single-layer $2 \mathrm{D}$ membranes}

Different from the layer-stacked membranes with interlayer channels achieving molecular sieving ability, single-layer 2D membranes achieve molecular separation via nanopores on the nanosheets. These membranes can be as thin as a monolayer of the nanosheet, and thus they exhibit high permeance. The uniform pore size can perform precise molecular sieving. ${ }^{279,304}$

An important example of a $2 \mathrm{D}$ nanosheet membrane is a nanoporous single-layer graphene membrane. Graphene is impermeable to molecules, but drilled graphenes with subnanometer pores have proven to be efficient for molecular separations. ${ }^{305}$ It usually takes three steps to obtain a nanoporous graphene membrane, including fabrication of a largearea graphene nanosheet, drilling nanopores, and transferring to a porous substrate. These steps are time-consuming and hard to be used for large-scale fabrication. ${ }^{21}$ Efforts are ongoing to simplify the fabrication process. ${ }^{306,307}$

In conclusion, membranes based on $2 \mathrm{D}$ materials have achieved significant progress for OSN applications, and their promise for practical applications can be realized if the following issues can be addressed.

(1) The transport mechanism for the molecules confined in nano-capillaries is not well understood but needed to guide the design of membranes for OSN. For example, the relationship between the viscosity and permeance of different solvents was often explained using Hagen-Poiseuille equation. This may be valid for a limited amount of solvents, and it should be evaluated for a broad range of solvents. Additionally, it is hard to define the exact states of the solvents inside a nanosized confined space. $^{308}$

(2) The production of the $2 \mathrm{D}$ materials and membranes on a large scale needs to be demonstrated. The consistency in fabricating single-layer or few-nanometer nanosheets and the associated defect-free membranes in a low-cost manner would be critical for their practical use. ${ }^{309,310}$

(3) Long-term stability (6 months or longer) of 2D materialbased membranes needs to be demonstrated, as well as their 
cleaning with typical acid or base solutions at desired temperatures.

\section{Conclusion}

This review provides a timely update on the tremendous progress made in the membrane material development for organic solvent separations. We first present the key challenges for membranes to be practiced for organic solvent separations, i.e., instability caused by the solvents and harsh operating conditions, permeability/selectivity tradeoff, and fabrication of defect-free TFC membranes on a large scale. Then we highlight novel molecular architectures and strategies demonstrated to achieve superior permeability, selectivity, and stability, including polymers, porous materials (PIMs, MOFs, COFs, POCs, and CMS), 2D materials, and MMMs, as well as their fabrication into TFC or TFN membranes with thin selective layers and high permeance. This review sheds light on the structure/property relationship for OSN membranes and on a variety of strategies to control structures at the nano- and subnano-scales, which should be of interest to a broad audience in the membranes, materials, and nanotechnology fields.

\section{Author contributions}

AMT, WG, and KB: investigation, formal analysis, writing original draft, and writing - review and editing; LH: formal analysis and writing - review and editing, MG: investigation, supervision, writing - original draft, and writing - review and editing; HL: conceptualization, funding acquisition, project administration, supervision, and writing - review and editing.

\section{Conflicts of interest}

There are no conflicts to declare.

\section{Acknowledgements}

This work was supported by the U.S. National Science Foundation (NSF \#1554236). MG and KPB acknowledge the donors of the American Chemical Society Petroleum Research Fund (ACS-PRFDNI) for partial support of this work (Grant \# 60079-DNI7).

\section{Notes and references}

1 K. A. Thompson, R. Mathias, D. Kim, J. Kim, N. Rangnekar, J. R. Johnson, S. J. Hoy, I. Bechis, A. Tarzia, K. E. Jelfs, B. A. McCool, A. G. Livingston, R. P. Lively and M. G. Finn, Science, 2020, 369, 310-315.

2 H. Wang, M. Wang, X. Liang, J. Yuan, H. Yang, S. Wang, Y. Ren, H. Wu, F. Pan and Z. Jiang, Chem. Soc. Rev., 2021, 50, 5468-5516.

3 P. Marchetti, M. F. Jimenez Solomon, G. Szekely and A. G. Livingston, Chem. Rev., 2014, 114, 10735-10806.
4 D.-Y. Koh, B. A. McCool, H. W. Deckman and R. P. Lively, Science, 2016, 353, 804-807.

5 R. P. Lively and D. S. Sholl, Nat. Mater., 2017, 16, 276-279.

6 D. S. Sholl and R. P. Lively, Nature, 2016, 532, 435-437.

7 Y. Yang, P. Bai and X. Guo, Ind. Eng. Chem. Res., 2017, 56, 14725-14753.

8 M. L. Jue, D.-Y. Koh, B. A. McCool and R. P. Lively, Chem. Mater., 2017, 29, 9863-9876.

9 X. Cheng, Z. Wang, X. Jiang, T. Li, C. Lau, Z. Guo, J. Ma and L. Shao, Prog. Mater. Sci., 2018, 92, 258-283.

10 B. Liang, X. He, J. Hou, L. Li and Z. Tang, Adv. Mater., 2019, 31, 1806090.

11 G. Szekely, M. F. Jimenez-Solomon, P. Marchetti, J. F. Kim and A. G. Livingston, Green Chem., 2014, 16, 444-4473.

12 M. Takht Ravanchi, T. Kaghazchi and A. Kargari, Desalination, 2009, 235, 199-244.

13 M. G. Buonomenna and J. Bae, Sep. Purif. Rev., 2015, 44, 157-182.

14 M. Galizia and K. P. Bye, Front. Chem., 2018, 6, 511.

15 A. Malakhov and A. Volkov, Russ. J. Appl. Chem., 2020, 93, 14-24. 16 A. Asadi Tashvigh, Y. Feng, M. Weber, C. Maletzko and T.-S. Chung, Ind. Eng. Chem. Res., 2019, 58, 10678-10691.

17 B. Zheng, X. Lin, X. Zhang, D. Wu and K. Matyjaszewski, Adv. Funct. Mater., 2020, 30, 1907006.

18 C. Zhang, B.-H. Wu, M.-Q. Ma, Z. Wang and Z.-K. Xu, Chem. Soc. Rev., 2019, 48, 3811-3841.

19 X. Li, Y. Liu, J. Wang, J. Gascon, J. Li and B. Van der Bruggen, Chem. Soc. Rev., 2017, 46, 7124-7144.

20 S. Yuan, X. Li, J. Zhu, G. Zhang, P. Van Puyvelde and B. Van der Bruggen, Chem. Soc. Rev., 2019, 48, 2665-2681.

21 F. Moghadam and H. Park, 2D Mater., 2019, 6, 42002.

22 W.-J. Lau, G.-S. Lai, J. Li, S. Gray, Y. Hu, N. Misdan, P.-S. Goh, T. Matsuura, I. W. Azelee and A. F. Ismail, J. Ind. Eng. Chem., 2019, 77, 25-59.

23 M. Amirilargani, M. Sadrzadeh, E. J. R. Sudhölter and L. C. P. M. de Smet, Chem. Eng. J., 2016, 289, 562-582.

24 G. Zhu, D. O'Nolan and R. P. Lively, Chem. - Eur. J., 2020, 26, 3464-3473.

25 M. H. Davood Abadi Farahani, D. Ma and P. Nazemizadeh Ardakani, Sep. Purif. Rev., 2020, 49, 177-206.

26 D. Peshev and A. G. Livingston, Chem. Eng. Sci., 2013, 104, 975-987.

27 D. Zedel, M. Kraume and A. Drews, J. Membr. Sci., 2017, 544, 323-332.

28 G. Belfort, Angew. Chem., Int. Ed., 2019, 58, 1892-1902.

29 P. Marchetti, L. Peeva and A. Livingston, Annu. Rev. Chem. Biomol. Eng., 2017, 8, 473-497.

30 M. Schaepertoens, C. Didaskalou, J. F. Kim, A. G. Livingston and G. Szekely, J. Membr. Sci., 2016, 514, 646-658.

31 L. Peeva, J. Da Silva Burgal, Z. Heckenast, F. Brazy, F. Cazenave and A. Livingston, Angew. Chem., Int. Ed., 2016, 55, 13576-13579.

32 A. Asadi Tashvigh and T.-S. Chung, J. Membr. Sci., 2019, 572, 580-587.

33 A. Asadi Tashvigh and T.-S. Chung, J. Membr. Sci., 2018, 560, 115-124. 
34 M. H. Davood Abadi Farahani and T.-S. Chung, Sep. Purif. Technol., 2019, 209, 182-192.

35 C. Didaskalou, J. Kupai, L. Cseri, J. Barabas, E. Vass, T. Holtzl and G. Szekely, ACS Catal., 2018, 8, 7430-7438.

36 M. Razali, C. Didaskalou, J. F. Kim, M. Babaei, E. Drioli, Y. M. Lee and G. Szekely, ACS Appl. Mater. Interfaces, 2017, 9, 11279-11289.

37 Y. Li, E. Wong, A. Volodine, C. Van Haesendonck, K. Zhang and B. Van der Bruggen, J. Mater. Chem. A, 2019, 7, 19269-19279.

38 M. B. Martínez, N. Jullok, Z. R. Negrin, B. Van der Bruggen and P. Luis, Chem. Eng. Process., 2013, 70, 241-249.

39 F. v. A. Ferreira, T. Esteves, M. P. Carrasco, J. o. Bandarra, C. A. M. Afonso and F. C. Ferreira, Ind. Eng. Chem. Res., 2019, 58, 10524-10532.

40 T. Esteves, A. I. Vicente, F. A. Ferreira, C. A. M. Afonso and F. C. Ferreira, React. Funct. Polym., 2018, 131, 258-265.

41 T. Fodi, C. Didaskalou, J. Kupai, G. T. Balogh, P. Huszthy and G. Szekely, ChemSusChem, 2017, 10, 3435-3444.

42 W. E. Siew, C. Ates, A. Merschaert and A. G. Livingston, Green Chem., 2013, 15, 663-674.

43 J. Shen, K. Beale, I. Amura and E. A. C. Emanuelsson, Front. Chem., 2020, 8, 375.

44 P. Marchetti, A. Butté and A. G. Livingston, Chem. Eng. Sci., 2013, 101, 200-212.

45 I. Sereewatthanawut, F. C. Ferreira, N. F. Ghazali and A. G. Livingston, AlChE J., 2010, 56, 893-904.

46 N. F. Ghazali, D. A. Patterson and A. G. Livingston, Chem. Commun., 2004, 962-963.

47 N. F. Ghazali, F. C. Ferreira, A. J. P. White and A. G. Livingston, Tetrahedron: Asymmetry, 2006, 17, 1846-1852.

48 Y. Lu, H. Zhang, J. Y. Chan, R. Ou, H. Zhu, M. Forsyth, E. M. Marijanovic, C. M. Doherty, P. J. Marriott, M. M. B. Holl and H. Wang, Angew. Chem., Int. Ed., 2019, 58, 16928-16935.

49 Y. Ma, M. L. Jue, F. Zhang, R. Mathias, H. Y. Jang and R. P. Lively, Angew. Chem., Int. Ed., 2019, 58, 13259-13265.

50 M. Namvar-Mahboub, M. Pakizeh and S. Davari, J. Membr. Sci., 2014, 459, 22-32.

51 R. M. Gould, L. S. White and C. R. Wildemuth, Environ. Prog., 2001, 20, 12-16.

52 N. Stafie, D. F. Stamatialis and M. Wessling, J. Membr. Sci., 2004, 228, 103-116.

53 M. H. Abdellah, L. Liu, C. A. Scholes, B. D. Freeman and S. E. Kentish, J. Membr. Sci., 2019, 573, 694-703.

54 S. K. Lim, K. Goh, T.-H. Bae and R. Wang, Chin. J. Chem. Eng., 2017, 25, 1653-1675.

55 G. M. Shi, M. H. Davood Abadi Farahani, J. Y. Liu and T.-S. Chung, J. Membr. Sci., 2019, 588, 117202.

56 R. Othman, A. W. Mohammad, M. Ismail and J. Salimon, J. Membr. Sci., 2010, 348, 287-297.

57 H. Werhan, A. Farshori and P. Rudolf von Rohr, J. Membr. Sci., 2012, 423-424, 404-412.

58 K. P. Bye and M. Galizia, J. Membr. Sci., 2020, 603, 118020.

59 P. Silva, S. Han and A. G. Livingston, J. Membr. Sci., 2005, 262, 49-59.
60 P. Marchetti and A. Livingston, J. Membr. Sci., 2015, 476, 530-553.

61 K. P. Bye, V. Loianno, T. N. Pham, R. Liu, J. S. Riffle and M. Galizia, J. Membr. Sci., 2019, 580, 235-247.

62 V. Loianno, K. P. Bye, M. Galizia and P. Musto, J. Polym. Sci., 2020, 58, 2547-2560.

63 M. H. Abdellah, C. A. Scholes, B. D. Freeman, L. Liu and S. E. Kentish, Sep. Purif. Technol., 2018, 207, 470-476.

64 P. Vandezande, L. E. M. Gevers and I. F. J. Vankelecom, Chem. Soc. Rev., 2008, 37, 365-405.

65 E. L. Cussler, Diffusion: Mass Transfer in Fluid Systems, Cambridge University Press, Cambridge, 2009.

66 J. D. Ferry, Chem. Rev., 1936, 18, 373-455.

67 S.-I. Nakao and S. Kimura, J. Chem. Eng. Jpn., 1982, 15, 200-205.

68 B. Van der Bruggen and C. Vandecasteele, Environ. Sci. Technol., 2001, 35, 3535-3540.

69 W. R. Bowen and H. Mukhtar, J. Membr. Sci., 1996, 112, 263-274.

70 H. Park, J. Kamcev, L. M. Robeson, M. Elimelech and B. D. Freeman, Science, 2017, 356, eaab0530.

71 M. F. Jimenez-Solomon, Q. Song, K. E. Jelfs, M. MunozIbanez and A. G. Livingston, Nat. Mater., 2016, 15, 760-767.

72 H. Yang, L. Yang, H. Wang, Z. Xu, Y. Zhao, Y. Luo, N. Nasir, Y. Song, H. Wu, F. Pan and Z. Jiang, Nat. Commun., 2019, 10, 2101.

73 Z. Ali, B. S. Ghanem, Y. Wang, F. Pacheco, W. Ogieglo, H. Vovusha, G. Genduso, U. Schwingenschlögl, Y. Han and I. Pinnau, Adv. Mater., 2020, 32, 2001132.

74 C. Wang, C. Li, E. R. C. Rutledge, S. Che, J. Lee, A. J. Kalin, C. Zhang, H.-C. Zhou, Z.-H. Guo and L. Fang, J. Mater. Chem. A, 2020, 8, 15891-15899.

75 R. W. Baker, J. G. Wijmans and Y. Huang, J. Membr. Sci., 2010, 348, 346-352.

76 L. S. White, J. Membr. Sci., 2006, 286, 26-35.

77 A. V. Volkov, V. V. Parashchuk, D. F. Stamatialis, V. S. Khotimsky, V. V. Volkov and M. Wessling, J. Membr. Sci., 2009, 333, 88-93.

78 Y. Zhang, M. Zhong, B. Luo, J. Li, Q. Yuan and X. J. Yang, J. Membr. Sci., 2017, 544, 119-125.

79 R. Heffernan, A. J. C. Semião, P. Desmond, H. Cao, A. Safari, O. Habimana and E. Casey, J. Membr. Sci., 2013, 448, 170-179.

80 S. Darvishmanesh, J. Degrève and B. Van Der Bruggen, Phys. Chem. Chem. Phys., 2010, 12, 13333-13342.

81 S. Darvishmanesh, L. Firoozpour, J. Vanneste, P. Luis, J. Degrève and B. V. d. Bruggen, Green Chem., 2011, 13, 3476-3483.

82 S. Darvishmanesh, T. Robberecht, P. Luis, J. Degrève and B. Van Der Bruggen, J. Am. Oil Chem. Soc., 2011, 88, 1255-1261.

83 H. Siddique, L. G. Peeva, K. Stoikos, G. Pasparakis, M. Vamvakaki and A. G. Livingston, Ind. Eng. Chem. Res., 2013, 52, 1109-1121.

84 J. D. S. Burgal, L. G. Peeva, S. Kumbharkar and A. Livingston, J. Membr. Sci., 2015, 479, 105-116. 
85 H. Siddique, E. Rundquist, Y. Bhole, L. G. Peeva and A. G. Livingston, J. Membr. Sci., 2014, 452, 354-366.

86 N. Joseph, J. Thomas, P. Ahmadiannamini, H. Van Gorp, R. Bernstein, S. De Feyter, M. Smet, W. Dehaen, R. Hoogenboom and I. F. J. Vankelecom, Adv. Funct. Mater., 2017, 27, 1605068.

87 B. Scharzec, J. Holtkötter, J. Bianga, J. M. Dreimann, D. Vogt and M. Skiborowski, Chem. Eng. Res. Des., 2020, 157, 65-76.

88 M. F. Jimenez Solomon, Y. Bhole and A. G. Livingston, J. Membr. Sci., 2012, 423, 371-382.

89 M. Morshed, H. Simonaire, H. Alem and D. Roizard, J. Appl. Polym. Sci., 2019, 137, 48359.

90 L. Pérez-Manríquez, J. Aburabi'e, P. Neelakanda and K.-V. Peinemann, React. Funct. Polym., 2015, 86, 243-247.

91 K. Tempelman, J. A. Wood, F. Kremer and N. E. Benes, J. Phys. Chem. B, 2019, 123, 4017-4024.

92 A. V. Bildyukevich, T. V. Plisko, A. A. Shustikov, Y. S. Dzyazko, L. M. Rozhdestvenska and S. A. Pratsenko, J. Mater. Sci., 2020, 55, 9638-9654.

93 I. Soroko, M. Makowski, F. Spill and A. Livingston, J. Membr. Sci., 2011, 381, 163-171.

94 L. Pérez-Manríquez, A. R. Behzad and K. V. Peinemann, Macromol. Mater. Eng., 2016, 301, 1437-1442.

95 L. Perez-Manriquez, P. Neelakanda and K.-V. Peinemann, J. Membr. Sci., 2017, 541, 137-142.

96 H. Zhang, Y. Zhang, L. Li, S. Zhao, H. Ni, S. Cao and J. Wang, Chem. Eng. Sci., 2014, 106, 157-166.

97 R. Ding, H. Zhang, Y. Li, J. Wang, B. Shi, H. Mao, J. Dang and J. Liu, Chem. Eng. Sci., 2015, 138, 227-238.

98 I. Soroko, M. P. Lopes and A. Livingston, J. Membr. Sci., 2011, 381, 152-162.

99 I. Soroko, M. Sairam and A. G. Livingston, J. Membr. Sci., 2011, 381, 172-182.

100 Z. Gao, Y. Feng, D. Ma and T.-S. Chung, J. Membr. Sci., 2019, 574, 124-135.

101 Y. Li, J. Xue, X. Zhang, B. Cao and P. Li, Ind. Eng. Chem. Res., 2019, 58, 6712-6720.

102 Y. Li, R. Yang, R. Zhang, B. Cao and P. Li, Ind. Eng. Chem. Res., 2020, 59, 14096-14105.

103 R. Valadez-Blanco and A. G. Livingston, J. Membr. Sci., 2009, 326, 332-342.

104 S. Xu, Z.-Y. Wang, S. Li, L. Tian and B. Su, Sep. Purif. Technol., 2020, 241, 116751.

105 C. Li, S. Li, L. Lv, B. Su and M. Z. Hu, J. Membr. Sci., 2018, 564, 10-21.

106 Z. Gao, G. Shi, Y. Cui and T.-S. Chung, J. Membr. Sci., 2018, 565, 169-178.

107 S. Yang, H. Zhen and B. Su, RSC Adv., 2017, 7, 42800-42810.

108 H. M. Tham, K. Wang, D. Hua, S. Japip and T.-S. Chung, J. Membr. Sci., 2017, 542, 289-299.

109 H. M. Tham, S. Japip and T.-S. Chung, J. Membr. Sci., 2019, 588, 117219.

110 D. Chen, J. Appl. Polym. Sci., 2013, 129, 3156-3161.

111 I. B. Valtcheva, S. C. Kumbharkar, J. F. Kim, Y. Bhole and A. G. Livingston, J. Membr. Sci., 2014, 457, 62-72.
112 D. Y. Xing, S. Y. Chan and T.-S. Chung, Green Chem., 2014, 16, 1383-1392.

113 A. Asadi Tashvigh, L. Luo, T.-S. Chung, M. Weber and C. Maletzko, J. Membr. Sci., 2018, 551, 204-213.

114 F. Fei, L. Cseri, G. Szekely and C. F. Blanford, ACS Appl. Mater. Interfaces, 2018, 10, 16140-16147.

115 G. Ignacz, F. Fei and G. Szekely, ACS Appl. Nano Mater., 2018, 1, 6349-6356.

116 D. Zhao, J. F. Kim, G. Ignacz, P. Pogany, Y. M. Lee and G. Szekely, ACS Nano, 2019, 13, 125-133.

117 M. Sairam, X. X. Loh, Y. Bhole, I. Sereewatthanawut, K. Li, A. Bismarck, J. H. G. Steinke and A. G. Livingston, J. Membr. Sci., 2010, 349, 123-129.

118 X. X. Loh, M. Sairam, A. Bismarck, J. H. G. Steinke, A. G. Livingston and K. Li, J. Membr. Sci., 2009, 326, 635-642.

119 M. Sairam, X. X. Loh, K. Li, A. Bismarck, J. H. G. Steinke and A. G. Livingston, J. Membr. Sci., 2009, 330, 166-174.

120 J. Shen, S. Shahid, A. Sarihan, D. A. Patterson and E. A. C. Emanuelsson, Sep. Purif. Technol., 2018, 204, 336-344.

121 K. Hendrix, M. Eynde, G. Koeckelberghs and I. Vankelecom, J. Membr. Sci., 2013, 447, 212-221.

122 L. Xia, J. Ren, M. Weyd and J. R. McCutcheon, J. Membr. Sci., 2018, 563, 857-863.

123 S. K. Das, P. Manchanda and K.-V. Peinemann, Sep. Purif. Technol., 2019, 213, 348-358.

124 T. Huang, T. Puspasari, S. P. Nunes and K. V. Peinemann, Adv. Funct. Mater., 2019, 30, 1906797.

125 S. Karan, Z. Jiang and A. G. Livingston, Science, 2015, 348, 1347-1351.

126 X. L. Cao, J. L. Guo, J. Cai, M. L. Liu, S. Japip, W. Xing and S. P. Sun, AlChE J., 2019, 66, e16879.

127 J. Hou, M. Jiang, X. He, P. Liu, C. Long, L. Yu, Z. Huang, J. Huang, L. Li and Z. Tang, Chem. - Asian J., 2019, 15, 2341-2345.

128 C. Ong, G. Falca, T. Huang, J. Liu, P. Manchanda, S. Chisca and S. P. Nunes, ACS Sustainable Chem. Eng., 2020, 8, 11541-11548.

129 Y. Li, S. Li, J. Zhu, A. Volodine and B. van der Bruggen, Chem. Sci., 2020, 11, 4263-4271.

130 X. Zheng, A. Zhou, Y. Wang, X. He, S. Zhao, J. Zhang and W. Li, Sep. Purif. Technol., 2019, 223, 211-223.

131 S. Zhou, Y. Zhao, J. Zheng and S. Zhang, J. Membr. Sci., 2019, 591, 117347.

132 L. Sarango, L. Paseta, M. Navarro, B. Zornoza and J. Coronas, J. Ind. Eng. Chem., 2018, 59, 8-16.

133 P. H. H. Duong, D. H. Anjum, K.-V. Peinemann and S. P. Nunes, J. Membr. Sci., 2018, 563, 684-693.

134 J. Liu, W. Mu, J. Wang, H. Liu, Y. Qin, J. He, F. Guo, Y. Li, Y. Li, X. Cao, P. Zhang and E. Lu, Sep. Purif. Technol., 2018, 205, 140-150.

135 H. Abadikhah, E. N. Kalali, S. Behzadi, S. A. Khan, X. Xu, M. E. Shabestari and S. Agathopoulos, Chem. Eng. Sci., 2019, 204, 99-109. 
136 Y. Liang, C. Li, S. Li, B. Su, M. Z. Hu, X. Gao and C. Gao, Chem. Eng. J., 2020, 380, 122462.

137 S.-J. Xu, Q. Shen, G.-E. Chen and Z.-L. Xu, ACS Omega, 2018, 3, 11770-11787.

138 S. Sorribas, P. Gorgojo, C. Téllez, J. N. Coronas and A. G. Livingston, J. Am. Chem. Soc., 2013, 135, 15201-15208.

139 Y. Li, C. Li, S. Li, B. Su, L. Han and B. Mandal, J. Mater. Chem. A, 2019, 7, 13315-13330.

140 M. Navarro, J. Benito, L. Paseta, I. Gascón, J. N. Coronas and C. Téllez, ACS Appl. Mater. Interfaces, 2018, 10, 1278-1287.

141 X. Wu, G. Zhou, X. Cui, Y. Li, J. Wang, X. Cao and P. Zhang, ACS Appl. Mater. Interfaces, 2019, 11, 17804-17813.

142 H. Mao, H. Zhang, Y. Li, Y. Xue, F. Pei, J. Wang and J. Liu, ACS Sustainable Chem. Eng., 2015, 3, 1925-1933.

143 C. Echaide-Górriz, S. Sorribas, C. Téllez and J. Coronas, RSC Adv., 2016, 6, 90417-90426.

144 C. Echaide-Górriz, M. Navarro, C. Téllez and J. Coronas, Dalton Trans., 2017, 46, 6244-6252.

145 L. Paseta, J. M. Luque-Alled, M. Malankowska, M. Navarro, P. Gorgojo, J. Coronas and C. Téllez, Sep. Purif. Technol., 2020, 247, 116995.

146 S.-J. Xu, Q. Shen, Y.-H. Tong, Z.-Q. Dong and Z.-L. Xu, Sep. Purif. Technol., 2020, 240, 116619.

147 G. Zhu, F. Zhang, M. P. Rivera, X. Hu, G. Zhang, C. W. Jones and R. P. Lively, Angew. Chem., Int. Ed., 2019, 58, 2638-2643.

148 J. Campbell, J. D. S. Burgal, G. Szekely, R. P. Davies, D. C. Braddock and A. Livingston, J. Membr. Sci., 2016, 503, 166-176.

149 S.-D. Jiang, A. Y. K. Koh, K. H. Chong and S. Zhang, J. Membr. Sci., 2019, 585, 60-66.

150 C. Chen, J. Wang, D. Liu, C. Yang, Y. Liu, R. S. Ruoff and W. Lei, Nat. Commun., 2018, 9, 1902.

151 Z. Zhou, X. Li, D. Guo, D. B. Shinde, D. Lu, L. Chen, X. Liu, L. Cao, A. M. Aboalsaud, Y. Hu and Z. Lai, Nat. Commun., 2020, 11, 5323.

152 Z. Si, Z. Wang, D. Cai, G. Li, S. Li and P. Qin, Sep. Purif. Technol., 2020, 241, 116545.

153 M. H. Davood Abadi Farahani, D. Hua and T.-S. Chung, J. Membr. Sci., 2018, 548, 319-331.

154 M. H. Davood Abadi Farahani, D. Hua and T.-S. Chung, Sep. Purif. Technol., 2017, 186, 243-254.

155 Z. Wang, Z. Si, D. Cai, G. Li, S. Li, P. Qin and T. Tan, Sep. Purif. Technol., 2019, 227, 115687.

156 S. Wei, Y. Xie, Y. Xing, L. Wang, H. Ye, X. Xiong, S. Wang and K. Han, J. Membr. Sci., 2019, 582, 414-422.

157 D. Fritsch, P. Merten, K. Heinrich, M. Lazar and M. Priske, J. Membr. Sci., 2012, 401, 222-231.

158 J. Gao, S. Japip and T.-S. Chung, Chem. Eng. J., 2018, 353, 689-698.

159 J. Li, M. Zhang, W. Feng, L. Zhu and L. Zhang, J. Membr. Sci., 2020, 601, 117951.

160 E. K. McGuinness, F. Zhang, Y. Ma, R. P. Lively and M. D. Losego, Chem. Mater., 2019, 31, 5509-5518.

161 P. Gorgojo, S. Karan, H. C. Wong, M. F. Jimenez-Solomon, J. T. Cabral and A. G. Livingston, Adv. Funct. Mater., 2014, 24, 4728.
162 L. Zhu, M. T. Swihart and H. Lin, Energy Environ. Sci., 2017, 11, 94-100.

163 A. Naderi, A. Asadi Tashvigh, T.-S. Chung, M. Weber and C. Maletzko, J. Membr. Sci., 2018, 563, 726-733.

164 C. Ji, S. Xue, C.-W. Lin, W. H. Mak, B. T. McVerry, C. L. Turner, M. Anderson, J. C. Molas, Z. Xu and R. B. Kaner, ACS Appl. Mater. Interfaces, 2020, 12, 30796-30804.

165 D. Chen, S. Yu, H. Zhang and X. Li, Sep. Purif. Technol., 2015, 142, 299-306.

166 I. B. Valtcheva, P. Marchetti and A. G. Livingston, J. Membr. Sci., 2015, 493, 568.

167 S.-P. Sun, S.-Y. Chan, W. Xing, Y. Wang and T.-S. Chung, ACS Sustainable Chem. Eng., 2015, 3, 3019-3023.

168 L. Zhu, M. Swihart and H. Lin, J. Mater. Chem. A, 2017, 5, 19914-19923.

169 J. D. S. Burgal, L. Peeva, P. Marchetti and A. Livingston, J. Membr. Sci., 2015, 493, 524-538.

170 J. Wang, Y. Yao, Z. Yue and J. Economy, J. Membr. Sci., 2009, 337, 200-207.

171 M. G. Buonomenna, G. Golemme, J. C. Jansen and S. H. Choi, J. Membr. Sci., 2011, 368, 144.

172 X. Dong, Q. Zhang, S. Zhang and S. Li, J. Colloid Interface Sci., 2016, 463, 332-341.

173 C. Liu, R. Takagi, T. Shintani, L. Cheng, K.-L. Tung and H. Matsuyama, ACS Appl. Mater. Interfaces, 2020, 12, 7586-7594.

174 X. Jin, L. Li, R. Xu, Q. Liu, L. Ding, Y. Pan, C. Wang, W. Hung, K. Lee and T. Wang, Polymers, 2018, 10, 539.

175 J. Wang, J. Zhu, M. T. Tsehaye, J. Li, G. Dong, S. Yuan, X. Li, Y. Zhang, J. Liu and B. Van Der Bruggen, J. Mater. Chem. A, 2017, 5, 14847-14857.

176 Z. Yuan, X. Wu, Y. Jiang, Y. Li, J. Huang, L. Hao, J. Zhang and J. Wang, J. Membr. Sci., 2018, 549, 1-11.

177 Y. Yampolskii, N. Belov and A. Alentiev, J. Membr. Sci., 2020, 598, 117779.

178 J. Chau, P. Basak, J. Kaur, Y. Hu and K. K. Sirkar, Sep. Purif. Technol., 2018, 199, 233-241.

179 G. M. Shi and T.-S. Chung, J. Membr. Sci., 2020, 602, 117972.

180 X. Li, W. Cai, T. Wang, Z. Wu, J. Wang, X. He and J. Li, Sep. Purif. Technol., 2017, 181, 223-229.

181 J. Chau and K. K. Sirkar, J. Membr. Sci., 2021, 618, 118663.

182 I. I. Yusoff, R. Rohani, L. Y. Ng and A. W. Mohammad, J. Mater. Sci., 2019, 54, 12988-13005.

183 S. Ilyas, N. Joseph, A. Szymczyk, A. Volodin, K. Nijmeijer, W. M. de Vos and I. F. J. Vankelecom, J. Membr. Sci., 2016, 514, 322-331.

184 X. Li, S. De Feyter, D. Chen, S. Aldea, P. Vandezande, F. Du Prez and I. F. J. Vankelecom, Chem. Mater., 2008, 20, 3876-3883.

185 S. Fiori, O. Monticelli, V. Alzari and A. Mariani, J. Appl. Polym. Sci., 2010, 115, 3155-3160.

186 S. Hermans, E. Dom, H. Marieen, G. Koeckelberghs and I. Vankelecom, J. Membr. Sci., 2015, 476, 356-363.

187 M. F. Jimenez Solomon, Y. Bhole and A. G. Livingston, J. Membr. Sci., 2013, 434, 193-203.

188 Q. Jia, Y. Xu, J. Shen, H. Yang and L. Zhou, Appl. Surf. Sci., 2015, 356, 1105-1116. 
189 V. Polisetti and P. Ray, J. Appl. Polym. Sci., 2020, 137, 49351. 190 S. H. Chen, D. J. Chang, R. M. Liou, C. S. Hsu and S. S. Lin, J. Appl. Polym. Sci., 2002, 83, 1112-1118.

191 R. Han, Y. Xie, X. Ma, D. Teng, S. Zhang and X. Jian, J. Chem. Technol. Biotechnol., 2018, 94, 2838-2843.

192 C. Wu, S. Zhang, D. Yang and X. Jian, J. Membr. Sci., 2009, 326, 429-434.

193 Y. Liang, Y. Zhu, C. Liu, K.-R. Lee, W.-S. Hung, Z. Wang, Y. Li, M. Elimelech, J. Jin and S. Lin, Nat. Commun., 2020, 11, 2015.

194 A. K. Ghosh and E. M. V. Hoek, J. Membr. Sci., 2009, 336, 140-148.

195 K. Zhang, R. P. Lively, C. Zhang, R. R. Chance, W. J. Koros, D. S. Sholl and S. Nair, J. Phys. Chem. Lett., 2013, 4, 3618-3622.

196 K. Zhang, R. P. Lively, C. Zhang, W. J. Koros and R. R. Chance, J. Phys. Chem. C, 2013, 117, 7214-7225.

197 M. Tu, S. Wannapaiboon, K. Khaletskaya and R. A. Fischer, Adv. Funct. Mater., 2015, 25, 4470-4479.

198 K. Zhang, R. P. Lively, M. E. Dose, A. J. Brown, C. Zhang, J. Chung, S. Nair, W. J. Koros and R. R. Chance, Chem. Commun., 2013, 49, 3245-3247.

199 A. A. Yushkin, T. S. Anokhina, S. D. Bazhenov, I. L. Borisov, P. M. Budd and A. V. Volkov, Pet. Chem., 2018, 58, 1154-1158.

200 T. S. Anokhina, A. A. Yushkin, P. M. Budd and A. V. Volkov, Sep. Purif. Technol., 2015, 156, 683-690.

201 M. Cook, P. R. J. Gaffney, L. G. Peeva and A. G. Livingston, J. Membr. Sci., 2018, 558, 52-63.

202 J. Zhu, S. Yuan, J. Wang, Y. Zhang, M. Tian and B. Van der Bruggen, Prog. Polym. Sci., 2020, 110, 101308.

203 M. A. Abdulhamid, S.-H. Park, H. Vovusha, F. H. Akhtar, K. C. Ng, U. Schwingenschlogl and G. Szekely, J. Mater. Chem. A, 2020, 8, 24445-24454.

204 W. Zhao, L. Xia and X. Liu, CrystEngComm, 2018, 2, 1613-1634.

205 W. Wei, J. Liu and J. Jiang, ACS Sustainable Chem. Eng., 2019, 7, 1734-1744.

206 X. Sui, Z. Yuan, Y. Yu, K. Goh and Y. Chen, Small, 2020, 16, e2003400.

207 L. Valentino, M. Matsumoto, W. R. Dichtel and B. J. Mariñas, Environ. Sci. Technol., 2017, 51, 14352-14359.

208 S. Hao, J. Wen, S. Li, J. Wang and Z. Jia, J. Mater. Sci., 2020, 55, 14817-14828.

209 A. P. Côté, A. I. Benin, N. W. Ockwig, M. Keeffe, A. J. Matzger and O. M. Yaghi, Science, 2005, 310, 1166-1170.

210 K. Dey, H. S. Kunjattu, A. M. Chahande and R. Banerjee, Angew. Chem., Int. Ed., 2020, 59, 1161-1165.

211 C. Li, S. Li, L. Tian, J. Zhang, B. Su and M. Z. Hu, J. Membr. Sci., 2019, 572, 520-531.

212 J.-S. Bae, E. Jeon, M. Byeon and J.-W. Park, ACS Macro Lett., 2015, 4, 991-995.

213 D. Zhou, X. Tan, H. Wu, L. Tian and M. Li, Angew. Chem., Int. Ed., 2019, 58, 1376-1381.

214 X. Shi, A. Xiao, C. Zhang and Y. Wang, J. Membr. Sci., 2019, 576, 116-122.
215 H. Fan, J. Gu, H. Meng, A. Knebel and J. Caro, Angew. Chem., Int. Ed., 2018, 57, 4083-4087.

216 K. Dey, M. Pal, K. C. Rout, H. S. Kunjattu, A. Das, R. Mukherjee, U. K. Kharul and R. Banerjee, J. Am. Chem. Soc., 2017, 139, 13083-13091.

217 J. Liu, G. Han, D. Zhao, K. Lu, J. Gao and T.-S. Chung, Sci. $A d v .$, 2020, 6, eabb1110.

218 Y. Li, Q. Wu, X. Guo, M. Zhang, B. Chen, G. Wei, X. Li, X. Li, S. Li and L. Ma, Nat. Commun., 2020, 11, 599.

219 D. B. Shinde, G. Sheng, X. Li, M. Ostwal, A.-H. Emwas, K.-W. Huang and Z. Lai, J. Am. Chem. Soc., 2018, 140, 14342-14349.

220 D. B. Shinde, L. Cao, A. D. D. Wonanke, X. Li, S. Kumar, X. Liu, M. N. Hedhili, A.-H. Emwas, M. Addicoat, K.-W. Huang and Z. Lai, Chem. Sci., 2020, 11, 5434-5440.

221 W. Zhang, L. Zhang, H. Zhao, B. Li and H. Ma, J. Mater. Chem. A, 2018, 6, 13331-13339.

222 H. Wang, Z. Zeng, P. Xu, L. Li, G. Zeng, R. Xiao, Z. Tang, D. Huang, L. Tang, C. Lai, D. Jiang, Y. Liu, H. Yi, L. Qin, S. Ye, X. Ren and W. Tang, Chem. Soc. Rev., 2019, 48, 488-516.

223 D. W. Burke, C. Sun, I. Castano, N. C. Flanders, A. M. Evans, E. Vitaku, D. C. McLeod, R. H. Lambeth, L. X. Chen, N. C. Gianneschi and W. R. Dichtel, Angew. Chem., Int. Ed., 2020, 59, 5165-5171.

224 J. L. Fenton, D. W. Burke, D. Qian, M. Olvera de la Cruz and W. R. Dichtel, J. Am. Chem. Soc., 2021, 143, 1466-1473.

225 M. Amirilargani, G. N. Yokota, G. H. Vermeij, R. B. Merlet, G. Delen, L. D. B. Mandemaker, B. M. Weckhuysen, L. Winnubst, A. Nijmeijer, L. C. P. M. de Smet and E. J. R. Sudhölter, ChemSusChem, 2020, 13, 136-140.

226 S. Kandambeth, B. P. Biswal, H. D. Chaudhari, K. C. Rout, H. S. Kunjattu, S. Mitra, S. Karak, A. Das, R. Mukherjee, U. K. Kharul and R. Banerjee, Adv. Mater., 2017, 29, 1603945.

227 M. Rungta, L. Xu and W. J. Koros, Carbon, 2015, 85, 429-442.

228 S. Fu, E. S. Sanders, S. S. Kulkarni and W. J. Koros, J. Membr. Sci., 2015, 487, 60-73.

229 S. Fu, G. B. Wenz, E. S. Sanders, S. S. Kulkarni, W. Qiu, C. Ma and W. J. Koros, J. Membr. Sci., 2016, 520, 699-711.

230 M. Rungta, G. B. Wenz, C. Zhang, L. Xu, W. Qiu, J. S. Adams and W. J. Koros, Carbon, 2017, 115, 237-248.

231 H. Park, Y. Kim, J. Lee, S. Lee and Y. Lee, J. Membr. Sci., 2004, 229, 117-127.

232 H. Kim, D.-G. Kim, K. Lee, Y. Baek, Y. Yoo, Y. S. Kim, B. G. Kim and J.-C. Lee, Sci. Rep., 2016, 6, 36078.

233 M. Omidvar, H. Nguyen, H. Liang, C. M. Doherty, A. J. Hill, C. M. Stafford, X. Feng, M. T. Swihart and H. Lin, ACS Appl. Mater. Interfaces, 2019, 11, 47365-47372.

234 J. Robertson, Pure Appl. Chem., 1994, 66, 1789-1796.

235 S. Aisenberg and R. Chabot, J. Appl. Phys., 1971, 42, 2953-2958.

236 S. Karan, S. Samitsu, X. Peng, K. Kurashima and I. Ichinose, Science, 2012, 335, 444-447.

237 J. L. Xiangyu Li, R. Qu, W. Zhang, Y. Liu, H. Zhai, Y. Wei, H. Hu and L. Feng, Nat. Commun., 2021, 12, 80. 
238 J. Campbell, R. P. Davies, D. C. Braddock and A. G. Livingston, J. Mater. Chem. A, 2015, 3, 9668-9674.

239 G. Liu, V. Chernikova, Y. Liu, K. Zhang, Y. Belmabkhout, O. Shekhah, C. Zhang, S. Yi, M. Eddaoudi and W. J. Koros, Nat. Mater., 2018, 17, 283-289.

240 H. Fan, M. Peng, I. Strauss, A. Mundstock, H. Meng and J. Caro, Nat. Commun., 2021, 12, 38.

241 L. Paseta, M. Navarro, J. Coronas and C. Téllez, J. Ind. Eng. Chem., 2019, 77, 344-354.

242 Y. Zhang, L. Lin, Q. Wang, R. Qiang, Y. Gao, S. Ma, Q. Cheng and Y. Zhang, J. Mater. Sci., 2020, 55, 8403-8419.

243 L. Hu, J. Liu, L. Zhu, X. Hou, L. Huang, H. Lin and J. Cheng, Sep. Purif. Technol., 2018, 205, 58-65.

244 D. K. Panchariya, R. K. Rai, E. Anil Kumar and S. K. Singh, ACS Omega, 2018, 3, 167-175.

245 C. Van Goethem, R. Verbeke, S. Hermans, R. Bernstein and I. F. J. Vankelecom, J. Mater. Chem. A, 2016, 4, 16368-16376.

246 J. Zhu, L. Qin, A. Uliana, J. Hou, J. Wang, Y. Zhang, X. Li, S. Yuan, J. Li, M. Tian, J. Lin and B. Van der Bruggen, ACS Appl. Mater. Interfaces, 2017, 9, 1975-1986.

247 Z. Wang, Z. Wang, S. Lin, H. Jin, S. Gao, Y. Zhu and J. Jin, Nat. Commun., 2018, 9, 2004.

248 X. Cheng, X. Jiang, Y. Zhang, C. H. Lau, Z. Xie, D. Ng, S. J. D. Smith, M. R. Hill and L. Shao, ACS Appl. Mater. Interfaces, 2017, 9, 38877-38886.

249 H. Shen, S. Wang, H. Xu, Y. Zhou and C. Gao, J. Membr. Sci., 2018, 565, 145-156.

250 B. Khorshidi, I. Biswas, T. Ghosh, T. Thundat and M. Sadrzadeh, Sci. Rep., 2018, 8, 1-10.

251 H. Sun and P. Wu, J. Membr. Sci., 2018, 564, 394-403.

252 S. Li, C. Li, X. Song, B. Su, B. Mandal, B. Prasad, X. Gao and C. Gao, ACS Appl. Mater. Interfaces, 2019, 11, 6527-6540.

253 B. Li, S. Japip and T.-S. Chung, Nat. Commun., 2020, 11, 1198.

254 R. Zhang, S. Ji, N. Wang, L. Wang, G. Zhang and J. R. Li, Angew. Chem., Int. Ed., 2014, 53, 9775-9779.

255 M. S. Denny and S. M. Cohen, Angew. Chem., Int. Ed., 2015, 54, 9029-9032.

256 M. R. Abdul Hamid, S. Park, J. S. Kim, Y. M. Lee and H.-K. Jeong, J. Mater. Chem. A, 2019, 7, 9680-9689.

257 S. Park, K. Y. Cho and H.-K. Jeong, J. Mater. Chem. A, 2020, 8, 11210-11217.

258 S. Park and H.-K. Jeong, J. Membr. Sci., 2020, 596, 117689.

259 Q. Song, S. Jiang, T. Hasell, M. Liu, S. Sun, A. K. Cheetham, E. Sivaniah and A. I. Cooper, Adv. Mater., 2016, 28, 2629-2637.

260 Q. Song, S. Jiang, T. Hasell, M. Liu, S. Sun, A. K. Cheetham, E. Sivaniah and A. I. Cooper, Adv. Mater., 2016, 28, 2629-2637.

261 X. He, H. Sin, B. Liang, Z. A. Ghazi, A. M. Khattak, N. A. Khan, H. R. Alanagh, L. Li, X. Lu and Z. Tang, Adv. Funct. Mater., 2019, 29, 1900134.

262 J. Liu, W. Wei and J. Jiang, ACS Sustainable Chem. Eng., 2020, 8, 2892-2900.

263 B. Liang, H. Wang, X. Shi, B. Shen, X. He, Z. A. Ghazi, N. A. Khan, H. Sin, A. M. Khattak, L. Li and Z. Tang, Nat. Chem., 2018, 10, 961-967.
264 Y. Xu, S. Jin, H. Xu, A. Nagai and D. Jiang, Chem. Soc. Rev., 2013, 42, 812-831.

265 J.-X. Jiang, F. Su, A. Trewin, C. D. Wood, N. L. Campbell, H. Niu, C. Dickinson, A. Y. Ganin, M. J. Rosseinsky, Y. Z. Khimyak and A. I. Cooper, Angew. Chem., Int. Ed., 2007, 46, 8574-8578.

266 L. Huang, M. Zhang, C. Li and G. Shi, J. Phys. Chem. Lett., 2015, 6, 2806-2815.

267 L. Nie, C. Y. Chuah, T.-H. Bae and J.-M. Lee, Adv. Funct. Mater., 2020, 31, 2006949.

268 S. Wang, L. Yang, G. He, B. Shi, Y. Li, H. Wu, R. Zhang, S. Nunes and Z. Jiang, Chem. Soc. Rev., 2020, 49, 171-189.

269 L. Huang, J. Chen, T. Gao, M. Zhang, Y. Li, L. Dai, L. Qu and G. Shi, Adv. Mater., 2016, 28, 8669-8674.

270 E. H. Ang, S. Velioğlu and J. W. Chew, J. Membr. Sci., 2019, 591, 117318.

271 D. A. Dikin, S. Stankovich, E. J. Zimney, R. D. Piner, G. H. B. Dommett, G. Evmenenko, S. T. Nguyen and R. S. Ruoff, Nature, 2007, 448, 457-460.

272 C. Chen, Q. H. Yang, Y. Yang, W. Lv, Y. Wen, P. X. Hou, M. Wang and H. M. Cheng, Adv. Mater., 2009, 21, 3007-3011.

273 H. Kim, H. Yoon, S.-M. Yoon, B.-M. Yoo, B. Ahn, Y. Cho, H. Shin, H. Yang, U. Paik, S. Kwon, J. Choi and H. Park, Science, 2013, 342, 91-95.

274 G. Liu, W. Jin and N. Xu, Angew. Chem., Int. Ed., 2016, 55, 13384-13397.

275 J. Zhang, Z. Li, K. Zhan, R. Sun, Z. Sheng, M. Wang, S. Wang and X. Hou, Electrophoresis, 2019, 40, 2029-2040.

276 Q. Yang, Y. Su, C. Chi, C. T. Cherian, K. Huang, V. G. Kravets, F. C. Wang, J. C. Zhang, A. Pratt, A. N. Grigorenko, F. Guinea, A. K. Geim and R. R. Nair, Nat. Mater., 2017, 16, 1198-1202.

277 L. Nie, K. Goh, Y. Wang, J. Lee, Y. Huang, H. E. Karahan, K. Zhou, M. D. Guiver and T.-H. Bae, Sci. Adv., 2020, 6, eaaz9184.

278 X. Lin, X. Shen, Q. Zheng, N. Yousefi, L. Ye, Y.-W. Mai and J.-K. Kim, ACS Nano, 2012, 6, 10708-10719.

279 B. Mi, Science, 2019, 364, 1033-1034.

280 L. Huang, W. Jia and H. Lin, AlChE J., 2020, 66, e17022.

281 X. Chen, Z. Feng, J. Gohil, C. M. Stafford, N. Dai, L. Huang and H. Lin, ACS Appl. Mater. Interfaces, 2020, 12, 1387-1394.

282 L. Huang, Y. Li, Q. Zhou, W. Yuan and G. Shi, Adv. Mater., 2015, 27, 3797-3802.

283 T. Gao, L. Huang, C. Li, G. Xu and G. Shi, Carbon, 2017, 124, 263-270.

284 S. Wang, D. Mahalingam, B. Sutisna and S. P. Nunes, J. Mater. Chem. A, 2019, 7, 11673-11682.

285 D. K. Mahalingam, S. Wang and S. P. Nunes, Ind. Eng. Chem. Res., 2019, 58, 23106-23113.

286 L. Chen, W. Wang, Q. Fang, K. Zuo, G. Hou, Q. Ai, Q. Li, L. Ci and J. Lou, Appl. Mater. Today, 2020, 20, 100791.

287 S. Park, K.-S. Lee, G. Bozoklu, W. Cai, S. T. Nguyen and R. S. Ruoff, ACS Nano, 2008, 2, 572-578.

288 L. Chen, G. Shi, J. Shen, B. Peng, B. Zhang, Y. Wang, F. Bian, J. Wang, D. Li, Z. Qian, G. Xu, G. Liu, J. Zeng, L. Zhang, Y. Yang, G. Zhou, M. Wu, W. Jin, J. Li and H. Fang, Nature, 2017, 550, 415-418. 
289 W.-S. Hung, C.-H. Tsou, M. De Guzman, Q.-F. An, Y.-L. Liu, Y.-M. Zhang, C.-C. Hu, K.-R. Lee and J.-Y. Lai, Chem. Mater., 2014, 26, 2983-2990.

290 S. Wang, Y. Xie, G. He, Q. Xin, J. Zhang, L. Yang, Y. Li, H. Wu, Y. Zhang, M. D. Guiver and Z. Jiang, Angew. Chem., Int. Ed., 2017, 56, 14246-14251.

291 Y. Zhang, K. Su and Z. Li, J. Membr. Sci., 2018, 563, 718-725.

292 J. Yang, D. Gong, G. Li, G. Zeng, Q. Wang, Y. Zhang, G. Liu, P. Wu, E. Vovk, Z. Peng, X. Zhou, Y. Yang, Z. Liu and Y. Sun, Adv. Mater., 2018, 30, 1705775.

293 J. D. Caldwell, I. Aharonovich, G. Cassabois, J. H. Edgar, B. Gil and D. N. Basov, Nat. Rev. Mater., 2019, 4, 552-567. 294 W. Lei, V. N. Mochalin, D. Liu, S. Qin, Y. Gogotsi and Y. Chen, Nat. Commun., 2015, 6, 8849.

295 B.-Y. Guo, S.-D. Jiang, M.-J. Tang, K. Li, S. Sun, P.-Y. Chen and S. Zhang, J. Phys. Chem. Lett., 2019, 10, 4609-4617.

296 J. Ran, P. Zhang, C. Chu, P. Cui, X. Ai, T. Pan, Y. Wu and T. Xu, J. Membr. Sci., 2020, 602, 117963.

297 Q. Wang and D. O'Hare, Chem. Rev., 2012, 112, 4124-4155.

298 S. Manzeli, D. Ovchinnikov, D. Pasquier, O. V. Yazyev and A. Kis, Nat. Rev. Mater., 2017, 2, 17033.

299 E. H. Ang and J. W. Chew, Chem. Mater., 2019, 31, 10002-10007.

300 H. E. Karahan, K. Goh, C. Zhang, E. Yang, C. Yıldırım, C. Y. Chuah, M. G. Ahunbay, J. Lee, Ş. B. Tantekin-Ersolmaz, Y. Chen and T. H. Bae, Adv. Mater., 2020, 32, 1906697.
301 M. Naguib, M. Kurtoglu, V. Presser, J. Lu, J. Niu, M. Heon, L. Hultman, Y. Gogotsi and M. W. Barsoum, Adv. Mater., 2011, 23, 4248-4253.

302 J. Wang, P. Chen, B. Shi, W. Guo, M. Jaroniec and S. Z. Qiao, Angew. Chem., 2018, 130, 6819.

303 Y. Xing, G. Akonkwa, Z. Liu, H. Ye and K. Han, ACS Appl. Nano Mater., 2020, 3, 1526-1534.

304 L. Wang, M. S. H. Boutilier, P. R. Kidambi, D. Jang, N. G. Hadjiconstantinou and R. Karnik, Nat. Nanotechnol., 2017, 12, 509-522.

305 S. P. Surwade, S. N. Smirnov, I. V. Vlassiouk, R. R. Unocic, G. M. Veith, S. Dai and S. M. Mahurin, Nat. Nanotechnol., 2015, 10, 459-464.

306 P. R. Kidambi, D. D. Mariappan, N. T. Dee, A. Vyatskikh, S. Zhang, R. Karnik and A. J. Hart, ACS Appl. Mater. Interfaces, 2018, 10, 10369-10378.

307 P. R. Kidambi, G. D. Nguyen, S. Zhang, Q. Chen, J. Kong, J. Warner, A. P. Li and R. Karnik, Adv. Mater., 2018, 30, 1870376.

308 W. Guo, J. Chen, S. Sun and Q. Zhou, J. Phys. Chem. C, 2016, 120, 7451-7456.

309 N. F. D. Aba, J. Y. Chong, B. Wang, C. Mattevi and K. Li, J. Membr. Sci., 2015, 484, 87-94.

310 A. Akbari, S. E. Meragawi, S. T. Martin, B. Corry, E. Shamsaei, C. D. Easton, D. Bhattacharyya and M. Majumder, ACS Appl. Mater. Interfaces, 2018, 10, 2067-2074. 